\title{
KÖP DEN HÄR! 1 \\ How IKEA North York Visually Communicates Persuasive Messages to Shoppers
}

\author{
Nima Naik
}

\author{
Supervisor: Dr. Janice Fung Second Reader: Dr. Isabel Pederson
}

1 "BUY THIS!" in Swedish 


\section{i. Abstract}

This Major Research Paper (MRP) closely examines IKEA North York as an organization that constructs visual messages in their retail environments and persuasively communicates to its shoppers through visuals in product displays, including display structure, signage, and location, to encourage consumer behaviour and impact purchasing decisions. Three product displays were closely examined in the "Cookshop \& Tableware" department of IKEA North York's Market Hall through a thorough visual analysis of each product display utilizing four guiding concepts derived from document design and visual communication (information hierarchy, white space, colour, and ambience) and examining corresponding consumer behaviour through on-site observations. Preliminary conclusions state that while IKEA North York effectively designs its retail space on a 2-dimensional plane, further consideration needs to be taken when designing the 3-dimensional nature of the store environment. This research could be furthered through the inclusion of a broader data set and wider criteria for examination. 


\section{ii. Author's Declaration}

I hereby declare that I am the sole author of this Major Research Paper and the accompanying Research Poster. This is a true copy of the MRP and the research poster, including any required final revisions, as accepted by my examiners. I authorize Ryerson University to lend this major research paper and/or poster to other institutions or individuals for the purpose of scholarly research. I further authorize Ryerson University to reproduce this MRP and/or poster by photocopying or by other means, in total or in part, at the request of other institutions or individuals for the purpose of scholarly research. I understand that my MRP and/or my MRP research poster may be made electronically available to the public. 
iii. Table of Contents

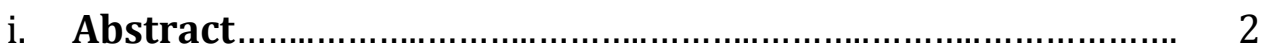

ii. Author's Declaration.................................................................. 3

iii. Table of Contents................................................................. 4 4-5

1. Introduction .............................................................................

2. Importance of Research ........................................................

3. Research Questions................................................................... 8

4. Theoretical Orientation ………………………..................... 8-9

a. Document Design ........................................................... 9-10

b. Visual Rhetoric ................................................................. 10-11

c. Retail Design and Visual Merchandising........................... 11-12

5. Selective Literature Review................................................. 12

a. Using Design to Communicate to Consumers.................. 12-14

b. Store Atmosphere and Consumer Behaviour................... 14-18

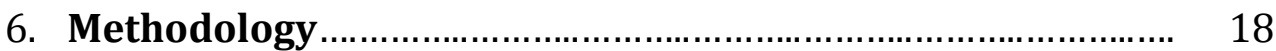

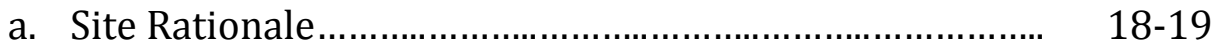

b. Visual Analysis.............................................................. 19

c. Guiding Concepts for Visual Analysis.............................. 19-20

i. Information Hierarchy....................................... 20-21

ii. White Space ................................................... 21-22

iii. Colour................................................................... 22

iv. Ambience.......................................................... 22-23

d. Observation ................................................................... 23-26

e. Photo Documentation.................................................... 26-27

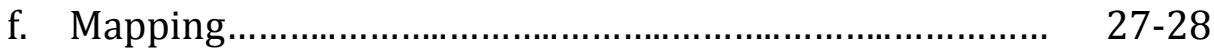

7. Observation Results................................................................. 29-31

8. Visual Analysis ................................................................... 31

a. FÄRGRIK ............................................................... 32-46

i. Signage ............................................................ $\quad 32-37$

ii. Product Display Structure .................................... 3 38-43 
iii. Location and Ambience....................................... 43-45

iv. FÄRGRIK Visual Analysis Summary ...................... 46

b. FÖRNUFT ....................................................................... 4 4-58

i. Signage ................................................................ 4 $47-51$

ii. Product Display Structure.................................... 51-54

iii. Location and Ambience....................................... 54-57

iv. FÖRNUFT Visual Analysis Summary .................... 58

c. LUGN/ÖPPEN ................................................................ 59-74

i. Signage ......................................................... $59-64$

ii. Product Display Structure.................................... 64-70

iii. Location and Ambience....................................... $\quad 70-73$

iv. LUGN/ÖPPEN Visual Analysis Summary............... 74

9. Discussion..........................................................................

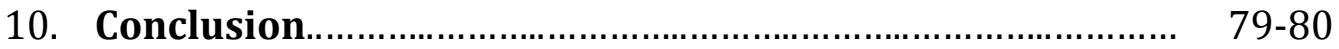

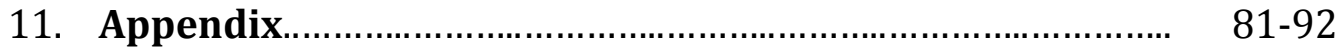

12. References .................................................................. 93-97 


\section{Introduction}

Paco Underhill (1999), founder of the field of retail geography and author of Why We Buy: The Science of Shopping, states, "many purchasing decisions are made, or can be heavily influenced, on the floor of [a] store itself. Shoppers are susceptible to impressions and information they acquire in stores... As a result, an important medium for transmitting messages and closing sales is now the store and the aisle" (p. 32). A store is not merely a physical space in which products are sold; it is also a medium to subtly communicate persuasive messages to consumers.

My Major Research Paper (MRP) closely examines IKEA North York as an organization that constructs visual messages in their retail environments. These messages seek to attract shoppers' attention, create consumer-driven desires, and motivate the viewing public to respond to aesthetically rich communication through consumption. My research investigates how IKEA North York persuasively communicates to its shoppers through visuals in product displays, including display structure, signage, and location, to encourage consumer behaviour and impact purchasing decisions.

The theoretical orientation for my MRP examines document design in the field of visual communication, as well as professional research pertaining to retail design and visual merchandising. The site of my research is the "Cookshop \& Tableware" department of IKEA North York's Market Hall. In order to collect my visual documents and monitor consumer's shopping behaviour on site I observed consumer behaviour through a microethnographical approach, photo documented product displays, and mapped IKEA North York's retail space from my research site. Following my data collection, I applied a predetermined set of guiding concepts, derived from document design and visual 
communication, to each product display through visual analysis in order to deconstruct the communication latent behind the display's aesthetic design elements. My overall goal for my MRP is to contribute to the definition of "communication" to include forms of mediation that are more implicit and inherent in everyday spaces and environments, namely visual design and its function to drive consumer behaviour.

\section{Importance of Research}

Although literature and current research exists in the fields of retail design and visual merchandising, and the subsequent effect of these environmental cues on consumer behaviour and shopper patronage intentions, there is no evidence of an in-depth analysis of IKEA's visual retail design. However, IKEA has been discussed in current academic literature in regards to their overall brand. Edvardsson, Enquist, and Hay (2006) use IKEA as a case study to create a framework that focuses on how corporate values are communicated to customers. Furthermore, Roncha (2008) asserts that Nordic brands, such as IKEA, differentiate themselves from competitors in a global market by promoting their heritage through various forms of communication. Finally, Elliott, Eccles, and Ritson (1996) discuss DIKEA, a lesbian group in the United Kingdom, and describe how symbolic meanings derived from shopping at IKEA are used to create group identity.

Regardless of the brand's recognition in past research, IKEA represents a successful cross-cultural organization whose entire global brand is famous for designing their retail environments to keep shoppers consuming. As such, my MRP fills a void in an increasingly important field of study. Through my MRP I hope to demonstrate the effects of visual forms of communication in retail environments, which is an important field in both academic and applied contexts. In regards to professional communication, my MRP looks at the 
interdisciplinary themes regarding the rhetoric of space. In a professional context, my MRP can aid retailers who, in our consumer-driven market, aim to persuade more shoppers to conspicuously consume, and shoppers themselves, who have found themselves bombarded with corporate messaging and are on the other end of the aisle interested in bypassing retailer strategies.

\section{Research Questions}

My MRP will attempt to answer the following questions:

- How does IKEA North York use elements of visual communication to persuade its shoppers to make purchases through the visual components of their product displays?

- To what degree are the visual product displays in the "Cookshop and Tableware" department at IKEA North York effective in garnering sales from shoppers?

- What visual communication changes, if any, can be made to make IKEA's Market Hall retail space more conducive to consumer's behaviours and shopping habits?

\section{Theoretical Orientation}

The theoretical orientation for my MRP examines the fields of document design, visual communication, and visual rhetoric, in addition to highlighting an applied approach to the study of retail design and visual merchandising. More specifically, document design and visual merchandising will be the basis of the theoretical framework for my MRP and, as such, provide the guiding concepts for my research. However, while I will argue that elements of visual communication in the retail environment have persuasive qualities, the area of visual rhetoric will act as a theoretical supplement to my research. That is, the area of visual rhetoric will be addressed to cover the theoretical landscape associated with 
persuasive messaging. The integration of the practical field of retail design in my MRP will provide supplementary theories and proven-results to complement my research. As my MRP has both theoretical and practical implications, I think it is important to begin my research from both an academic communications perspective as well as from a corporate and marketing point-of-view.

\section{a. Document Design}

One area of scholarly research that will serve as a starting point for my MRP is document design, which stems from the larger field of visual communication and design. Professional communication scholars have worked extensively in this field and many of the concepts discussed will serve as the theoretical foundation for my work. Schriver (1997) defines document design as the "field concerned with creating texts (broadly defined) that integrate words and pictures in ways that help people to achieve their specific goals" (p. 10). Schriver (1997) elaborates that document design is the "act of bringing together prose, graphics, and typography for purposes of instruction, information, or persuasion" (p. 1011).

Primarily, document design discusses space as it relates to a two-dimensional plane, such as a page or screen. However, according to Schriver (1997) using the word 'document' may create some confusion because document design can also be used to interpret threedimensional fields, including retail environments, redefining what a document is in academic practice. Schriver (1997) states that documents are "no longer constrained to static and linear formats" (p. 4) explaining that the term 'document' is merely a "placeholder to a text-like artifact composed in print or mixed media" (p.5). From a page layout to a store layout, concepts derived from document design can be easily applied to 
any sort of design or visual artifact. Therefore, document design will be a highly relevant part of the foundation to my study of retail space especially from a professional communication perspective.

b. Visual Rhetoric

Simply put, visual rhetoric is the "relationship of visual images to persuasion" (Helmers and Hill, 2004, p. 1). More specifically, visual rhetoric discusses how various visual images communicate to create meaning or construct an aesthetic argument. The framing idea of visual rhetoric is that visual design can be interpreted in the same way as the interpretation of texts in more traditional rhetorical forms where "visual elements are [likewise] used to influence people's attitudes, opinions, and beliefs" (Helmers and Hill, 2004, p. 2). Kenneth Burke (1950) believed that "wherever there is persuasion, there is rhetoric. And wherever there is 'meaning' there is persuasion" (p. 172). Burke is suggesting that rhetoric exists not only in language and words, but can also be encapsulated in visual elements. Just as words can take on rhetorical qualities of persuasion, elements of design can also adopt basic rhetorical strategies. Similar to the rhetorical tradition, visual rhetoric has an inherent persuasive quality as specific messages can be created in a visual form to send to audiences (Kostenick and Roberts, 1998).

Based on this definition of visual rhetoric, I posit that the rhetoric of space can be described as how a physical space, which can also be viewed as a three-dimensional visual document in space, can persuade people to achieve specific goals such as driving purchasing behaviour. Dickenson and Maugh (2004) discuss visual rhetoric in the built environment in regards to the persuasive qualities in Wild Oats Market grocery stores, they state that the "grocery store - banal as it may be - is a crucial place for understanding 
everyday, visual rhetoric in a postmodern world" (p. 259). Additionally, the authors posit that "visual rhetoric in space becomes most compelling not simply when the vision is compelling, but when the rhetoric appeals to the intersections among the five senses" (Dickenson and Maugh, 2004, p. 272). Visual forms of communication, including retail design and the store environment, ultimately lead to some kind of rhetorical transformation such as persuading people to shop and consume.

\section{c. Retail Design and Visual Merchandising}

Retail design is a specialized field, which can be seen as a subsidiary of retail marketing, that seeks to create effective branded environments (Kerfoot, Davies, and Ward, 2003). The primary purpose of any retail space is to sell product to consumers and, therefore, retail environments must be designed in a way that promotes a pleasant shopping experience for the customer, as well as a profitable return for retailers (Colborne, 1996). Visual merchandising builds upon the retail design of a store, as it is the practice of crafting displays and creating floor plans in retail environments for the purpose of drawing shopper attention and maximizing sales (Pegler, 2006). Visual merchandisers use a variety of strategies in creating effective retail displays including color, lighting, signage, and product information (Kerfoot, Davies, and Ward, 2003). Many retailers have found ways of structuring man-made environments to make them more conducive for retail purposes and a more effective means of persuading shoppers to consume. While both retail design and visual merchandising can be seen as more applied, rather than theoretical, fields, substantial research has been done to trace the effects of the design of retail environments on consumer behaviour and patronage intention; for instance, researchers have explore various elements of store atmosphere, including colour and lighting (Bellizzi, Crowley, and 
Hasty, 1983; Babin, Hardesty, and Suter, 2003), social factors (Baker, Levy, and Grewal, 1992), ambient factors like music and lighting (Kellaris and Kent, 1992; Milliman, 1982; Baker, Levy, and Grewal, 1992), crowding (Eroglu and Harrell, 1986), and point-ofpurchase displays² (Phillips and Bradshaw, 1990), and the ensuing effects on shoppers.

\section{Selective Literature Review}

Due to the interdisciplinary nature of my MRP, my literature review is focused on the more applied fields of retail design, visual merchandising, and consumer behaviour, as they provide a solid practical and conceptual foundation from which I can further my research. I explore two major themes within the field of retail design, which provide a general overview of this highly-researched and frequently published discipline. First, I summarize how Bloch (1995), Kent $(2003,2007)$ and Kerfoot, Davies, and Ward (2003) all discuss how the design of a retail space and store environment can be used to communicate to consumers through creative means. Then, I provide a detailed overview of research based on store atmosphere and its affects on consumer behaviour, with a particular emphasis on atmospherics, environmental psychology, and visual cues.

\section{a. Using Design to Communicate to Consumers}

Bloch (1995) states that "good design attracts consumers to a product, communicates to them, and adds value to the product by increasing the quality of the usage experiences associated with it" (p. 16). Bloch posits that the design of a product may contribute to its success in various ways. This includes gaining consumer notice and attention in a cluttered marketplace through a product design's creation of an effective

\footnotetext{
${ }^{2}$ Point-of-purchase, or point-of-sale, displays are where a transaction occurs. This often refers to the checkout counter in retail environments.
} 
initial impression because, as Bloch (1995) emphasizes, "the exterior appearance of a product is important as a means of communicating information to consumers" (p. 18). Likewise, Kent (2007) posits that while creativity and ingenuity are often used in the design of products sold by retailers, they are often not utilized in the design of the retail environment itself. Kent claims that creativity in retail environments is manifested in store design. Kent (2007) emphasizes the importance of creatively designing a retail space for the purpose of creating individual consumer experiences. Rather than focus solely on the products being sold, Kent (2007) suggests that retailers must be "creative to find or invent new environments in which space, cost and flexibility are matched to the effective communication of the retailer's brand values and the stimulation of consumer purchasing activity" (p. 736). Above all else, Kent (2007) posits that retail design has to be "multifaceted by linking together art, instinct and business in a problem solving and planning process" (p. 736).

Furthermore, Kent (2003) discusses how retail branding must be approached from a multi-dimensional perspective. Retailer brands are more than just the two-dimensional visual expression of advertisements, as the field is expanding to embrace branding in the three-dimensional spaces of the store environment. In his discussion of the history of branding in the retail sector, Kent (2003) defines the concept of "brand personality", which describes the expression of the values, culture, and identity of an organization through the use of visual cues. While a store's image is the "overall perception of a store perceived by consumers", the "personality of the retail store" can lead to consumer's forming thoughts and feelings about how the store influences their shopping behaviour and loyalty. Historically, Kent (2003) posits, in comparison to product manufacturers, "retailers were 
slow to take up both product and corporate branding" (p. 133). Regardless, there has always been a strong relationship between products, the retail environment, and store patronage despite retailer's reluctance to acknowledge the importance of branding on a three-dimensional plane.

Designing store environments, that is, the use of three-dimensional planes rather than two-dimensional ones, can also be described as "visual merchandising". Kerfoot, Davies, and Ward (2003) define visual merchandising as how brands, and their requisite stores and products, are "visually communicated to the customer and also whether this message is decoded 'appropriately' in this context affecting a positive psychological or behavioural outcome, ultimately leading to purchase" (p. 143). As such, these authors suggest that retailers have implemented numerous methods to display merchandise and communicate product and retail brand in order to incite consumer interest in products. According to Kent (2003), the psychological impact of the store's environment creates an image of the retailer in the consumer's mind. Kent (2003) claims that, "environmental cues including signage and exterior design as well as the interior environment have been found to be significant in the predicative decision making by consumers of service provision" ( $p$. 134). Initial findings, from Kerfoot, Davies, and Ward (2003), suggest that consumers who like a product display will not completely determine if they will purchase a product; still, the design of a display does make it four times more likely.

b. Store Atmosphere and Consumer Behaviour

According to Bitner (1992), service environments, including commercial spaces, can influence consumer decision-making. Store environments are never natural as they include cues, messages, and suggestions to consumers (Markin, Lillis, and Narayana, 1976; Bitner, 
1992). Retailers design store environments in a manner that will enhance consumers' positive feelings, which they assume will lead to desirable consumer behaviour, such as a higher willingness to purchase products or longer stays in the store environment (Mano, 1999). Store environments themselves can offer unique atmospheric qualities that may influence a shopper's patronage intention (Baker, Grewal and Parasuraman, 1994). Creating a unique and effective atmospheric design should be the primary concern for retailers as it is an important retail strategy for the purposes of driving shopping behaviour (Turley and Chebat, 2002).

The concept of 'atmospherics' was first introduced by Kotler (1974) who defines store atmosphere as the effort to intentionally design retail spaces and structure environmental cues to produce specific psychological and emotional effects in shoppers, which will increase the likelihood of intended purchases and enhance the probability of buyer purchasing. Kotler (1974) states that store atmosphere can affect purchase behaviour by communicating messages to the store's intended audience because atmospherics can act as a message-creating medium.

Since Kotler (1974) introduced the concept of atmospherics, many researchers have used this approach to study the influence of retail design on consumer behaviour. Some researchers have focused their investigations on the influence of specific atmospheric elements and how they affect consumer response and patronage intention. Bellizzi, Crowley, and Hasty (1983) address how specific colors in retail applications can physically attract shoppers toward a retail display and can also affect the perception of store and merchandise image. Similarly, Babin, Hardesty, and Suter (2003) discuss how color 
perceptions, both alone and in combination with store lighting, influence shoppers' patronage intentions. Baker, Levy, and Grewal (1992) discuss how atmospheric qualities such as social factors, including the number and relative friendliness of store employees, and ambient cues, like music and lighting, impact retail patronage decision. Likewise, Kellaris and Kent (1992) write about how the influence of music affects consumers' temporal perceptions and Milliman's (1982) research examines how background music affects the behavior of supermarket shoppers. Phillips and Bradshaw (1990) claim that interactive influences are present in most buying situations, but exert greater influence with unplanned purchases at point-of-purchase displays. Atmospheric qualities are not limited to the physical and environmental surroundings in a retail space, as they can also include cues from fellow shoppers, Eroglu and Harrell (1986), for instance, examine the theoretical and strategic aspects of how consumers are influenced by retail crowding.

Many researchers use an environmental psychology model established by Mehrabian and Russell (1974) and tested by Donavan and Rossiter $(1982,1994)$ to study the influence of store atmosphere on consumer behaviour and provide explanation on how the design of retail environments results in psychological and subsequent behavioral responses from consumers. The M-R model is based on the Stimulus-Organism-Response (S-O-R) paradigm, which describes how features of the environment result in approachavoidance behaviours of shoppers within the space of the store. More specifically, positive psychological responses result in consumer's approaching behavior in the retail environment (Bloch, 1995). Approach responses are part of the aesthetic experience and indicate consumer desire (Bloch, 1995). For retailers, the most important approach behaviour is the purchase of the product. In contrast, negative feelings result in avoidance 
behavior, which can conclude with customers distancing themselves from a product (Bloch, 1995). Retailers are most concerned about avoidance behaviour manifesting in a customer's reluctance and refusal to make a purchase (Bloch, 1995). Researchers, using methods derived from the M-R model, have examined retail displays of women's intimate apparel (Law, Wong, and Yip, 2012), grocery stores (Gilboa and Rafael, 2003), and CD stores (Tai and Fung, 1997), amongst other retail environments.

Although multisensory atmospheric cues have been studied in regards to their effect on shopping behaviour, research indicates that visual design aspects of the store environment, in particular, yield positive consumer responses. Baker, Parasuraman, Grewal, and Voss (2002) found that design cues have a "stronger and more pervasive influence" on shoppers' perceptions than store employee or music cues (p.138). That is, visual cues in the retail environment influence customers' perceived shopping speed and efficiency in addition to perceived stress involved in shopping (Baker at al., 2002). The authors argue that retailers should give careful attention to the design features of stores, including store layout and arrangement of merchandise, as they have significant potential to influence customers' shopping experience and store patronage behaviour (Baker et al., 2002). Also, Babin, Hardesty, and Suter (2003) found that the combination of colours and lighting plays a critical role in influencing the purchase intention of consumers and store patronage. Lastly, Bellizi, Crowley, and Hasty (1983) discuss how particular colours can garner attention and result in the approach behaviour of consumers in response to retail product displays. It is clear that various atmospheric qualities in the store environment, including design cues and visual communication, play a prominent role in the behaviour and decision-making process of shoppers and, as a result, retailers have begun to take 
advantage of these subtle forms of communication to persuade casual shoppers to become loyal customers.

\section{Methodology}

The site of my research is IKEA's North York location. More specifically, I examined product displays in the "Cookshop \& Tableware" department of IKEA North York's Market Hall. My methods for my MRP included visual analysis using a predetermined set of guiding concepts. I collected data from my research site through observing consumer behaviour, photo documenting product displays, and mapping IKEA North York's retail space. a. Site Rationale

Although the focus of my MRP is visual communication and retail design at IKEA, the site for my research is specifically the Market Hall at IKEA North York, Canada. I chose to conduct my research at IKEA North York because it is one of the busiest stores in the GTA with over 40,000 visitors weekly. IKEA North York is also well established as an IKEA franchise as it is soon to be the oldest IKEA location in North America. Lastly, compared to the other GTA locations of IKEA, including Etobicoke and Vaughn, IKEA North York retains a high-level of design integrity in regards to the standards they maintain for their store environment.

Additionally, I deliberately chose to conduct my observations in IKEA North York's Market Hall, which is a warehouse where shoppers pick up smaller household items and accessories, rather than the more highly stylized Showroom space, because consumer patronage intention is easier to observe in this environment. Although IKEA North York shoppers browsing in the Showroom interact with displays, their intent to purchase items 
is not entirely clear as they must go to the "Self Serve" area to pick up their furniture before a purchase can be made. In contrast, IKEA North York's Market Hall is set up like a traditional store where shoppers can both interact with product displays and place items straight into bags or carts for purchase.

b. Visual Analysis

In order to decipher the information gathered, I applied concepts from document design to conduct a visual analysis and determine the success of the visual communication in IKEA North York's product displays. My MRP draws conclusions between the data collected on site from observing purchasing behaviour and analysis of the visual design in the product displays to assess the persuasive messaging in IKEA North York's retail environment. In addition to visual analysis, I completed some preliminary analysis on site when I conducted observational research on IKEA North York's premises; more specifically, I translated shoppers' movement patterns to their purchase intention immediately upon my observation.

\section{c. Guiding Concepts for Visual Analysis}

I used a pre-determined specified set of criteria to guide my visual analysis in order to ensure that all the visual elements of the product displays were studied in a consistent manner. The document design concepts I applied include: (i) information hierarchy, (ii) white space, (iii) colour, and (iv) ambience. These concepts were applied to three product displays (FÄRGRIK, LUGN/ÖPPEN, and FÖRNUFT) from the "Cookshop \& Tableware" department at IKEA North York through visual analysis to determine the overall effectiveness of the design and visual communication of the displays. Both 2-dimensional and 3-dimensional elements of each of the product displays were examined including 
signage, display structure, and location. In analyzing each of the product displays signage represents 2D visual artifacts while the display structure and location characterize 3D documents. Moreover, these concepts guided my observations while conducting research at IKEA North York. These four concepts were chosen because they represent a wide spectrum of design concepts while being unique theories in the discipline. Additionally, although I approached my research from a visual analysis perspective, this method is not used in the field of retail design and visual merchandising thus similar studies were not referenced when choosing my criteria for analysis.

\section{i. Information Hierarchy}

In regards to document design, information hierarchy, or visual hierarchy, refers to the levels of emphasis in a composition (Bowers, 2008). A clear hierarchy of information can be accomplished through the purposeful placement of visual and typographical information based on relative importance and the organization of the composition of a page to create a sense of order (Lascano, 2009). Clear information hierarchy provides a number of important benefits. Hierarchy allows for the understanding of complex information and provides a method of guiding the viewer through content as it clearly identifies important visual cues (Bowers, 2008). Bowers (2008) explains, a “form's composition can emphasize parts of information, reveal relationships among components, and guide interpretation" (p. 71). Clear information hierarchy in documents can result in a improved of legibility, which is an important factor as it allows viewers to quickly gain an understanding of the content being displayed and determine what is useful, usable, or relevant to their needs (Lascano, 2009). Information hierarchies organize, prioritize, and communicate visually by modifying the visual weights different elements carry. 
Information hierarchy is conveyed visually through basic elements of design including continuity, contrast, repetition, alignment, proximity, and scale (Lascano, 2009). Information hierarchy is a design element related to composition and, as such, includes other design concepts such as white space and colour. However, unlike these individual elements of design, information hierarchy looks at the overall composition of a document to determine what objects are most salient (Bowers, 2008). Although information hierarchy is easy to identify on a traditional composition, such as the document design of a retail sign, all forms of documents, including the structure of a product display, contain hierarchical elements.

\section{ii. White Space}

"White space", also known as negative space, is an element of design that is part of the aesthetics of composition. In A Primer of Visual Literacy, Donis A. Dondis (1973) distinguishes between positive and negative space. Dondis (1973) states that "the significance of positive and negative...means merely that there are separate yet unified elements in all visual events" (p. 35). Dondis (1973) emphasizes that "positive and negative are in no way meant to describe darkness or lightness or mirror image as they do in the description of film and prints in photography" (p. 35). Rather, in design, "what dominates the eye in visual experience would be considered the positive elements while those more passively displayed would be considered negative" (Dondis, 1973, p. 35).

In this sense, white space does not necessarily mean "blank space"; rather, it refers to an absence of visual content. White space can be literal when referring to the design of a document such as a retail sign. This type of white space includes the portion of a page left unmarked in the overall design of the document; more specifically, white space is the 
empty space between graphics, lines of type, and figures and objects depicted on a twodimensional plane. White space is not limited to traditional documents, as it can also be defined as the gap or space between two structural parts in a three-dimensional document such as a product display.

\section{iii. Colour}

For Dondis (1973), colour is an element of design that is "loaded with information and one of the most pervasive visual experiences we all have in common" (p. 50). Therefore, colour is "an invaluable source for visual communicators...[as] each colour has many meanings, associative and symbolic" (Dondis, 1973, p. 50). According to John Bowers (2003), author of Introduction to Two-Dimensional Design: Understanding Form and Function, "our understanding of a form's colour is influenced by variables, including the type and intensity of the lighting on the object viewed, our distance from it, learned colour associations, and surrounding colours" (p. 89). Therefore, Bowers' (2003) claims, "the definition of colour is relative and dependent on cultural and physical contexts" (p. 89). Characteristics of colour include hue, tonal value (or brightness), intensity (or saturation), and temperature (Dondis, 1973; Bowers, 2003). Colour is an element of design that is easy to apply to both two and three-dimensional documents; but, the commercial lighting in retail environments often skews the true nature of colours, which must be taken into consideration.

\section{iv. Ambience}

Ambience, in the context of my MRP, refers to the atmospheric qualities that border a product display. In regards to retail design and visual merchandising, ambience can also be defined as 'atmospherics', a term coined by Kotler (1974) who stated that store 
atmosphere and retail spaces could be intentionally designed and given environmental cues to produce specific psychological and emotional effects in shoppers. These retail design elements and environmental cues include, but are not limited to, neighboring displays, location, wall colour, lighting, and other elements of visual branding that are not a part of the structure of a product display itself (Kotler, 1974). These environmental surroundings provide contextual information for the design of a product display, which can aid in understanding why shoppers behave a certain way when faced with a particular display structure. Unlike the other concepts that will be applied to the product displays, ambience takes a much more macro approach in that it looks at the display as a whole in the context of design of the entire retail space.

\section{d. Observation}

I employed consumer observation to determine the effectiveness of the products displays at IKEA North York. While a significant amount of research has been done on the effects of various visual cues on consumer behaviour, observational research is not typically used in this area of research. In the past, researchers have used a diverse array of strategies including: focus groups (Law, Wong, \& Yip, 2012), videotapes used to simulate a store environment experience followed by a questionnaire (Baker, Parasuraman, Grewal, \& Voss, 2002), ordering photographs of retail environments based on specific criteria (Gilboa, \& Rafael, 2003), semi-structured interviews based around the use of visual stimulus material (Kerfoot, Davies, Ward, 2003), and questionnaires using a 5-point Likert scale (Tai \& Fung, 1997). 
I observed consumer behaviour at three different types of product displays in the “Cookshop \& Tableware" department in the Market Hall of IKEA North York. These three display types consisted of:

\begin{tabular}{|l|l|l|}
\hline 1 & $\begin{array}{l}\text { "Breathtaking Item" } \\
\text { (BTI) }\end{array}$ & $\begin{array}{l}\text { "Breathtaking Items", are practical and extremely } \\
\text { low-cost products found in IKEA North York's } \\
\text { Market Hall. BTIs are heavily promoted on the retail } \\
\text { floor to encourage impulse purchases due to the } \\
\text { inexpensive nature of the products. BTI product } \\
\text { displays can be identified easily as they are placed in } \\
\text { prominent locations on the retail floor, or "hot } \\
\text { spots", and their product displays often have added } \\
\text { visual elements. }\end{array}$ \\
\hline 2 & $\begin{array}{l}\text { "New Lower Price" } \\
\text { (NLP) }\end{array}$ & $\begin{array}{l}\text { A "New Lower Price" product is IKEA North York's } \\
\text { version of a sale, or heavily discounted, product. } \\
\text { Product displays include signage that clearly states } \\
\text { "New Lower Price". }\end{array}$ \\
\hline 3 & Simple/White & $\begin{array}{l}\text { This type of display can be used for a wide-range of } \\
\text { products. The display's distinguishing features are } \\
\text { that its signage and structure are extremely simple, } \\
\text { predominantly white, and lack any additional } \\
\text { graphic elements. }\end{array}$ \\
\hline
\end{tabular}

While I knew the type of product displays in the Market Hall before my observations began, the exact displays were not decided upon until my site visit. Due to the constantly changing nature of IKEA North York's product displays, it was impossible to select a specific display ahead of my observation dates. On my first day of observations, I chose the following product displays: FÄRGRIK, LUGN/ÖPPEN, and FÖRNUFT, which represent a BTI, New Lower Price, and Simple/White product displays respectively (see Figure 1). 
Figure 1: Breathtaking Item, New Lower Price, and Simple/White product displays
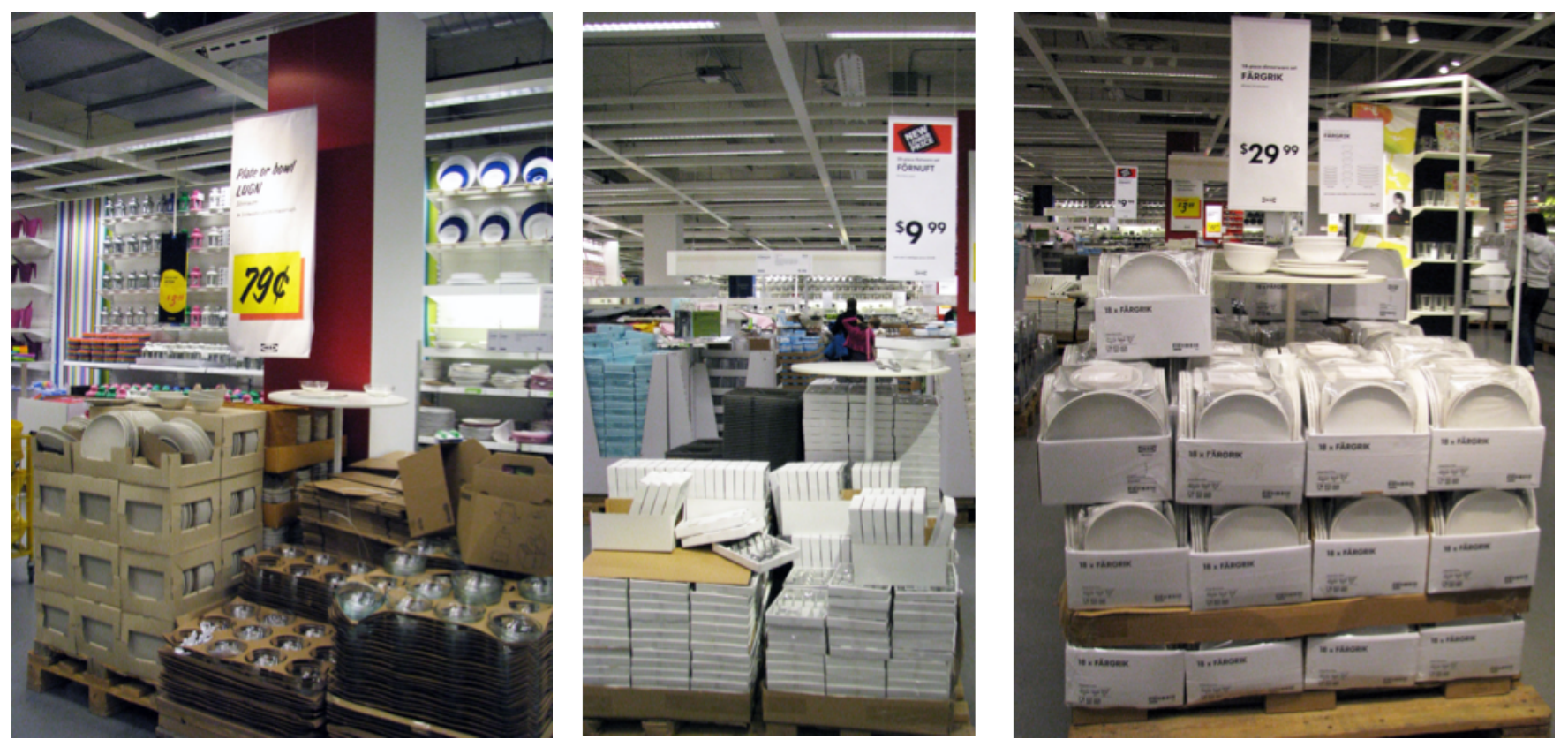

I examined shopper's interactions at each of the three displays for an hour over a period of two days in the same week. Table 1 refers to observation dates and times. My observation period began around 10:00am, as I wanted to observe consumer behaviour immediately after IKEA North York opened when each of the product displays were be in their intended configuration. Each morning IKEA North York staff members go through every department and conduct what they call "SISAN", or "Store In Shape As New", which means that the displays are put into correct order before shoppers arrive. As my MRP focuses on the visual nature and design qualities of these displays, it was pertinent that the displays were in pristine condition. By choosing consistent times for my observations, and consecutive observation days, I maintained control over external variables that could have altered consumer behaviour. I assumed that shoppers would behave similarly over the same period of time in the same week, which allowed me to collect a considerable amount of consistent data. 
Table 1: IKEA North York Observation Display, Date, and Time

\begin{tabular}{|l|l|l|}
\cline { 2 - 3 } \multicolumn{1}{c|}{} & Tuesday, April 24, 2012 & Thursday, April 26, 2012 \\
\hline $\begin{array}{l}\text { Product: FÄRGRIK } \\
\text { Display Type: Simple/White }\end{array}$ & $10: 24 \mathrm{am}-11: 24 \mathrm{am}$ & $12: 18 \mathrm{pm}-1: 18 \mathrm{pm}$ \\
\hline $\begin{array}{l}\text { Product: LUGN/ÖPPEN } \\
\text { Display Type: BTI }\end{array}$ & $11: 28 \mathrm{am}-12: 28 \mathrm{pm}$ & $10: 15 \mathrm{am}-11: 15 \mathrm{am}$ \\
\hline $\begin{array}{l}\text { Product: FÖRNUFT } \\
\text { Display Type: NLP }\end{array}$ & $12: 31 \mathrm{pm}-1: 31 \mathrm{pm}$ & $11: 17 \mathrm{am}-12: 17 \mathrm{pm}$ \\
\hline
\end{tabular}

Throughout my observation periods I varied my observation location in order to gain insight from different visual points of view. Due to ethical and privacy reasons, I did not interact with any of the shoppers I observed. In my fieldwork, my role as an observer at IKEA North York took a passive, participant-as-observer and ethnographic approach. Due to the purely observational nature of my data collection, Ryerson University's Research Ethics Board deemed research approval unnecessary. My observation field notes qualitatively described consumer behaviour around each display in addition to any other relevant information that I observed. I also coded shoppers' consumer behaviour who interacted with the displays based on a 3-point scale (see Table 2) to quantify the effectiveness of each display. During this time, I began preliminary analysis based on my initial impressions of consumer behaviour surrounding each display.

Table 2: 3-point scale for coding consumer interaction and behaviour at IKEA

\begin{tabular}{|l|l|}
\hline $\mathbf{1}$ & Shopper looks at the signage and/or product display (with or without pausing) \\
\hline $\mathbf{2}$ & Shopper stops to touch product on display, display base, or product packaging \\
\hline $\mathbf{3}$ & Shopper places product in bag/cart with the intention of purchasing it \\
\hline
\end{tabular}

\section{e. Photo Documentation}

I photo documented each observed product display. Each product display was photographed from multiple angles; but because the majority of shoppers saw the display from the "Long Natural Way", or from the direction of the store aisle, the front view of the display was the most important. As well, each element of the display was photographed 
separately including signage, product package, sample or test products, and the display structure itself. Refer to Figures 3-24 (pages 32-71) or the Appendix for photographs of each of the product displays.

f. Mapping

In order to proceed with the visual analysis, I created a map of the "Cookshop \& Tableware" department (see Figure 2), which included the specific location of each of the observed displays. This was done in order to determine the importance of the location and ambient surroundings of each of the displays to the resultant consumer behaviour. In addition to creating my own map, I collected a map of IKEA North York's entire retail store from the research site. 
Figure 2: Map of the "Cookshop and Tableware" Department, Market Hall, IKEA North York

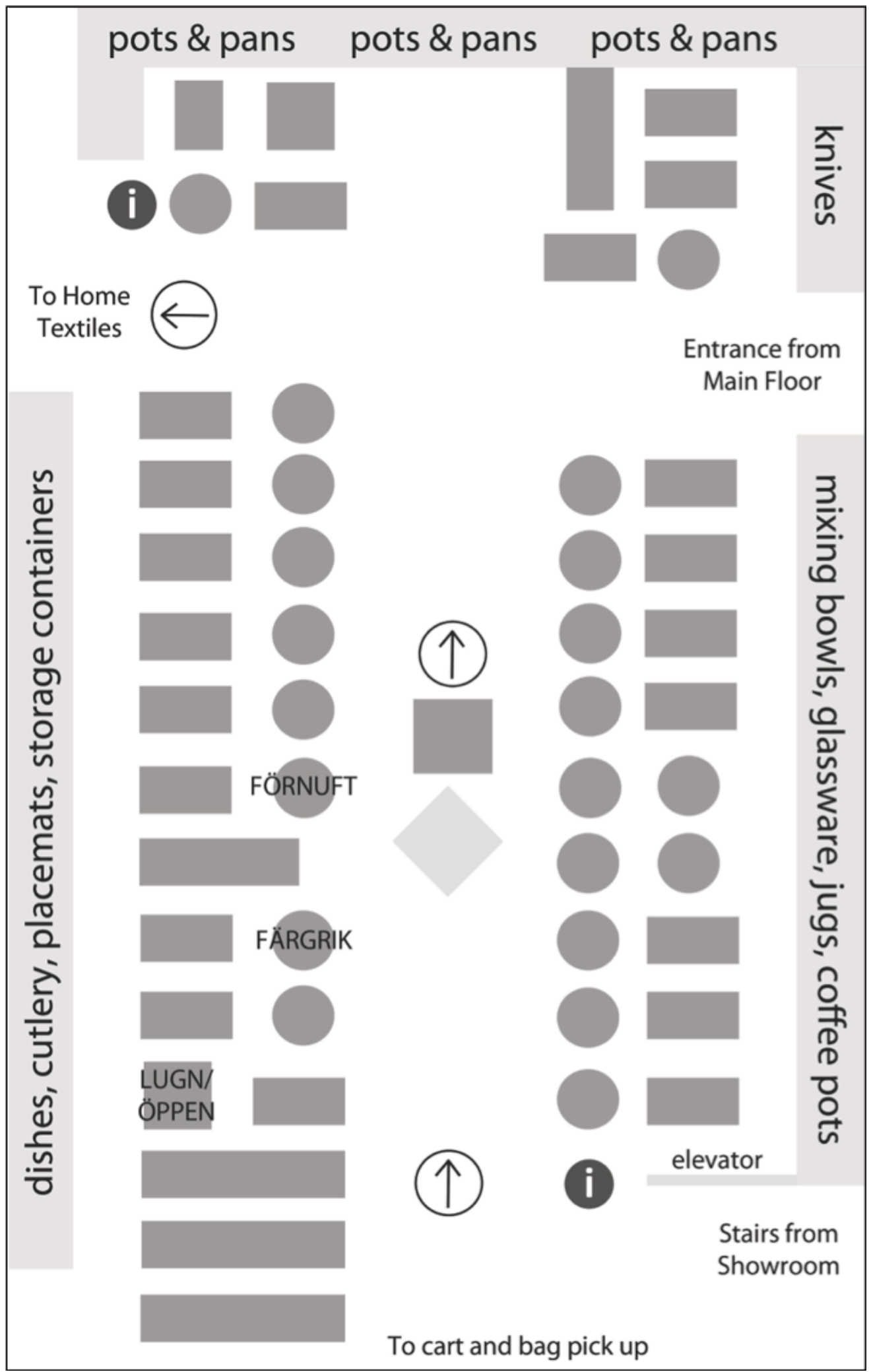

\begin{tabular}{|ll|}
\hline \multicolumn{2}{|c|}{ legend } \\
wall display with shelves \\
product displays & roll cage display \\
&
\end{tabular}




\section{Observation Results}

Coding shopper's interactions on a 3-point scale allowed for a quantifiable way to measure the success of each of the observed product displays (refer to Table 3). While simply garnering attention to a specific product display is important in the retail environment, which, in this research study, is defined as looking at or touching the product display, the number of sales of the product determines the overall effectiveness of the product display. The success rate of each of the product displays is based on the total number of intended purchases, or the third point on the three-point scale referring to the number of customers who placed the product in their cart or bag with the intention of purchasing it, and the total number of interactions after 2 hours at each display (see Table 4).

Table 3: 3-point scale for coding consumer interaction and behaviour at IKEA North York

\begin{tabular}{|c|l|}
\hline $\mathbf{1}$ & Shopper looks at the signage and/or product display (with or without pausing) \\
\hline $\mathbf{2}$ & Shopper stops to touch product on display, display base, or product packaging \\
\hline $\mathbf{3}$ & Shopper places product in bag/cart with the intention of purchasing it \\
\hline
\end{tabular}

Table 4: Success rate based on intended purchases and total interactions

\begin{tabular}{|l|l|l|l|}
\hline Display & Total Intended Purchases & Total Interactions & Success Rate \\
\hline FÄRGRIK & 0 & 122 & $0.00 \%$ \\
\hline LUGN/ÖPPEN & 7 & 67 & $10.45 \%$ \\
\hline FÖRNUFT & 6 & 113 & $0.05 \%$ \\
\hline
\end{tabular}

From data collected from the research site it is clear that $0.00 \%$ of shoppers who interacted in some way with the FÄRGRIK product display had any intention of purchasing the product. In contrast, only $0.05 \%$ of shoppers intended to buy the product at the FÖRNUFT display. Despite the lowest number of total interactions, 67, the LUGN/ÖPPEN product display was the most successful in garnering potential sales as $10.45 \%$ of shoppers who interacted with the display intended to purchase the product. 
Table 5: Observations Results from 2 days at IKEA North York using the 3-point scale

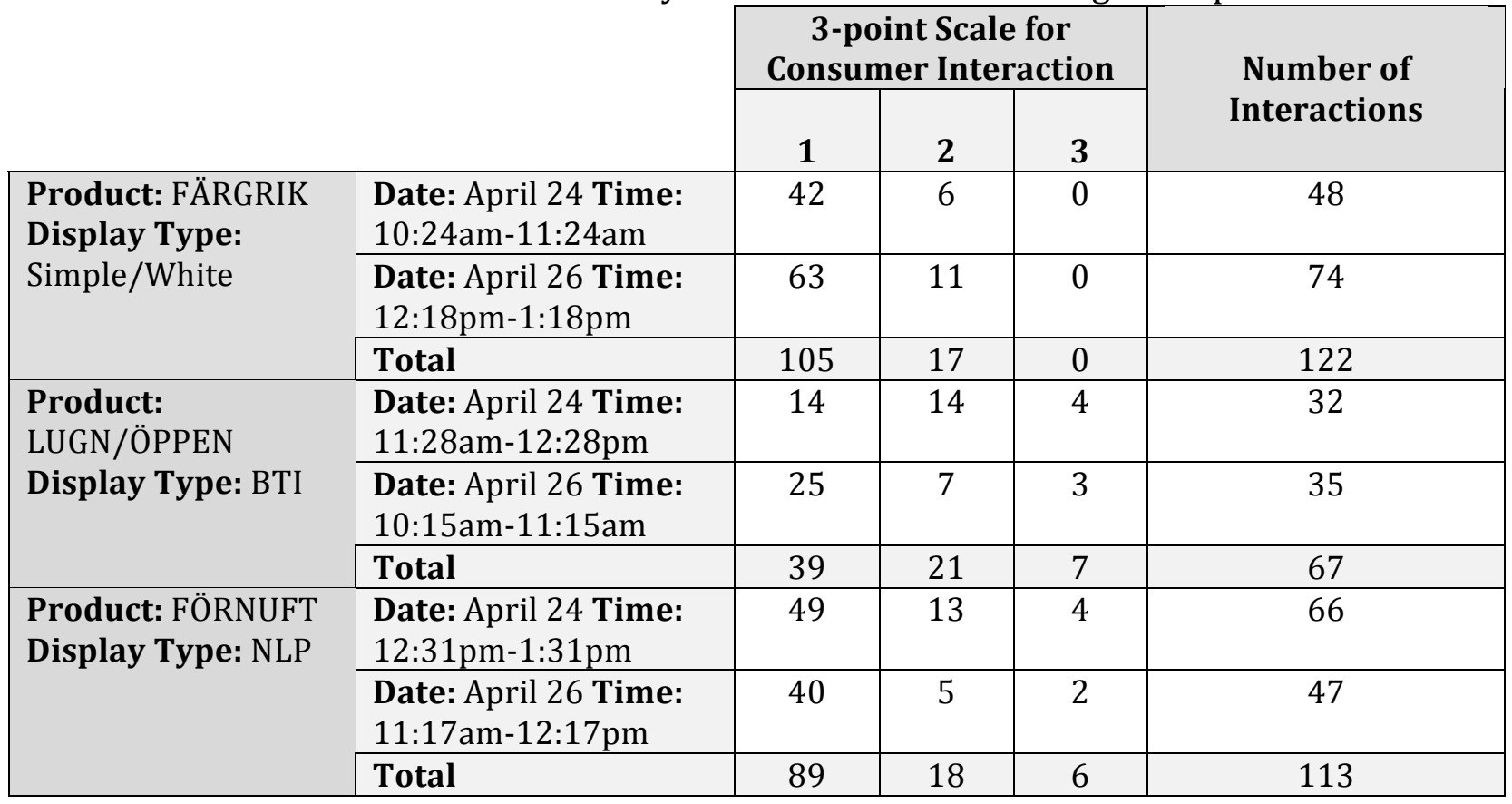

Despite having the lowest success rate, the FÄRGRIK display achieved the highest number of visual responses or the first point on the three-point scale. That is, 105 shoppers in IKEA North York's Market Hall looked at the FÄRGRIK display's signage or display over two days (see Table 5). In contrast, the FÖRNUFT display received only 89 visual responses while the LUGN/ÖPPEN display resulted in a meager 39 visual responses. Although the FÄRGRIK display received the highest number of visual responses from shoppers, no one in the two-day observation period actually intended to purchase the product. However, despite having lower visual response totals, both the FÖRNUFT and LUGN/ÖPPEN displays were generally more successful in garnering sales. Therefore, based purely on the data collected from observing shoppers, there does not seem to be a direct correlation between shoppers who simply viewed the product display and those who intended to purchase the product. 
One contributing factor that could have affected the quantity of intended purchases is the number of shoppers who touched the product or display on the retail floor. The LUGN/ÖPPEN display was the most successful display in garnering sales, but it also received the highest number of tactile responses at 21 (refer to Table 5). In contrast, the FÖRNUFT display received 18 tactile responses followed by FÄRGRIK at 17. From these results it is possible that the display that garners the most attention from shoppers through its visual design does not necessarily result in follow through from the shopper. More importantly, it appears as though the product display needs to be designed to attract shoppers' tactile responses because, according to the data collected, shoppers who touch the product display are more likely to purchase the product.

8. Visual Analysis

Information hierarchy, white space, and colour are all employed in the FÄRGRIK, LUGN/ÖPPEN, and FÖRNUFT product displays in the Market Hall of IKEA North York for the 2-dimensional retail signage and in the 3-dimensional display structure. Furthermore, each of the product displays can be examined as a whole for ambient qualities in the context of the retail environment, rather than for each of its individual parts. 
a. FÄRGRIK

i. Signage (2D)

Figure 1: FÄRGRIK product display signs

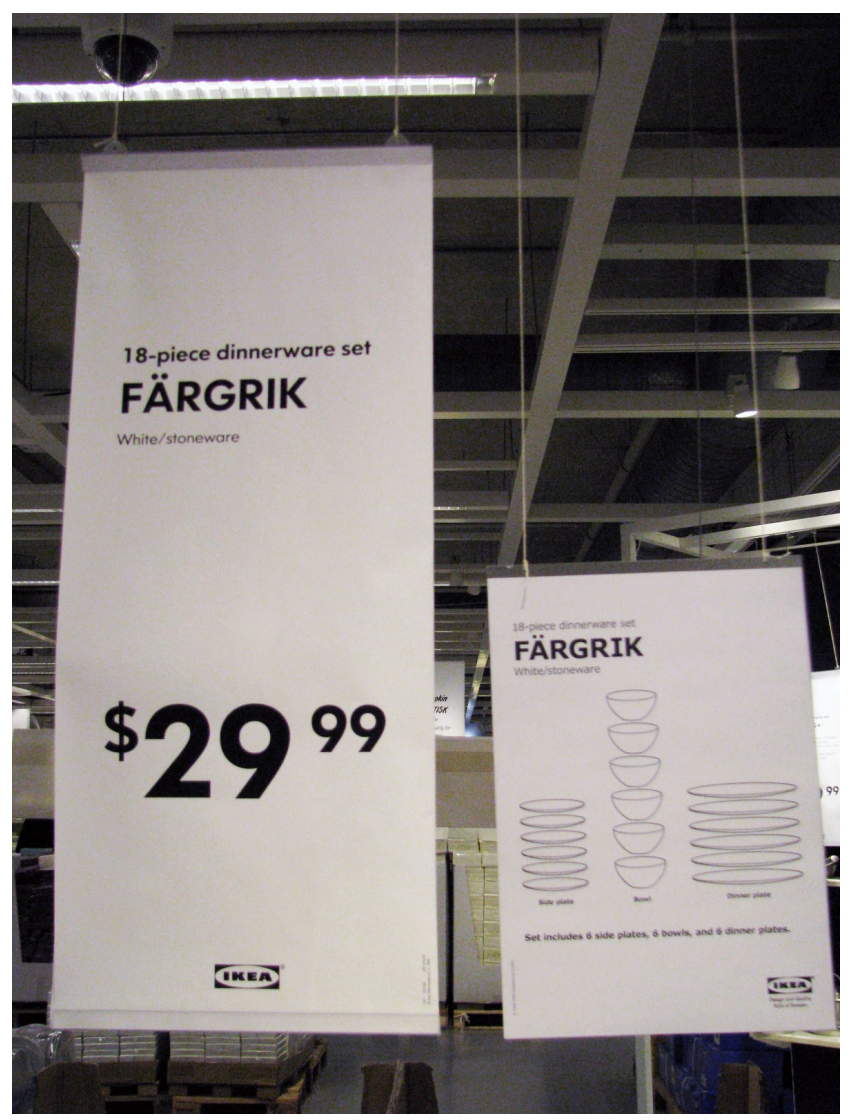

There are two signs above the

FÄRGRIK product display (see Figure 1).

The first sign includes information on the

product type, product name, the color and

material of the product, and the product

price. The second sign repeats the

information from the first sign, but does

not contain the price, and also includes a

graphic illustration of the items inside the

product package along with a written

description of the contents.

Both signs are completely void of colour; yet, the contrast between the stark black and white elements adds to the visual hierarchy of signage. As the signs themselves are white, any absence of visual content, whether typographical or image-related, can be construed as white space. More specifically, white space used in both of these signs is the empty space between the lines of type and graphics, which is left purposefully unmarked. Due to the abundance of white spaces in both signs, the information hierarchy is made very clear as certain elements in the signs are highlighted by the exaggerated negative space in the composition. 
Figure 2: First FÄRGRIK sign with white space identified

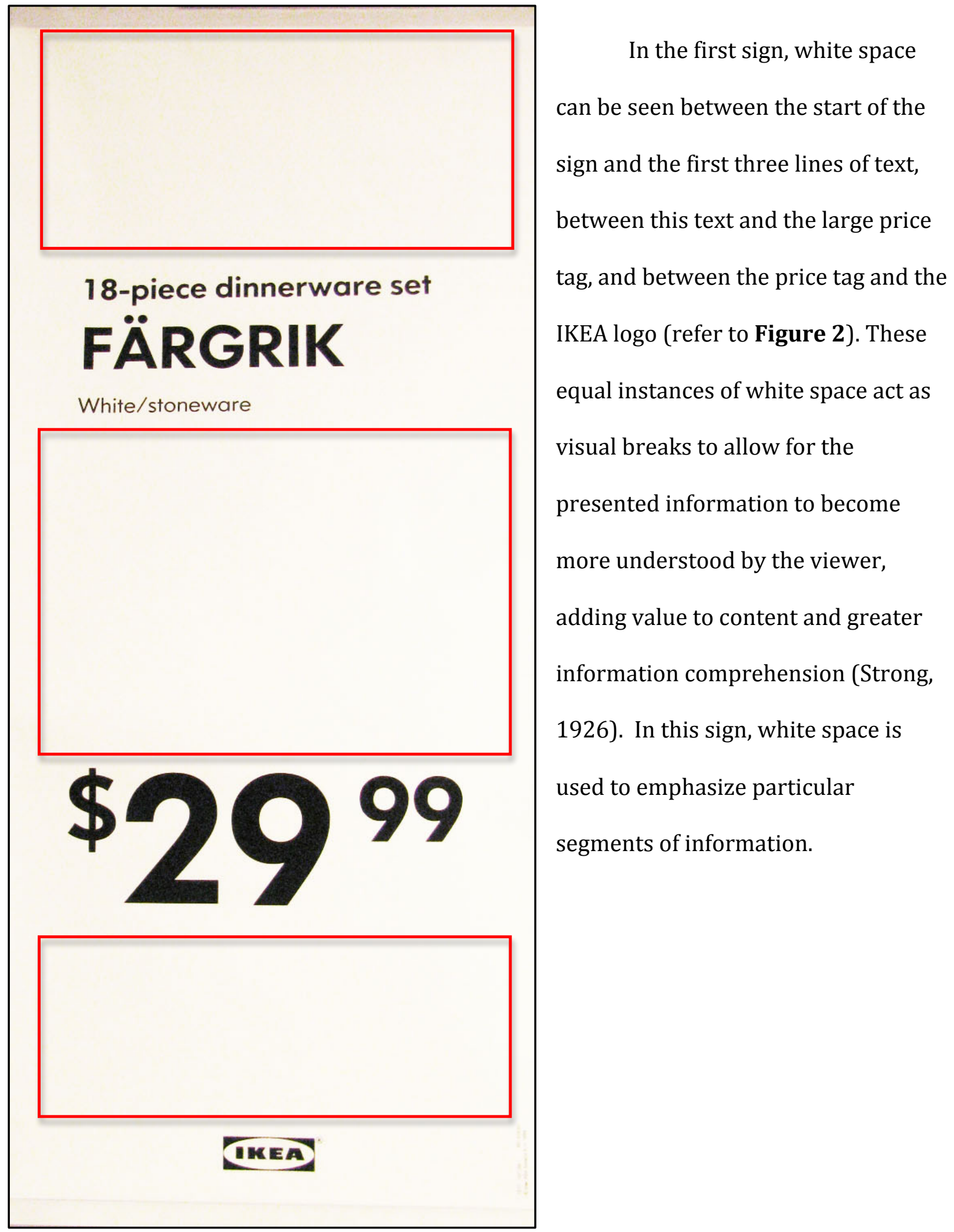


Figure 3: $1^{\text {st }}$ FÄRGRIK sign with identification of information hierarchy

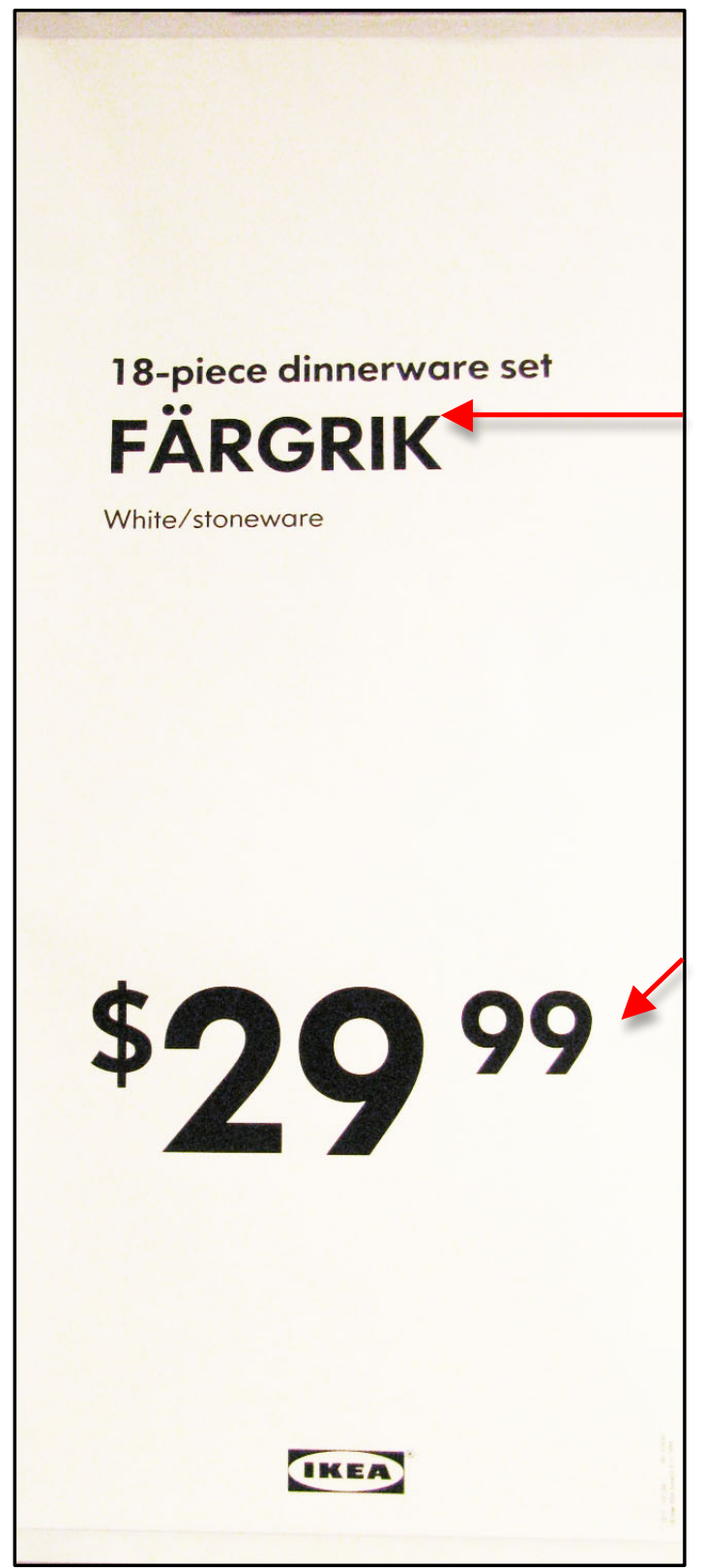

Information in each of these segments is

further emphasized through creating visual

hierarchy (see Figure 3). For instance, in the first

text block the word "FÄRGRIK" is capitalized,

bolded, and significantly larger than the other

lines of text surrounding it. Using these

typographical elements, and increasing the scale

of the text, the product name is made more

prominent in the sign (Spencer, Reynolds, and

Coe, 1974). By exaggerating the size of these

prices, this important information is highlighted.

By modifying the visual weight in different

graphical elements on this sign, information, such

as the product name and price is visually

prioritized. Without having to add color or any

additional graphics, this retail sign prominently

displays the name and price of the product being sold. As the price appears to be the "selling point" of this product, this number is surrounded by copious amounts of white space and has been increased in scale in order to avoid distraction from this important piece of information. 
Figure 4: $2^{\text {nd }} F A ̈ R G R I K$ sign with identification of white space and information hierarchy

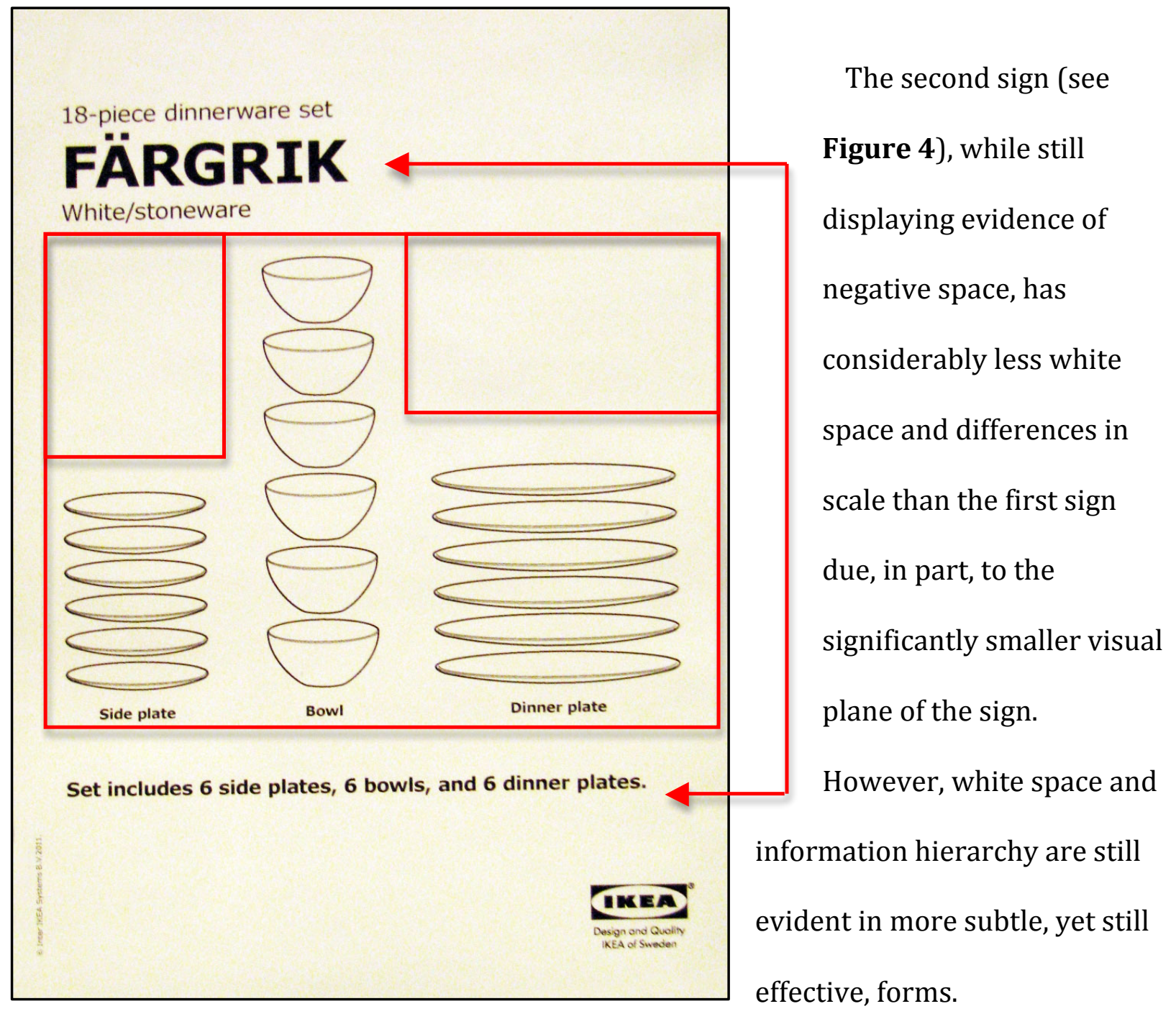

For instance, in comparison to the overall composition of the sign, the graphic illustration is the largest visual element on the 2-dimensional plane. As such, the relative importance of this graphic is naturally higher than the textual elements of the sign (Lascano, 2009). The use of white space in this sign also prioritizes the graphic illustration of the product contents over the sign's textual elements. The large amount of white space above the graphic illustration of the side and dinner plates isolates the product drawing in the context of the sign as a whole. As well, the use of bold typography both above and 
below the graphic illustration frames the graphic, which creates a sense of order in the sign (Spencer, Reynolds, and Coe, 1974). As such, the graphic illustration stands out to shoppers, while the text and the IKEA logo recede to the background.

Figure 5: White space in the graphic illustration from the $2^{\text {nd }}$ FÄRGRIK sign

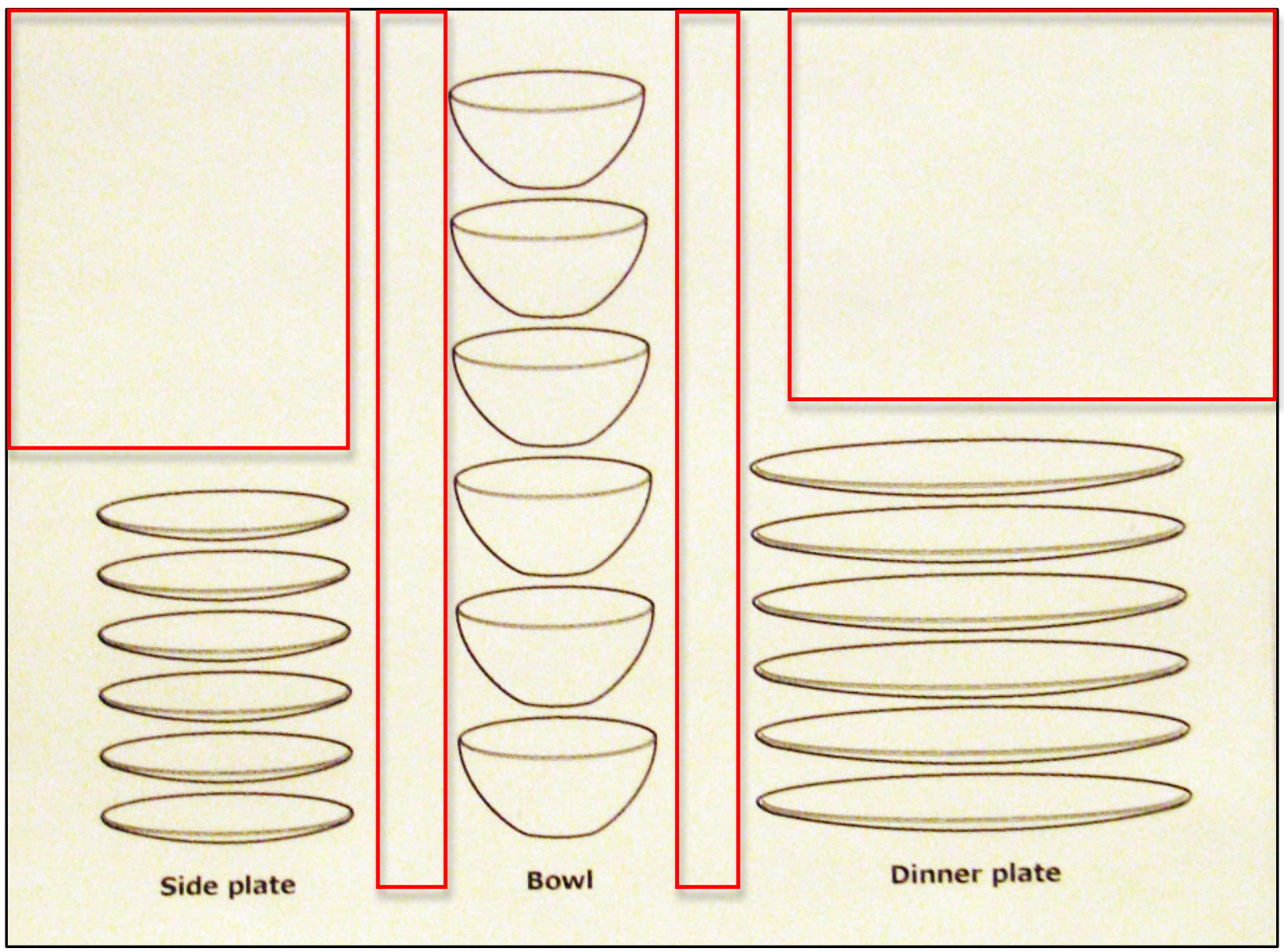

Although there is an insignificant amount of white space in between the text and the graphic illustration in this sign, the graphic illustration of the dinnerware set itself contains white space (refer to Figure 5). The three types of dinnerware in the product package are displayed prominently on the sign through simple line drawings, which indicate both the product type and the quantity. Each of these products is stacked into columns that are separated by white space. The use of white space in this instance indicates the variety of 
products to the shopper because it is made extremely clear, through negative space in the sign, that there are three different types of dinnerware in the product set. This is an important element of the product being sold because it informs the reader of the wide range of items in the product set, which is not visually displayed through the product packaging itself. Therefore, IKEA North York must rely on this sign, in particular, to notify shoppers of the true nature of the FÄRGRIK package's contents.

It is clear that white space and information hierarchy in the signs for the FÄRGRIK product display are strategically used to emphasize important points of visual information (Bowers, 2008). In the first sign, the price stands out, while, in the second sign, the product graphic illustration is prioritized. In using white space and information hierarchy for this purpose, IKEA North York is attempting to communicate key points of information to casual shoppers in the store. Based on my observed data, customers did not all stop to look at the display as a whole, most will absorb pertinent information from this well-designed retail sign. Observational results indicated that while many customers walked directly past the display, a total of 105 shoppers looked directly at the display before continuing on through the retail space. These results show that the effective use of white space and information hierarchy in the FÄRGRIK product display signs successfully leads to attracting shopper's attention (Strong, 1926). While it appears as though the FÄRGRIK signage was successful in garnering shoppers' attention, it appears as though something in the design of the display itself failed to gain their patronage intention as only 17 shoppers touched the display and none intended to buy the product. 


\section{ii. Product Display Structure (3D)}

White space and information hierarchy are not limited to traditional documents.

White space can also be defined as the pause or space between structural parts in a threedimensional document such as the FÄRGRIK product display and elements of information hierarchy, such as contrast and scale, can be seen in all forms of visual communication.

Figure 6: FÄRGRIK product display

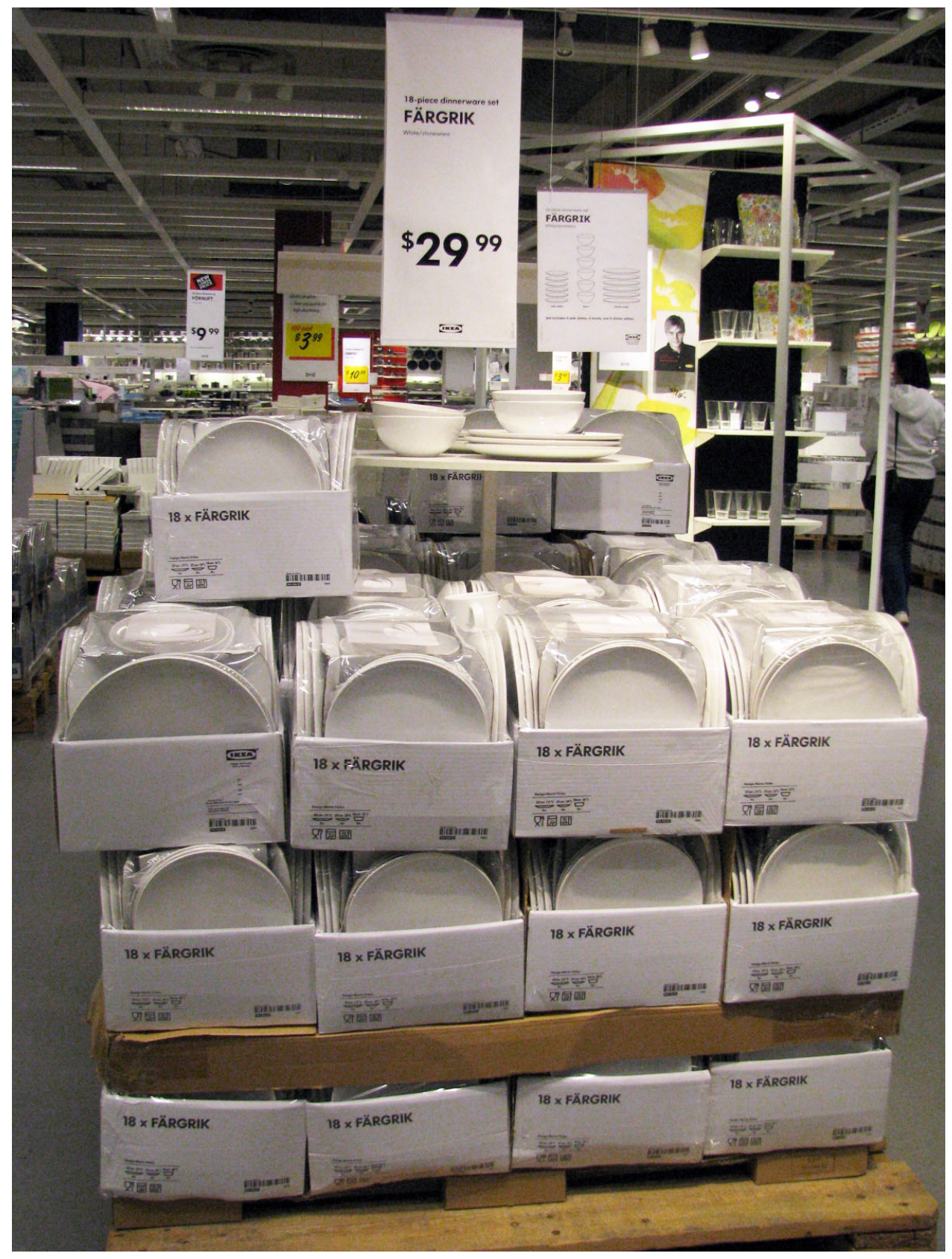


Figure 7: FÄRGRIK product display close-up with white space identified

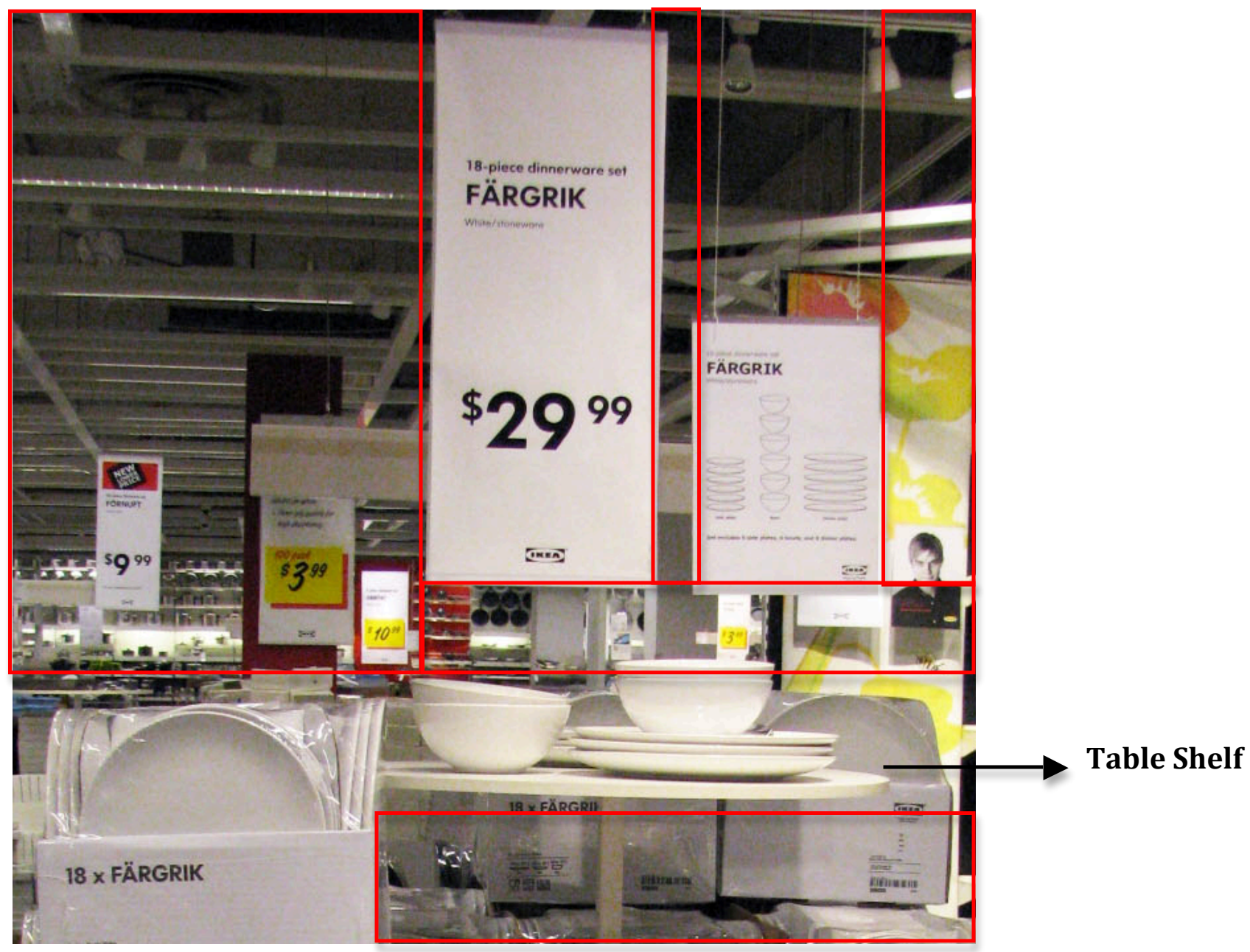

The design of the FÄRGRIK product display (refer to Figure 6) contains many instances of white space, which are achieved through the use of gaps in the display structure (see Figure 7). For instance, the retail signs, as discussed above, hang from the ceiling and appear to float above the base of the display. As such, white space is created between each of the signs and between the signs and the base of the display, which allows for a visual pause for shoppers before they look at the display structure. The FÄRGRIK product display signs are large and white and contain little visual information. Therefore, 
these signs, in addition to the space surrounding the signs, act as white space in the design of the display as a whole.

Additionally, comparable to the use of floating signs, white space is created in the FÄRGRIK product display through the use of a similarly suspended table shelf. This table allows for products to be displayed outside their product packaging and it is surrounded by white space, which emphasizes the products on view (see Figure 7). By surrounding this table, the positive element in the display structure, with empty space the table display is highlighted. Although the simple floating table structure is a subtle design element, the white space that results from the floating configuration emphasizes the importance of the table and the products sitting upon it. This table display clearly persuades shoppers to interact with the product as 17 shoppers had tactile responses to the display.

Although the use of white space around both the FÄRGRIK product display signs and table display highlight important information with the subsequent result of encouraging consumer behaviour, the display, as a whole, was ineffective in enticing purchases from shoppers. My observations indicate that, despite the display's success in garnering shortterm attention to the purchase of the product, no one, in the two-hour span over two days in which I observed, picked up a product with the intention of buying it. It is possible that this display, in its entirety, contained excessive white space, which left little visual interest to attract shoppers. Although small amounts of white space resulted in garnering attention for both the retail signs and the table display, when examining the complete FÄRGRIK product display, the overall appearance of the display is dull and lacks overall aesthetic appeal. 
Figure 8: Information hierarchy in the FÄRGRIK product display

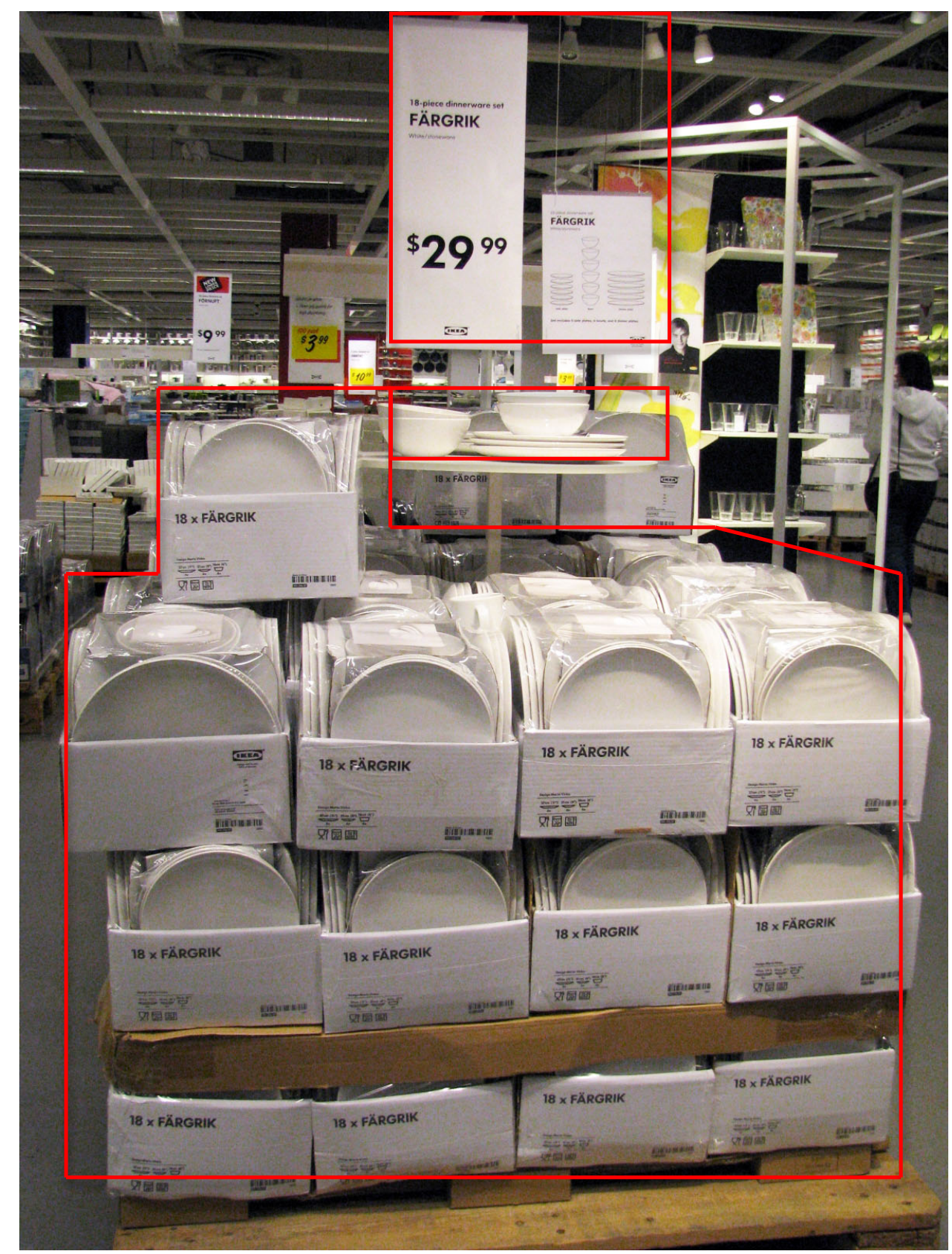

The entire display also lacks a clear hierarchy of information due to the absence of contrast (see Figure 8). For instance, the base display that contains many product packages lies below the table display. These packages contain considerably more negative than positive space and through the repetitive nature of stacked products, added amounts 
of white space were present in the structure of the FÄRGRIK product display (refer to Figure 9). By having significantly more white space than visual content in each of the product packages, in addition to the stark white products themselves, the product display design becomes unbalanced. The lack of contrast in the display, achieved through the overuse of white and repetitive visual elements, results in a lack of salience in the display's overall composition. As such, shoppers cannot differentiate or prioritize the information in the display because all of the visual elements blend together with no particular element standing out. Shoppers cannot effectively navigate the display's content or find useful information, which might be why most leave the display after a short period of time. During my observations, I noted that a customer had significant trouble determining the number of products contained in the FÄRGRIK product package. This shopper actually attempted to count the number of plates and bowls inside the sealed package, rather than refer to the signs that clearly and effectively indicated the number and type of products being sold. The strategic use of white space and information hierarchy demonstrate the effectiveness of each of the display signs; but, the scale of the signs could be improved to make important information more prominent in the display structure and overall retail space.

Figure 9: Predominantly white FÄRGRIK display base

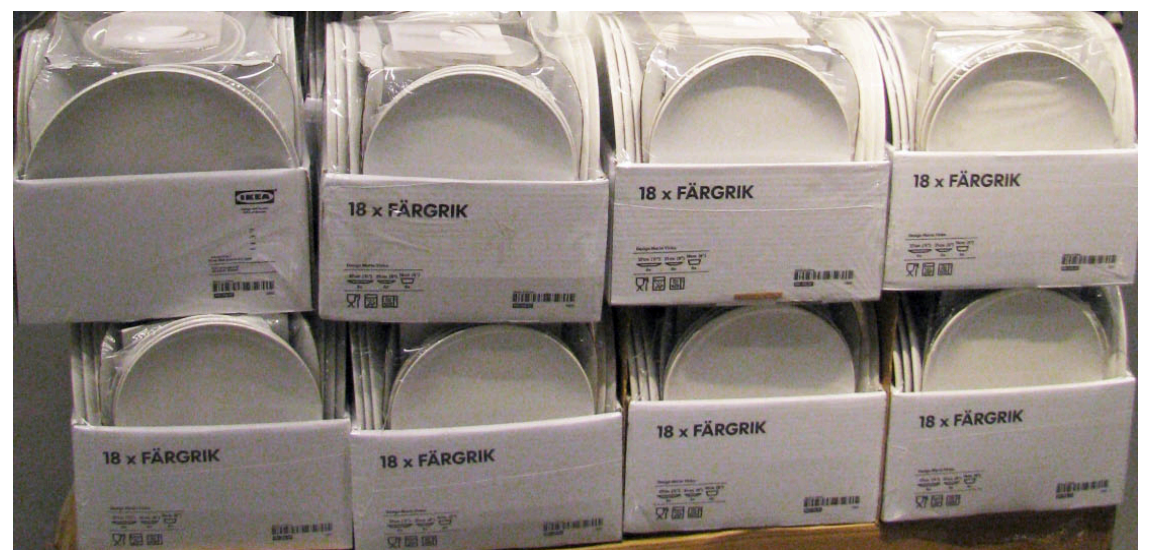


Individually, the parts of the display, such as the signs, use white space and information hierarchy somewhat effectively to draw attention to important information such as price, product content, and sample products; however, the entire display contains an unbalanced amount of white space with a significant lack of contrast, in both tone and scale, for the overall composition.

\section{iii. Location and Ambience (3D)}

In the context of the "Cookshop \& Tableware" department as a whole, the FÄRGRIK product display exists as an instance of white space. Just as white space emphasizes elements in the positive space of the display, the FÄRGRIK product display calls attention to the other displays surrounding it. White space on a two-dimensional plane allows for a visual break for the viewer or a pause before more important information is introduced. Likewise, the placement and design of the FÄRGRIK product display in the "Cookshop \& Tableware" department in the Market Hall of IKEA North York might have been done purposefully to attract attention to what the store deemed "more important" products.

Ambient and atmospheric elements surrounding the display emphasize the simplistic, white colour of the FÄRGRIK product display. For instance, three pot lights point directly at the base of the display structure. These lights accentuate the bright white nature of the display in the context of the Market Hall at IKEA North York. Additionally, IKEA North York chose to place the FÄRGRIK product display directly beside a more "showroomlike" visual merchandised table display (see Figure 10). This neighboring display was designed to look like someone's patio with furniture, tableware, and other decorative elements and accessories. In comparison to the FÄRGRIK product display, the showroomlike table display has significantly more color and its layout is more conducive to tactile 
responses and petting due to its use of a familiar piece of furniture. As well, the scale of the display is more varied with larger signs and large panels of color, which also greatly reduces the amount of white space in the display. The table display contrasts with the FÄRGRIK product display, which increases its prominence in the retail space. As such, the FÄRGRIK product display further recedes in the Market Hall and receives less overall attention from shoppers. By placing the FÄRGRIK product display next to a more visually interesting display in the Market Hall, IKEA North York is clearly using another technique to detract attention away from FÄRGRIK.

Figure 10: Highly-designed competitive display beside FÄRGRIK

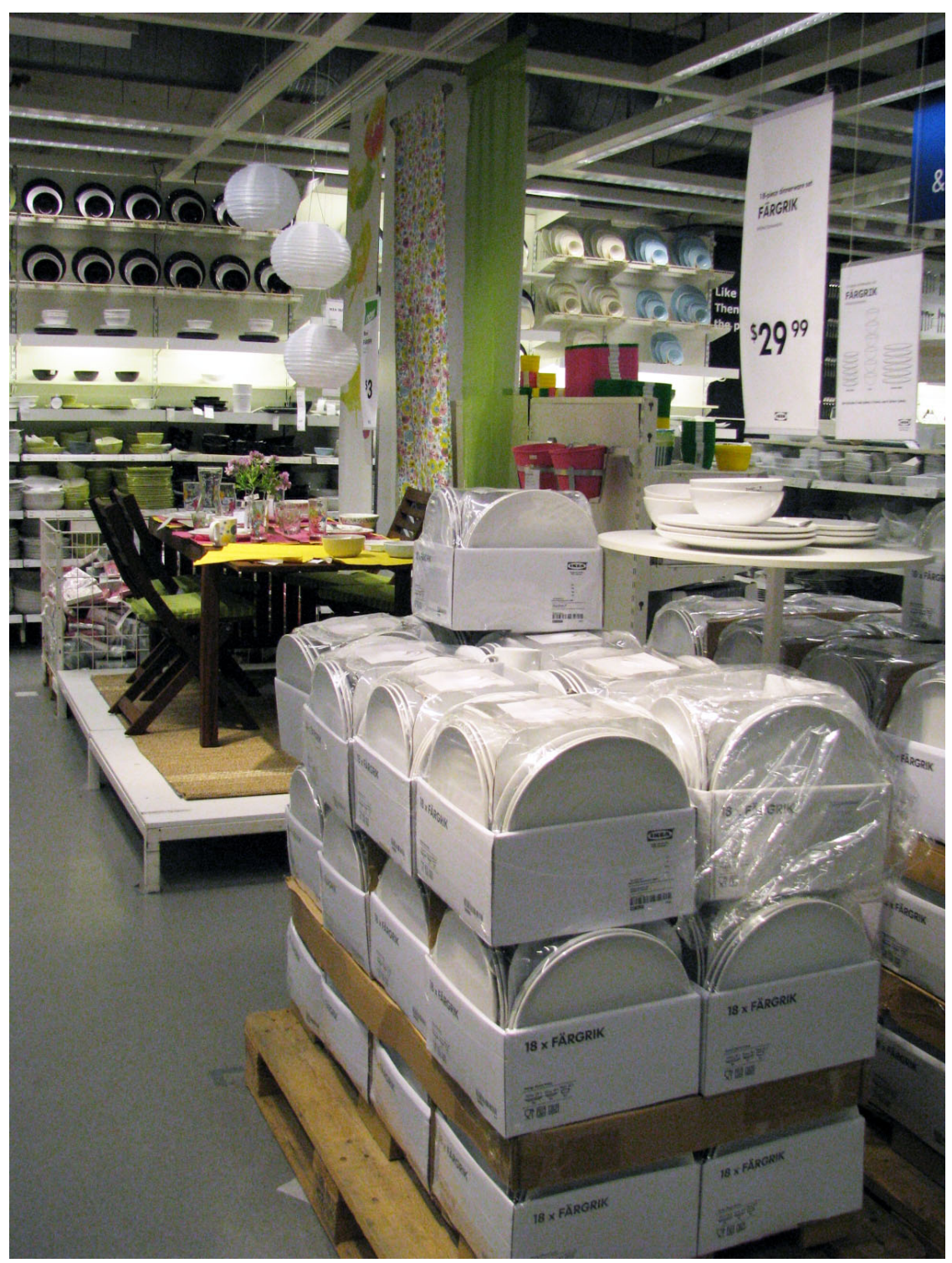


As the FÄRGRIK product display is among the first few displays in the introductory department of the Market Hall it is almost guaranteed that the display will be ignored. See Figure 2 for a map of IKEA North York's Market Hall. Techniques of retail geography must be used prior to visitors entering a store so that the retail experience is successful from the start. Shoppers need a landing strip before they cross the threshold of a store, a time to adjust to various external elements such as lighting and environmental changes. Underhill (1999) calls this space the Transition Zone, or Decompression Zone, and it must be effectively utilized by a store to ease consumers into the retail environment. According to Underhill (1999), "allowing some space between the entrance of a store and a product gives it more time in the shopper's eye as he or she approaches it. It builds a little visual anticipation" in the consumer (p.50). Shoppers need to orient themselves in the environment of the Market Hall and therefore will most likely be unable to digest any of the items that are displayed immediately upon their arrival. As such, the design of the FÄRGRIK product display reflects the fact that the product is possibly not supposed to be noticed. Rather, by composing the entire FÄRGRIK product display as an instance of white space in the department, the display acts a precursor to the rest of the store.

IKEA North York appears to use elements of design to persuade its shoppers to avoid purchasing FÄRGRIK products through the visual elements of the retail display. Rather than use the design of the FÄRGRIK product display to incite purchases, IKEA North York seems to overuse design strategies to draw attention away from a low priority product to an item of more value. As such, while the FÄRGRIK product display was strategically designed, its visual messages sought to evade shoppers' attention. 


\section{iv. FÄRGRIK Visual Analysis Summary}

\begin{tabular}{|c|c|}
\hline $\begin{array}{l}\text { Information } \\
\text { Hierarchy }\end{array}$ & $\begin{array}{l}\text { Signage } \\
\circ \text { Information hierarchy is made clear through the effective use of white } \\
\text { space. } \\
\text { Use of exaggerated scale and modifying visual weights of graphic and } \\
\text { textual elements prioritizes product price. } \\
\text { Product Display Structure } \\
\text { The entire display lacks a clear hierarchy of information due to the } \\
\text { absence of contrast caused by the overuse of white and repetitive visual } \\
\text { elements. } \\
\text { Results in a lack of salience in the display's overall composition; therefore, } \\
\text { shoppers cannot differentiate or prioritize information in the display. }\end{array}$ \\
\hline White Space & $\begin{array}{l}\text { Signage } \\
\circ \text { White space is used to emphasize particular segments of information } \\
\text { including product price and product diversity through the graphic } \\
\text { illustration. } \\
\text { Product Display Structure } \\
\circ \text { White space exists in the gaps of the display. } \\
\circ \text { The display self and signs, the positive elements in the display which are } \\
\text { surrounded by white space, are emphasized. }\end{array}$ \\
\hline Colour & $\begin{array}{l}\text { Product Display Structure } \\
\circ \text { The display is primarily white and void of colour, as such, the display acts } \\
\text { as an instance of white space on the retail floor. }\end{array}$ \\
\hline Ambience & $\begin{array}{l}\text { Location } \\
\circ \text { The FÄRGRIK product display calls attention to the other displays } \\
\text { surrounding it due to its lack of visual interest in the Market Hall. } \\
\text { Ambience } \\
\circ \text { Pot lights pointed at the FÄRGRIK display emphasize its bright, white } \\
\text { nature. } \\
\circ \quad \begin{array}{l}\text { Neighbouring "showroom-like" display detracts shopper attention away } \\
\text { from the FÄRGRIK product display. }\end{array}\end{array}$ \\
\hline
\end{tabular}




\section{b. FÖRNUFT}

\section{i. Signage (2D)}

Figure 11: FÖRNUFT signage

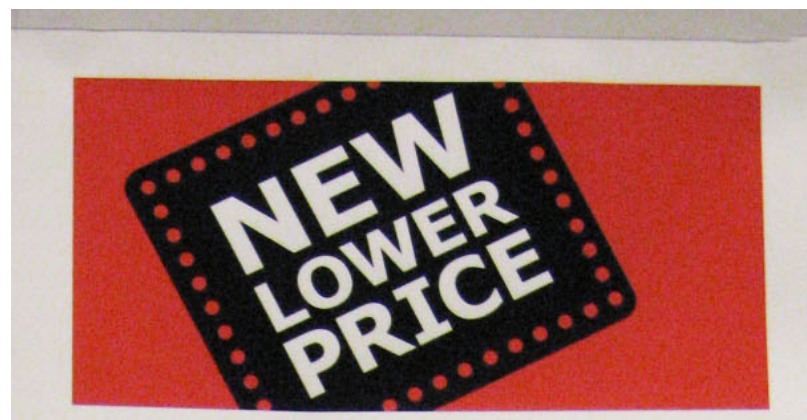

20-piece flatware set

FÖRNUFT

Stainless steel
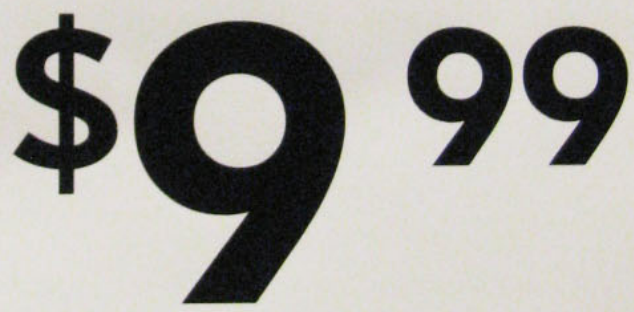

Last year's catalogue price: $\$ 10.99$
There is a single sign above the

FÖRNUFT product display (Figure 11).

This sign clearly indicates that the product is a "New Lower Price" due to the bold graphic at the top of the sign, the sign also includes information on the product name, the product type, the number of objects contained within the product package, and the product price. The use of the colour red in the sign directs attention to the "New Lower Price" graphic on the sign. While white space and aspects of information hierarchy emphasize important pieces of information on the sign (Bowers, 2008). 
Figure 12: "New Lower Price" graphic

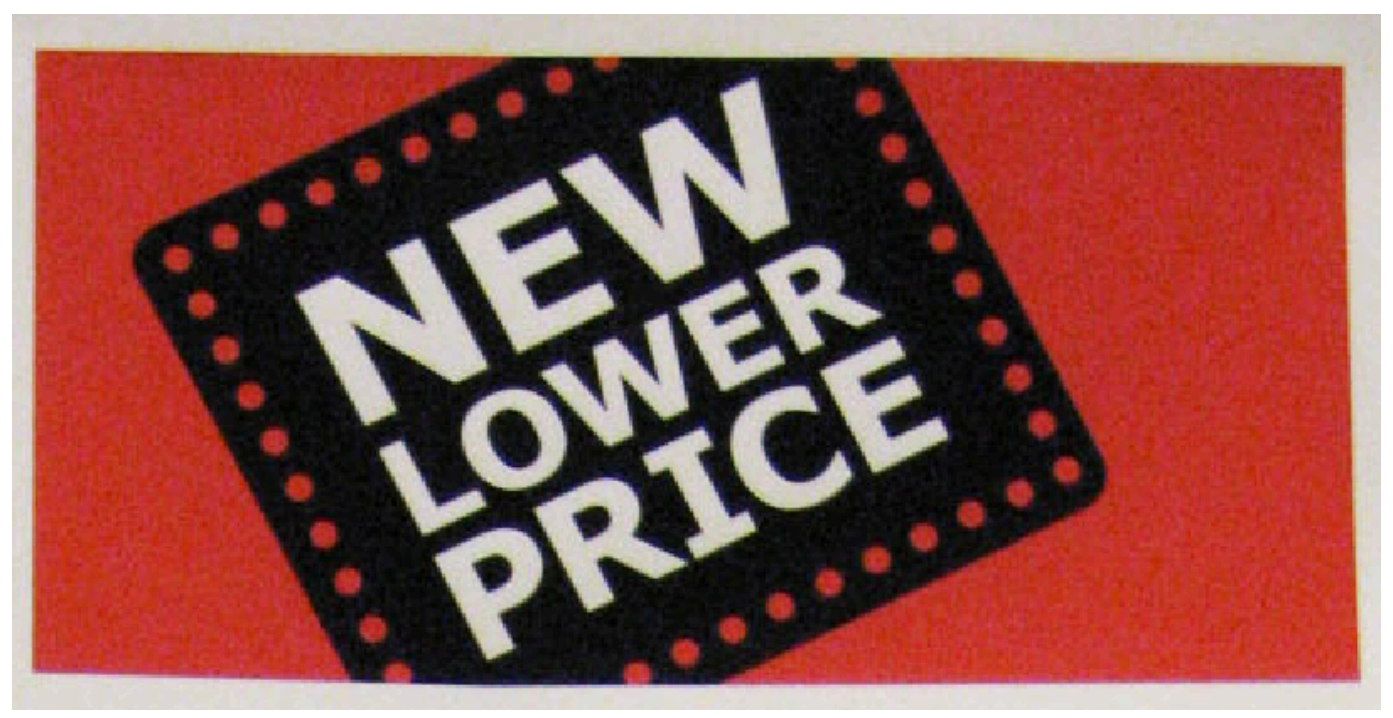

The only use of colour, another than black and white, is in the graphic at the top of the FÖRNUFT sign (refer to Figure 12). A large red rectangle is used as a bright and colorful backdrop for the information that is placed over it. By using colour in this manner, the design of the sign strategically highlights a key piece of information to shoppers. As well, as many of the signs in the Market Hall do not include much colour, this simple graphic element makes the sign stand out to shoppers. The use of red has many cultural connotations; for instance, in the retail environment red often denotes a sense of urgency and is more physically stimulating (Bellizzi, Crowley, and Hasty, 1983). As well, Bellizzi, Crowley, and Hasty (1983) found that red "lends [itself] to application in retail settings where unplanned (impulse) buying by customers is found" (p. 41), as such, red can be seen as the indicative colour of a "sale" or discounted product. By using this specific colour on the sign, shoppers immediately understand that a value-based product is being sold without actually having to read any of the information on the sign. 
As well, the use of red aids in the contrast of the sign as the information placed over the red rectangle stands out resulting in a high degree of legibility (Dondis, 1973). This is important factor as it allows viewers to quickly gain an understanding of the content being displayed. White space in the graphic, unlike in the sign for the FÄRGRIK product display, is not literally white. Rather the space between the "New Lower Price" block of text and the edge of the sign is red. Again, this adds to the stand out quality of the "New Lower Price" graphic. Lastly, the text in the graphic is bold, capitalized, and has an angled orientation. These compositional elements add contrast to the graphic, and the sign as a whole, and therefore place the graphic higher on the information hierarchy of the sign.

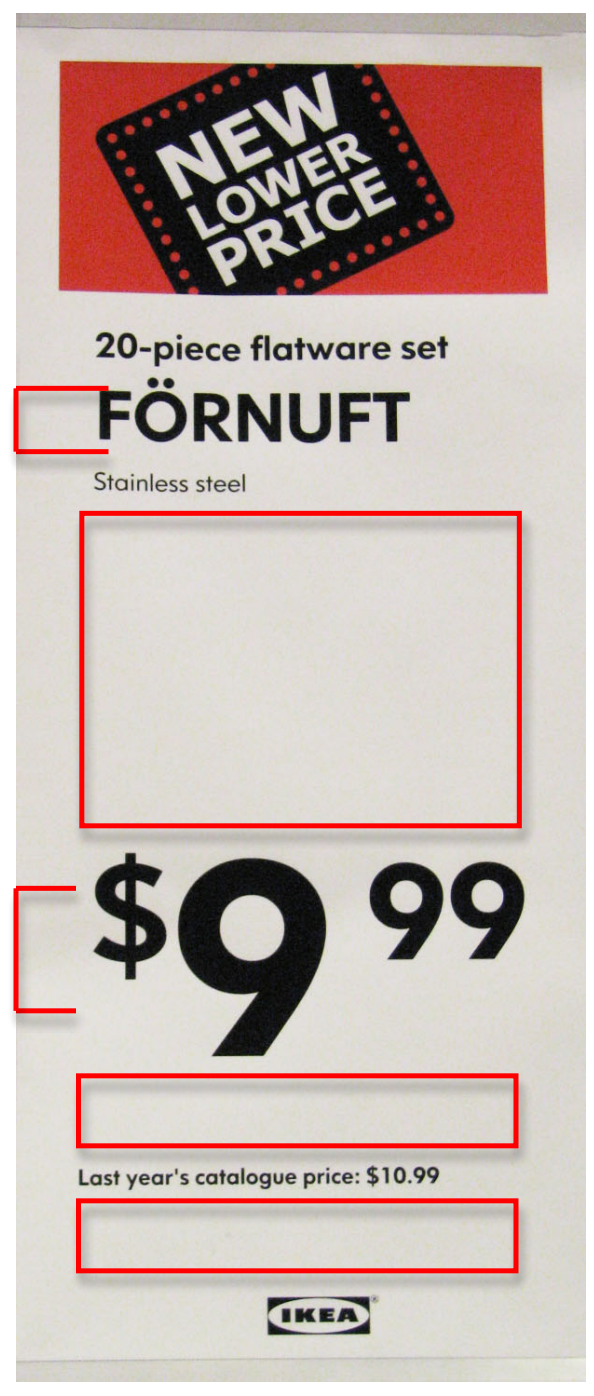

Figure 13: FÖRNUFT signage with white space and information hierarchy

Although the rest of the sign does not include any colour, white space and elements of information hierarchy are used to prioritize certain pieces of information that are most pertinent to shoppers. As indicated by the well-designed "New Lower Price" graphic, the selling feature of FÖRNUFT appears to be price. As such, both white space and scale are used to place a significant amount of visual importance on the price on the sign (refer to Figure 13). White space can be seen between the first three lines of text and the large type price tag, and between the price tag and the single 
line of text, and between this line of text and the IKEA logo. These unequal instances of white space allow for the reader to prioritize the price of the product, as it is the one key piece of information in the sign (Smith and McComb, 1971). As there is an insignificant amount of white space between the "New Lower Price" graphic and the first segment of copy, these lines of text do not stand out. Rather, this body of text almost blends into the rest of the sign despite the presence of hierarchical elements including bold and capitalized typography (Spencer, Reynold, and Coe, 1974). However, a large segment of white space follows the body of text, which allows for ample free space for shoppers to read this information (Smith and McComb, 1971). Additionally, the price is extremely large in the context of the overall composition of the sign making it the most prominent piece of information for shoppers. The significant amounts of white space surrounding the price and the exaggerated use of scale in the design of this sign allows for the information present to become more valuable to readers (Strong, 1926). Though, the final line in the sign could be made more prominent in the sign as it is currently illegible from a distance. For instance, through elements of information hierarchy, including scale, weight, proximity, or colour, the display could be made more visible to shoppers as this line of text emphasizes the value and current price of the product (Bowers, 2008). As this copy is not adequately emphasized through the design of the sign, shoppers are unaware of what could be an equally important characteristic of the product. Regardless of this small shortfall, the FÖRNUFT sign clearly identifies important visual cues through colour, white space, and information hierarchy.

The design of the FÖRNUFT product display sign clearly places a significant amount of important on the price and value of the product. This is evident because colour, white 
space, and elements of hierarchy were all used in conjunction with one another to place visual weight on the "New Lower Price" graphic and the product price. This conclusion can be verified from observational data on consumer behaviour surrounding this display. I noted that a significant number of customers walked directly past the display and 89 of these shoppers looked directly at the display before continuing on through the Market Hall. Therefore, the FÖRNUFT product display sign was somewhat successful in attracting shopper's attention; still, some aspect of the design of the display itself was able to garner further notice from shoppers as 18 shoppers touched the display and six intended to buy the product.

\section{ii. Product Display Structure (3D)}

Just as elements of design can be used to emphasize pertinent pieces of information to shoppers on a two-dimensional plane, they can also be used for the same purpose on a three-dimensional document such as the FÖRNUFT product display (see Figure 14). The design of the FÖRNUFT product display contains many instances of white space, which are achieved through the use of gaps in the display structure. Additionally, scale and proximity are used to create a clear hierarchy of information in the product display.

The FÖRNUFT product display contains a significant amount of white space in its display structure. This is, in part, due to the fact that at the time of observation the display appeared to be running low on product packages and was generally quite "empty". Regardless, the white space between the sign and the table shelf is about half the size of the space between the table shelf and the boxes of product packages resting on the display's base. In theory, by framing the table shelf with white space, the table shelf should stand out 
visually to viewers. However, the table shelf, which holds sample products intended to entice tactile responses, is lost amongst the display structure. This is due to the scale of the

Figure 14: White space and information hierarchy in the FÖRNUFT product display

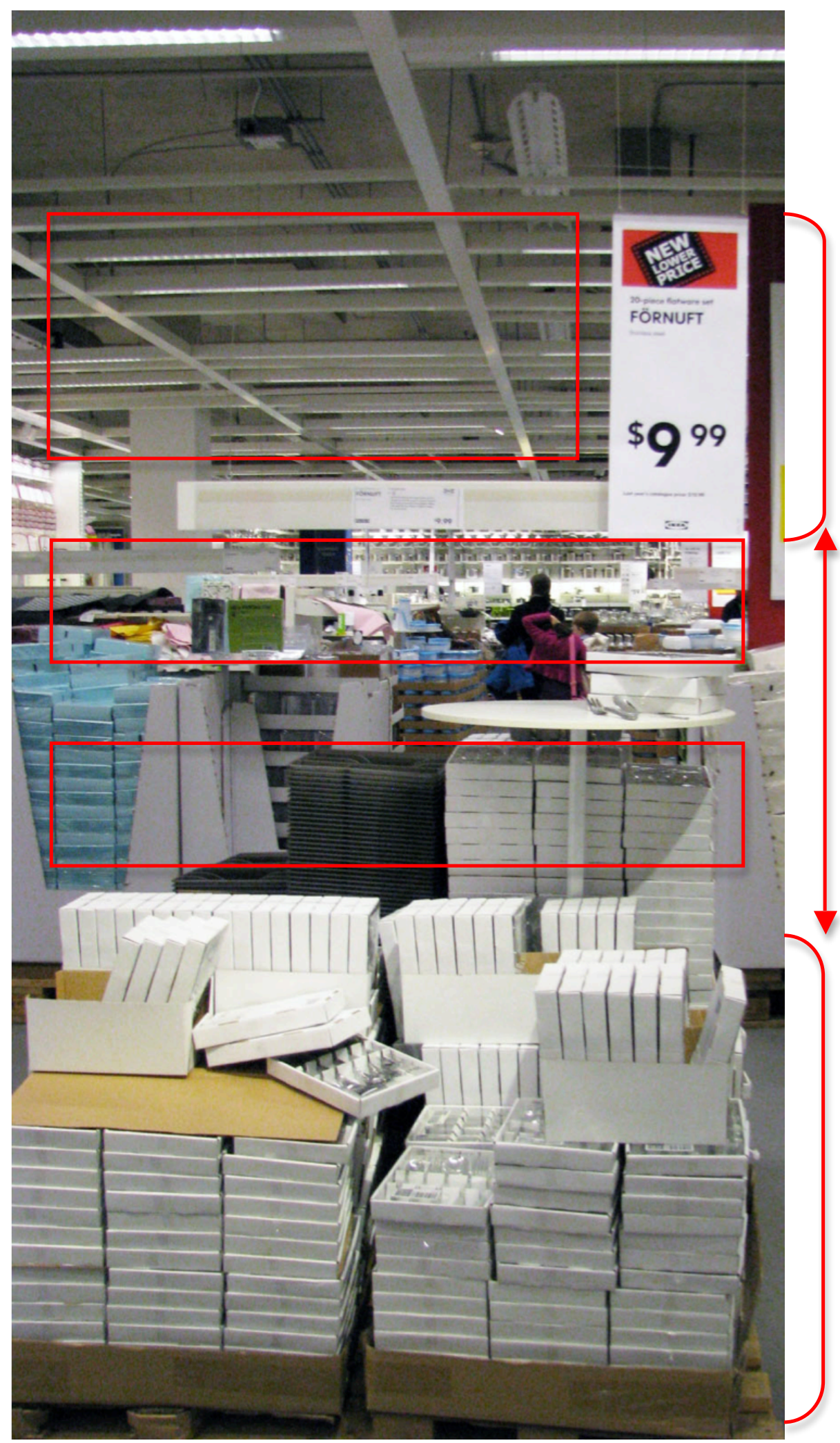

Sign is too small

Distance too great between sign and product packages

Too much visual weight at the base of the display 
display structure as the table shelf is too small and innocuous for the display as a whole. The table shelf disappears because there is more negative than positive space in the display structure and therefore the positive element in the display, the table shelf, simply disappears. Therefore, due to its size and surroundings, the table shelf does not encourage tactile responses from shoppers. In fact, from my observations I found that most shoppers interacted with the product packages on the display base and not the sample products on the table shelf. There was even an open product package on the display where a shopper had clearly tried to get a closer look at the product, as they obviously did not see the table shelf with samples already on display.

Just as the size of the table shelf was too small for the large display, the scale of the display's signage deemphasized its importance. The purpose of the sign is to both attract and inform shoppers of the product being sold at the display; but, while the sign effectively informs shoppers, its small size cannot be seen from a distance. Additionally, the entire display, which is large and quite clunky in nature, overwhelms the sign in the overall composition of the display structure. The weight of the display structure appears unbalanced because there is more substance at the bottom of the display due to the large amount of white packages on the display base. These packages stood out due to the stark contrast between them and the rest of the display structure, in which the Market Hall acts as the backdrop. Additionally, the FÖRNUFT product display has issues regarding the proximity of its visual elements, which detract from the display's message. The distance between the sign and the products is too great due to the "empty" nature of the display and the extremely small nature of the signage, Therefore, even if shoppers were attracted to the 
sign on its own, this attraction did not always translate to increased interaction with the display as the structural elements of the display are visually disconnected.

Scale, weight, proximity, and white space are used in the FÖRNUFT product display to create a hierarchy of information. However, these elements may not have been used in an advantageous manner. Therefore, although there is a clear hierarchy of information in the FÖRNUFT product display, the visually heavy display base, not the signage or the table shelf, are the most prominent segments of the entire composition.

\section{iii. Location and Ambience (3D)}

Figure 15: BTI beside the FÖRNUFT product display

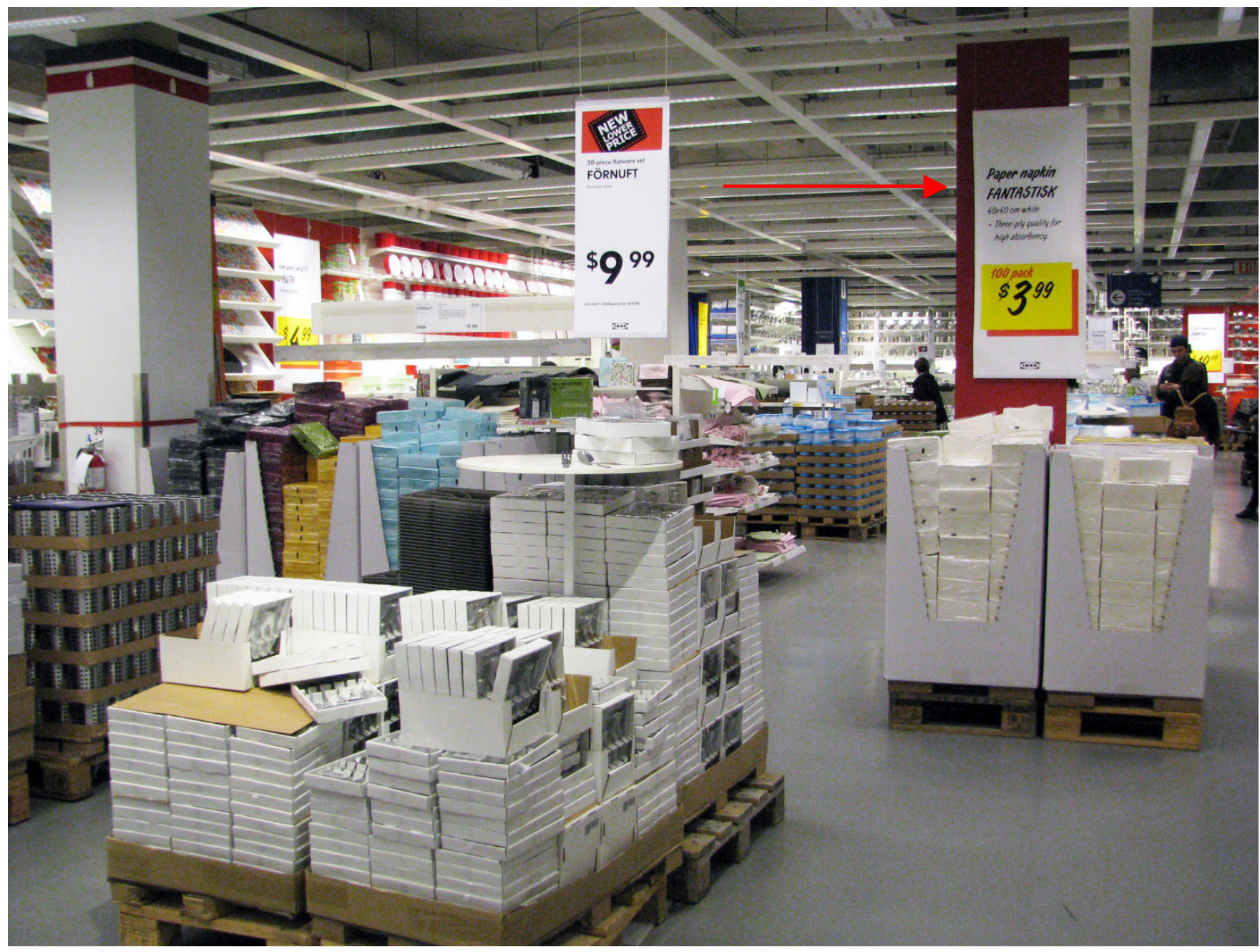


Just as with the FÄRGRIK product display, the FÖRNUFT product display, in the context of the "Cookshop \& Tableware" department, is not very effective in part due to its ambient qualities including location and retail context (see Figure 15).

Figure 16: 'Fork' and FÖRNUFT product display in the Market Hall

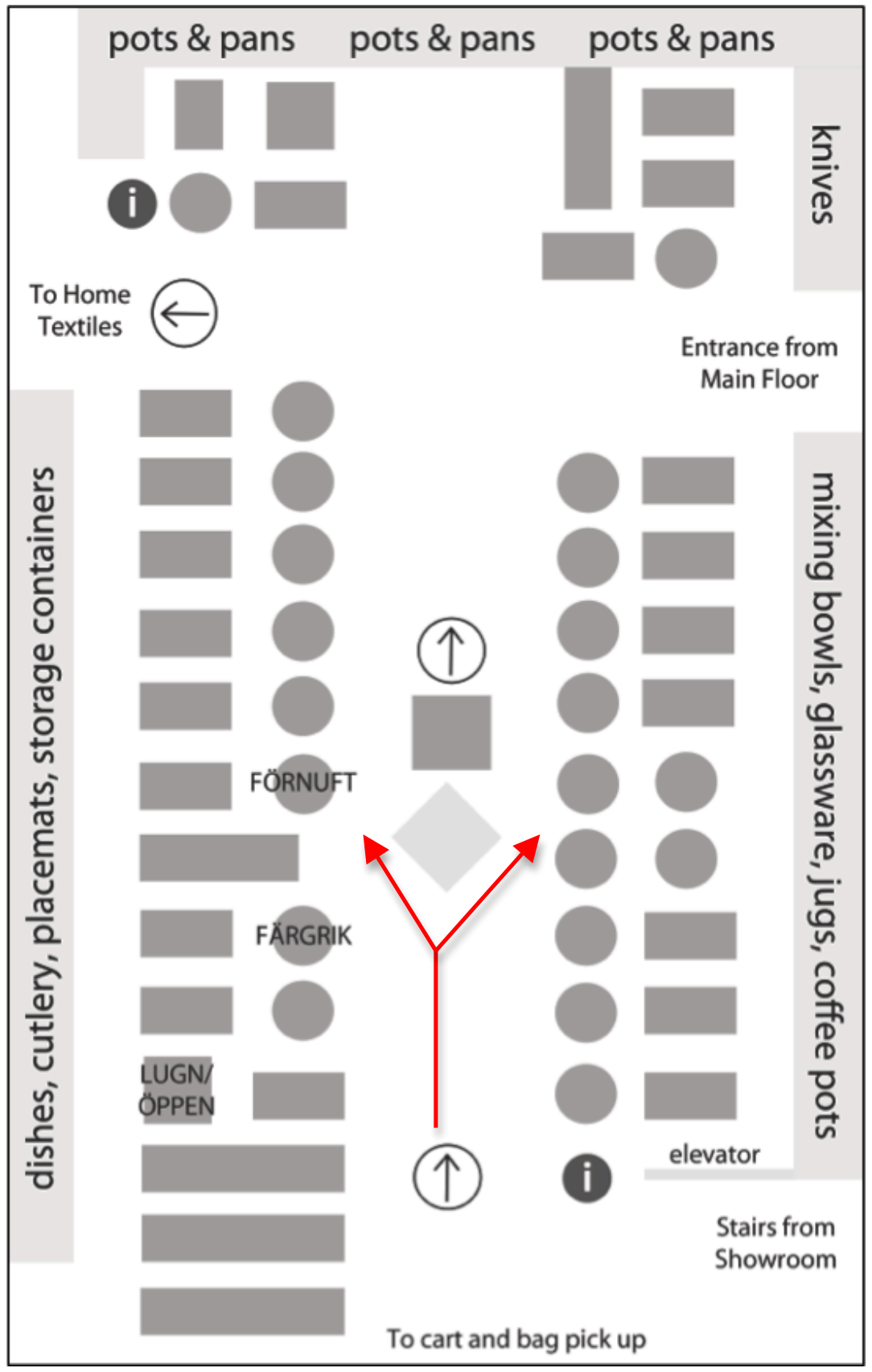

The FÖRNUFT

product display is located at

a "fork" in the "Long Natural

Way", or intended route in

the aisle, in the "Cookshop

and Tableware" department

(refer to Figure 16).

Therefore, due to the

display's location, most

shoppers are forced to

confront the display head on.

Nevertheless, most likely due

to the design display

structure and the size and

location of the signage,

during my observations I

noticed that shoppers often

walked right past the display 
without paying any attention to it. The location of the FÖRNUFT product display is ideal because it essentially forces shoppers to pass the display due to its location, which is adjacent to the main aisle. However, despite the ideal location, the display's structure failed to garner a considerable amount of consumer notice. Additionally, I noticed that despite the intended wayfinding trajectory of the Market Hall and the "Long Natural Way", many shoppers approached the display from the side or from the main aisle, rather than the foot of the fork. Furthermore, the FÖRNUFT product display's signage in particular does not accommodate for viewing from multiple perspectives. Hence, the ideal display location is wasted on a product display with multiple design shortcomings.

While the FÖRNUFT product display location was successful, the display's retail context and surrounding environment pulled the focus away from this "New Lower Price" product. A BTI was located directly behind the FÖRNUFT product display, which included a large red panel and sign, similar to that of the LUGN/ÖPPEN display. Although IKEA North York prioritizes BTIs by placing them in hot spots throughout the retail floor and adding additional graphic elements to the display, the close proximity of the BTI detracted attention from the FÖRNUFT display. In fact, during my observations I noticed that many shoppers walked right past the FÖRNUFT display because they were immediately attracted to the BTI display right behind it. The focus pulling BTI behind the FÖRNUFT display pulled shoppers attention and therefore their patronage intention away from another seemingly important product on the retail floor.

Additionally, the FÖRNUFT display is the only freestanding display structure that is selling utensils, in the "Cookshop and Tableware" department. In contrast, both the FÄRGRIK and LUGN/ÖPPEN display, in addition to other freestanding displays, sold 
dishware. Being the only freestanding flatware display in IKEA North York's Market Hall should be a good thing as the display is seemingly more prominent to shoppers who are just casually browsing through the store. However, for shoppers who like to comparison shop in the retail environment and evaluate different products, the FÖRNUFT display is located too far away from similar products that are located on nearby wall display, which prevents shoppers from making quick comparisons. With the table shelf and sample products that are so hard to distinguish from the overall FÖRNUFT display, it is also very difficult for shoppers to take a sample product away from the display for comparison purposes. As such, while the placement of the FÖRNUFT product display is beneficial in some regard, it hinders shoppers' ability to browse the store with ease.

The location and retail context of the FÖRNUFT product display have both positive and negative repercussions. The display is located close to the aisle, yet is inaccessible from multiple angles. Additionally, despite the freestanding nature of the FÖRNUFT display, it is placed beside a highly designed competitive display and is not in close proximity to similar products. Despite their best intentions, IKEA North York's inconsistent use of design strategies results in the lack of focus in the visual elements of the FÖRNUFT display. As such, while small segments of the FÄRGRIK product display were strategically designed and effective forms of visual communication, its overall visual message appeared to dissuade the viewing public from responding to this example of visual communication through consumption. 


\section{iv. FÖRNUFT Visual Analysis Summary}

\begin{tabular}{|c|c|}
\hline $\begin{array}{l}\text { Information } \\
\text { Hierarchy }\end{array}$ & $\begin{array}{l}\text { Signage } \\
\text { Contrast, both colour and in orientation, in the "New Lower Price" graphic } \\
\text { place this element higher on the information hierarchy of the sign. } \\
\text { The large scale of the price tag makes it a prominent feature in the sign's } \\
\text { composition. } \\
\text { Product Display Structure } \\
\text { The scale of the table shelf and signage is too small for the display } \\
\text { structure as a whole and, therefore, both elements disappear. } \\
\text { The weight of the display structure is unbalanced due to the large amount } \\
\text { of white packages on the display base. } \\
\text { The proximity is too great between the visual elements in the display, } \\
\text { such as the signage and the display base, which detracts from the display's } \\
\text { message. }\end{array}$ \\
\hline White Space & $\begin{array}{l}\text { Signage } \\
\text { ○ Unequal instances of white space in the sign allow for the reader to } \\
\text { prioritize the price of the product. } \\
\text { Product Display Structure } \\
\text { The display appeared to be running low on product packages and was } \\
\text { generally quite "empty", which increased the amount of white space in the } \\
\text { structure. }\end{array}$ \\
\hline Colour & $\begin{array}{l}\text { Signage } \\
\circ \text { The use of the colour red in the "New Lower Price" strategically highlights } \\
\text { a key piece of information to shoppers. } \\
\circ \text { The colour red is also indicative of a "sale" or discounted product. }\end{array}$ \\
\hline Ambience & $\begin{array}{l}\text { Location } \\
\circ \text { Despite the ideal location, the display's structure fails to garner consumer } \\
\text { notice because it does not accommodate for viewing from multiple } \\
\text { perspectives. } \\
\text { Ambience } \\
\circ \text { A focus pulling BTI behind the FÖRNUFT display pulled shoppers } \\
\text { attention away from the display. } \\
\text { The display is located too far away from similar products hindering } \\
\text { shoppers' ability to browse the store with ease }\end{array}$ \\
\hline
\end{tabular}




\section{c. LUGN/ÖPPEN}

\section{i. Signage (2D)}

Figure 17: Sign at the LUGN/ÖPPEN product display

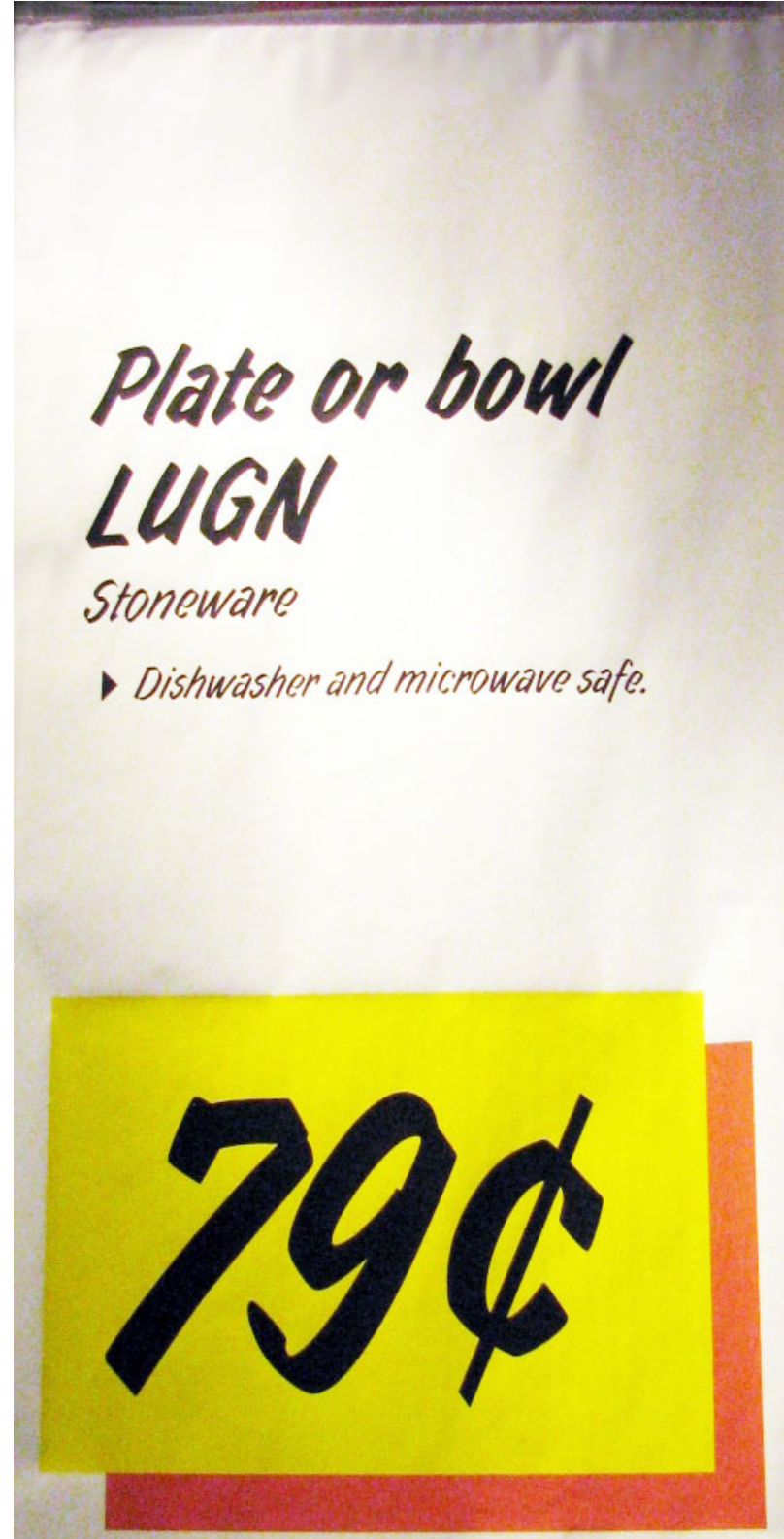

IKEA
There is a single sign above the LUGN/ÖPPEN product display (see Figure 17). In spite of this, the sign does not clearly state what items are being sold in the product display below. Currently, the signage above the LUGN/ÖPPEN product display only promotes LUGN products; yet, ÖPPEN products are sold on the same display structure and both products have the same price. Therefore, it appears as if customers regard the sign as applicable to both products when, in fact, it refers to only one. Upon initial impression, the sign could be made clearer, indicating that the display is selling two different product lines for the same price. Although the sign includes information on LUGN's product name, product type, and price, there is an element 
of miscommunication that causes confusion in the message delivery. The use of yellow and orange in the sign directs attention to the extremely low cost product. Additionally, both white space and hierarchical elements prioritize important pieces of information on the sign.

Figure 18: LUGN/ÖPPEN signage price tag graphic

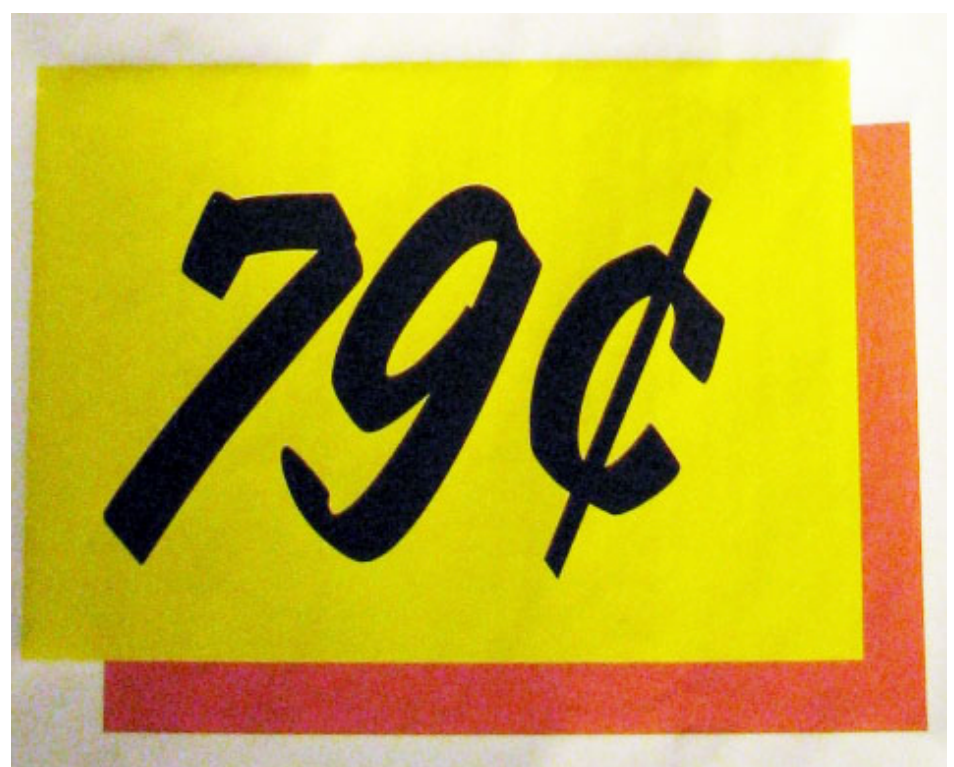

The only use of colour in the LUGN/ÖPPEN sign, other than black and white, is in the yellow and orange graphic beneath the price tag (refer to Figure 18). The simple yellow and orange squares makes both the graphic, and the overlapping price text, stand out due to the high degree of contrast between the bold colours and the stark white background of the sign (Dondis, 1973). By using colour in this manner, the design of the sign strategically highlights a key piece of information to shoppers. The Market Hall is generally void of colour, especially on signs, therefore, this simple graphic element makes this sign stand out to shoppers. Additionally, the use of warm colours has been proven to draw customer attention in retail settings (Bellizzi, Crowley, and Hasty, 1983), yet the bold and saturated nature of the colours still invoke a sense of urgency (Bellizzi, Crowley, and Hasty, 1983) that corresponds to the low price nature of the products being sold on the LUGN/ÖPPEN product display. Lastly, in comparison to the size of the sign as a whole, the yellow and 
orange graphic takes up a substantial amount of the overall composition of the sign. As such, whatever information is placed on the graphic is extremely prominent to shoppers due to the significant and purposeful use of colour.

Figure 19: White space and information hierarchy on the LUGN/ÖPPEN sign

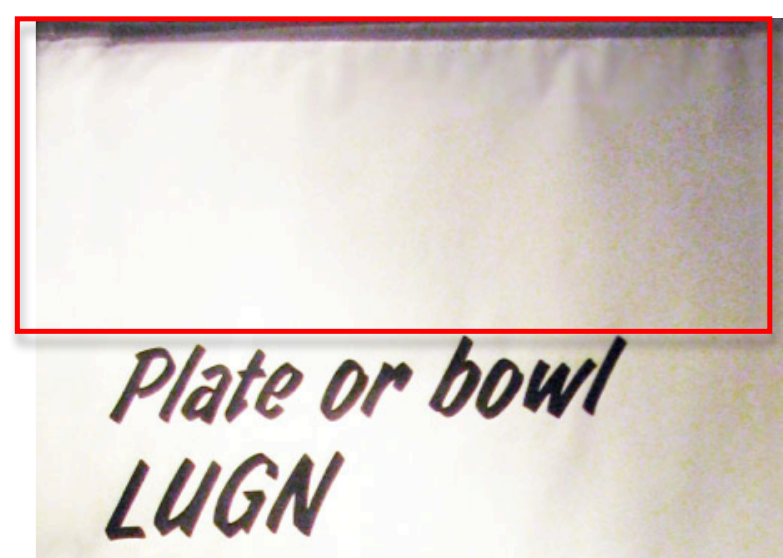

Stoneware

- Dishwasher and microwave safe.

Large price tag graphic and strong colour contrast

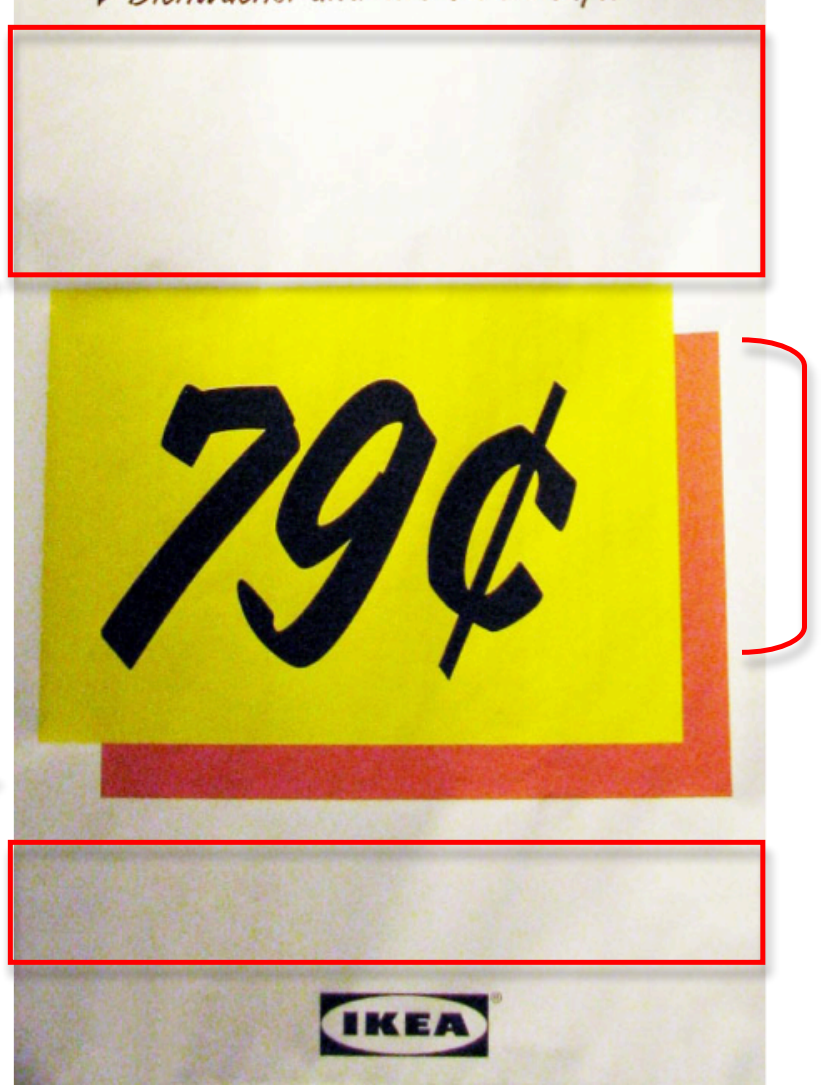

Large scale " $\$$ " symbol 
Although the rest of the sign in the LUGN/ÖPPEN display does not include any colour, both white space and elements of information hierarchy are used to prioritize a certain piece of information in the sign that IKEA North York deems is most pertinent to shoppers (refer to Figure 19). The primary selling point for both LUGN and ÖPPEN products appears to be price. Therefore, white space is used to visually emphasize and prioritize the price on the sign. White space can be seen between the first four lines of text and the large type price tag as well as between the price tag and the IKEA logo. While the sign may appear unbalanced, these unequal instances of white space allow for the reader to prioritize the price of the product in the overall composition of the sign as the price tag is isolated from all the other visual elements on the page. Although, white space emphasizes the price on the sign, it also overwhelms the top section of the sign. Here, the four small lines of black text are overpowered by the surrounding white space and, as such, almost blend into the rest of the sign. Again, white space is used in the sign to emphasize the price of the product, which is also done through deemphasizing all the other textual information in the document.

As information hierarchies organize, prioritize, and communicate visually by modifying the visual weights different elements carry, scale is an important indicator of the most salient parts in a document. The price tag on the LUGN/ÖPPEN sign is extremely large in the context of the overall composition making it the most prominent piece of information for shoppers. Additionally, the " $₫$ " symbol next to the price is the same size as the numbers themselves. By creating the unit of measure at the same scale as the price itself, IKEA North York clearly emphasizes the low cost and value of the product. From looking at the amplified visual weight on the LUGN/ÖPPEN sign, it is obvious that the sign 
is meant to be viewed from a distance. This explains the exaggerated scale of the yellow and orange graphic, the large price tag, and bigger than average currency symbol. The use of scale to prioritize the price of the product is done in order to draw shoppers, who are just entering the Market Hall, closer to the display.

The significant amounts of white space surrounding the price and the exaggerated use of scale in the design of this sign allows for the information present to become more valuable to readers. The design of the LUGN/ÖPPEN product display sign clearly places a significant amount of importance on the low cost nature of the product. This is evident because colour, white space, and elements of hierarchy, especially scale, were all used in combination with one another to place visual weight on the product price.

From my observations it was clear that the shoppers' response to the signage was to immediately look at the products on display. Overall, the large banner appeared to be very effective in garnering attention from shoppers. However, the signage at the LUGN/ÖPPEN display attracted only 39 shoppers over two days, which was the lowest total number of visual interactions out of all three observed displays. This can be partially attributed to the difficulty of observing responses to the signage from shoppers who had viewed the sign from a distance. Regardless, the visual elements in the display structure managed to motivate seven shoppers to purchase LUGN or ÖPPEN products, which was the highest number of total intended purchases. This demonstrates that though the sign was able to attract many shoppers' attention, it is generally not meant to be viewed within close proximity. Additionally, the data demonstrates that the LUGN/ÖPPEN product display was the most successful in garnering potential sales, as $10.45 \%$ of shoppers who interacted with the display intended to purchase the product. The LUGN/ÖPPEN display was the most 
successful display in garnering sales, but it also received the highest number of tactile responses at 21 . As such, from reviewing the data, the display signage was successful in garnering attention for the LUGN/ÖPPEN display from a distance and the actual structure of the display appears to be the defining point of visual persuasion for shoppers.

ii. Product Display Structure (3D)

Figure 20 and 21: LUGN/ÖPPEN product display structure
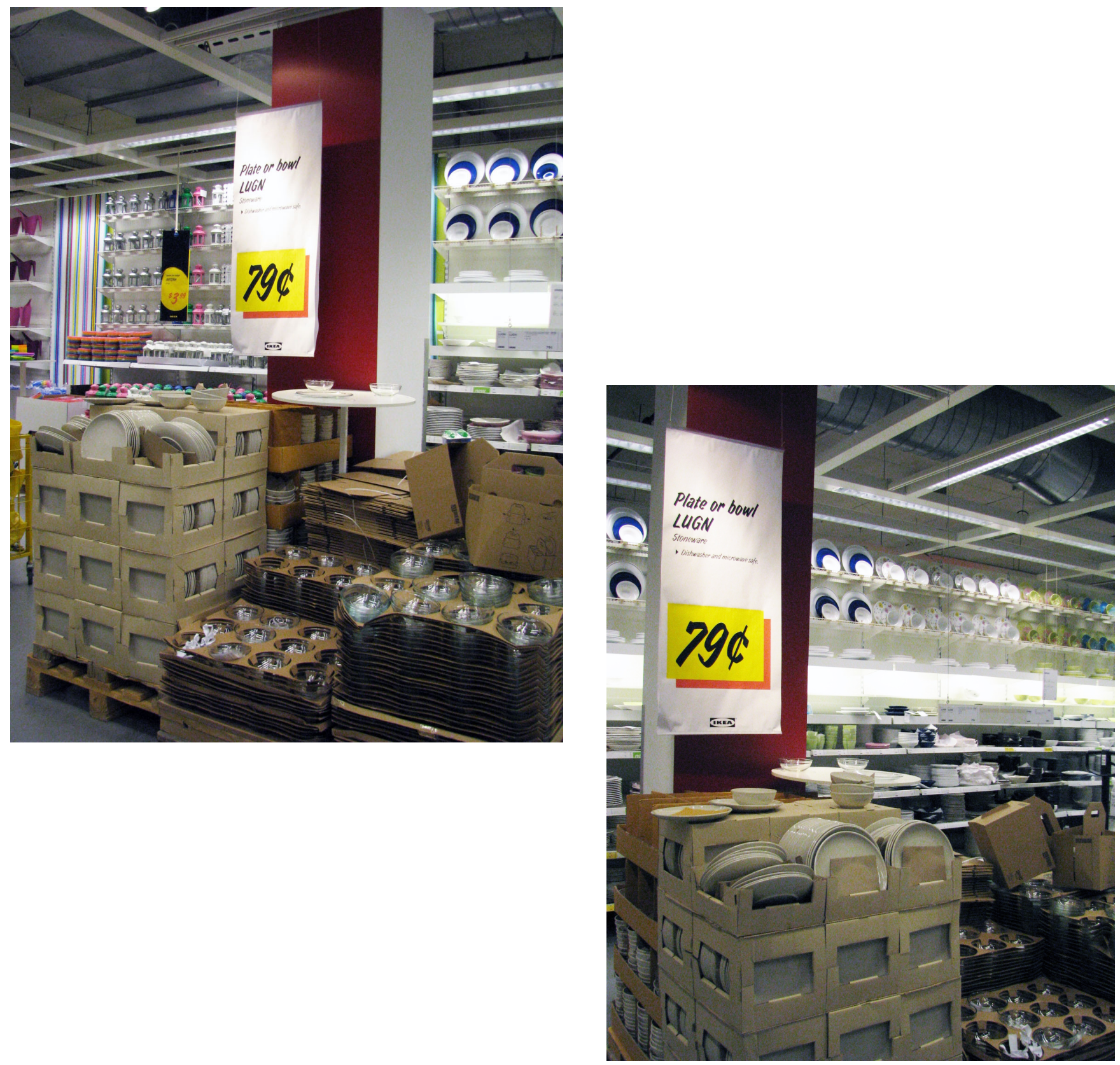
The LUGN/ÖPPEN display (see Figures 20 and 21) does not give off a positive first visual impression, because, at the time of observation, the display was extremely messy, disorganized, and cluttered, which gave the feeling that this already low cost product was even "cheaper" than it appeared. This disorganized appearance could have been a deterrent for shoppers who could not see the product clearly amongst all the cardboard scattered throughout the display structure. Furthermore, this display did not seem to correspond with IKEA North York's clean, minimalist aesthetic and style sense. Additionally, the untidy display structure cheapens the products being sold, which further emphasizes that LUGN/ÖPPEN products are value oriented, rather than design focused. Despite its state of disarray, the LUGN/ÖPPEN product display was extremely successful in attracting tactile responses, as 21 shoppers interacted with the display over a span of two hours. Additionally, due, in part, to these tactile responses, 7 shoppers intended to purchase items from the LUGN/ÖPPEN display.

Colour is one of the distinguishing features of a Breathtaking Item (BTI). In the Market Hall, BTIs are instantly recognizable due to the use of colour on both the retail signage and on accent walls. For instance, just like with other BTIs in IKEA North York's Market Hall, the LUGN/ÖPPEN product display features a large red pillar located immediately behind the display structure. Bellizzi, Crowley, and Hasty (1983) found that, in retail environments, the colour red has the ability to draw in shoppers and encourage impulsive and unplanned purchases, both of these elements are coincidentally characteristic of a BTI product display. This use of a strong, bold colour on a structural part retail space makes the LUGN/ÖPPEN product display really standout out in the store environment, which consists of predominantly white walls. This holds especially true in the 
Spring/Summer season where green is the featured accent colour in the retail environment at IKEA North York. As green is the complimentary colour to red, the colour contrast makes the pillar seem even more prominent in the space (Dondis, 1973). The colour red also has cultural connotations in the retail space as it is often used to denote "sale" or discounted products. Thus, the use of red is effective in garnering attention to the LUGN/ÖPPEN product display due to its high contrast with the rest of the retail space and with the colour green and because the colour immediately resonates with shoppers who understand that, conventionally, red in the retail space denotes a value based product for sale.

Although the LUGN/ÖPPEN product display effectively uses the colour red to promote the display in the Market Hall and emphasize the low cost nature of the product, the other colours used in the display are dull in comparison. For instance, there is a lot of brown in the product display due to the extensive use of cardboard as a means of product display and storage. As such, the overall feeling of the display is monochromatic and lackluster, which is not a good visual impression to make when trying to attract consumer attention. Additionally, the use of brown cardboard adds to the industrial feel of the Market Hall. While the Market Hall is essentially a warehouse appearance, elements of design and visual merchandising strategies are used to detract from the industrial feeling of the space. Nevertheless, by using copious amounts of brown in the design, the LUGN/ÖPPEN product display seems to have a warehouse feel. Regardless, shoppers remained intrigued by the product display, so while the use of the colour brown may not be visually appealing it is able to persuade shoppers the items being sold on the display are value based and worthy of their consideration. 
Figure 22: White space in the LUGN/ÖPPEN display structure

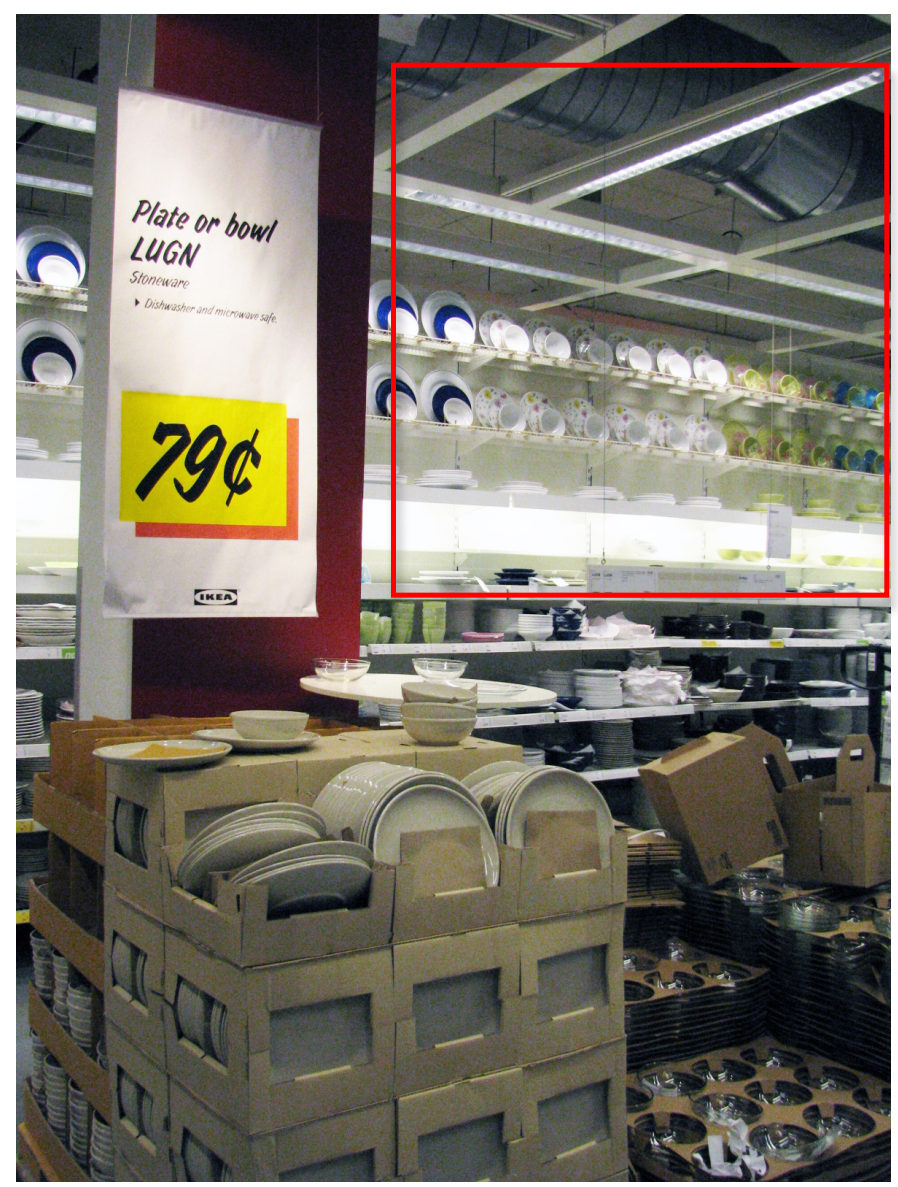

Unlike many of other product displays in the Market Hall at IKEA North York, the LUGN/ÖPPEN display structure contains a substantial amount of white space (see Figure 22), which, while visually unbalanced, draws attention to the display in the store environment. There is a significant amount of white space above the ÖPPEN items on the right side of the LUGN/ÖPPEN product display. Unlike the left part of the display, where the LUGN items are located, which is visually supported by a large red pillar and sign, the right side of the structure contains a large empty space. This large white space adds to the sense of emptiness and general disorganization in the LUGN/ÖPPEN display structure. Additionally, the display seems unbalanced as the right side of the display is not visually supported and fails to be grounded in the space. As such, due to the vast white space in the display structure, the right half of the LUGN/ÖPPEN product display essentially disappears in the store.

As the display seems to be selling both LUGN/ÖPPEN products, regardless of the misinformation on the signage, the design of the display could benefit from some content on the right side of the display. For instance, the red pillar or the signage could be 
expanded horizontally to cover the white space, which would also draw more attention from a distance to the display as a whole. However, despite the shortfalls in the aesthetics of the display structure, shoppers were continually drawn to the product display and, from my observations, to the ÖPPEN side of the display in particular. Therefore, although the design of the LUGN/ÖPPEN product display contained an unbalanced amount of white space, the consumer reactions to the display were generally quite positive.

Figure 23: Information hierarchy in the LUGN/ÖPPEN display

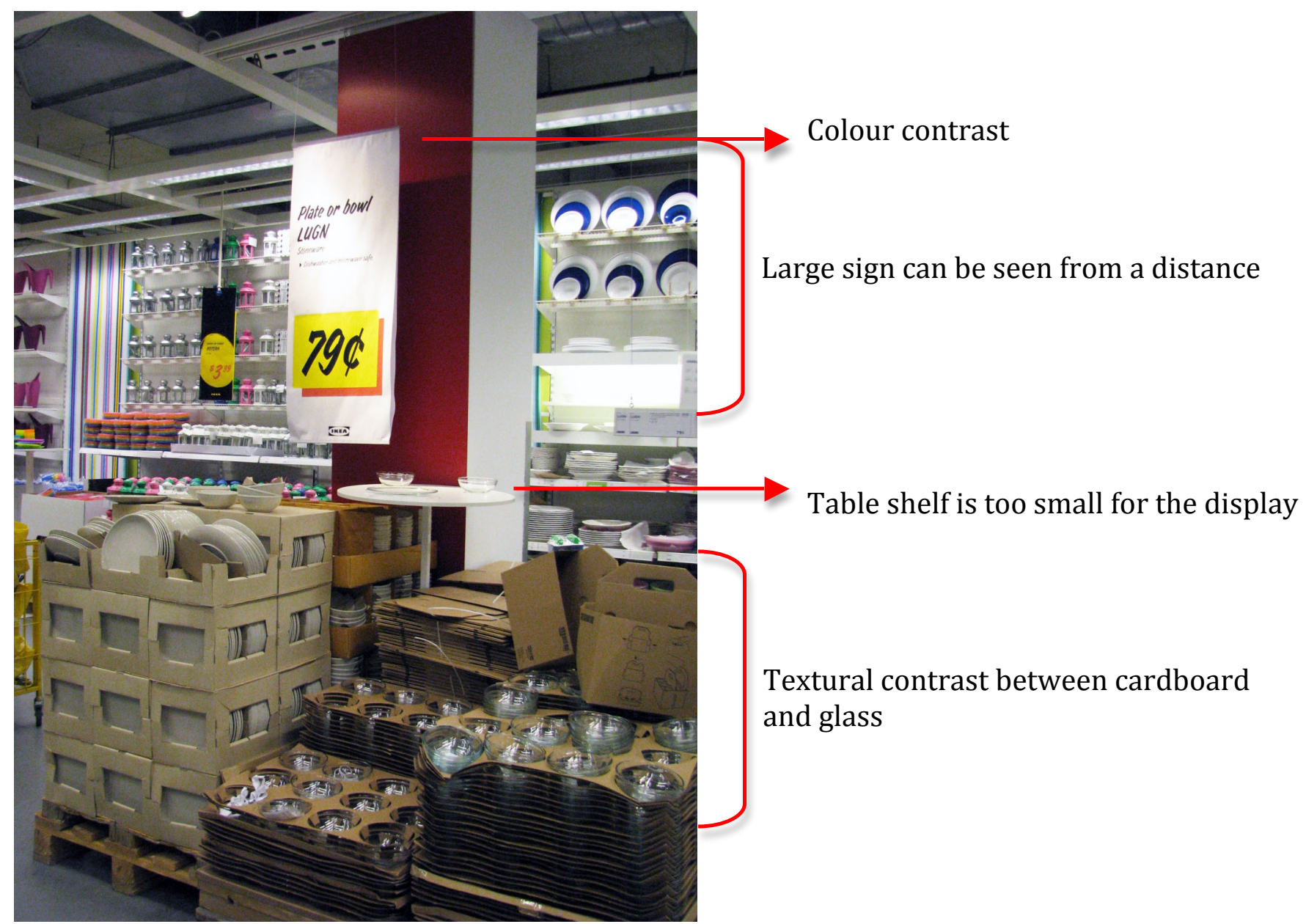


Scale and contrast are both used in the LUGN/ÖPPEN product display to create a succinct hierarchy of the visual elements of information (see Figure 23). The display contained colour contrast as the colour red, which was placed directly against the white walls of the Market Hall and the display signage, drew viewers to the display structure. Like the use of colour, the texture of the products was used to create contrast in the display structure as the smooth plate and bowls on display directly stood out against the rough surface of the cardboard (Dondis, 1973). This textural contrast could have been the motivation for shoppers to have tactile responses to the LUGN/ÖPPEN product display. In terms of scale, the table shelf, which is meant to entice tactile interaction, is disproportionately sized for the display structure. The table shelf is way too small for the overall composition of the display and, as such, discourages shoppers from interacting with the products on display. As the remainder of the products, located on the cardboard supports, takes up the majority of the display, this is what shoppers interact with and how the LUGN/ÖPPEN product display structure achieves tactile responses from customers. Although some shoppers clearly wanted to touch the products on display, the display structure was not very conducive to tactile responses. From my observations, I noticed that the incorrect products were placed on the display table shelf. Though, the table shelf may not be as important in the LUGN/ÖPPEN display because the products are not located in boxes and are therefore easier for shoppers to interact with. Just as the large display attracted shoppers' touch reaction, the exaggerated scale of the LUGN/ÖPPEN display signage likewise attracted the attention of shoppers' eyes. Unlike the other signs in the Market Hall, the sign for the LUGN/ÖPPEN product display is very large. As previously 
mentioned, this allows for shoppers to notice the display from a distance, but also distracts shoppers from the display's lack of design focus and industrial feel.

Although the LUGN/ÖPPEN display is meant to sell products for impulse purchases, during my period of observation, shoppers spent most of time deciding on whether or not to but the items. This could be due to the untidy nature of the display, which lacked clarity and focus that essentially hinders shoppers from making a quick decision. The messiness of the display requires a longer period of contemplation because the visual information in the display is not designed in a coherent manner. The display was very confusing and difficult to navigate, larger signs and clearer indicators are needed to clarify and differentiate between what products are being sold and how much they cost. Alternatively, more space can be placed between the two product displays to separate them visually. However, regardless of the design shortfalls in the display structure, including the overuse of the colour brown, the unbalanced amount of white space, and the exaggerated hierarchy of information, the display structure was successful in garnering tactile responses and potential sales.

\section{iii. Location and Ambience (3D)}

The LUGN/ÖPPEN display is a BTI, which means that IKEA North York purposefully placed in a hot spot in the Market Hall and considers it to be a high-priority item. However, the ambience of the display does not correspond with the display's role as a Breathtaking Item because, while the display is meant to be seen from a distance, the view of the LUGN/ÖPPEN display is obscured and the location of it is somewhat hidden. 
Figure 24: LUGN/ÖPPEN product display from the entrance of the Market Hall

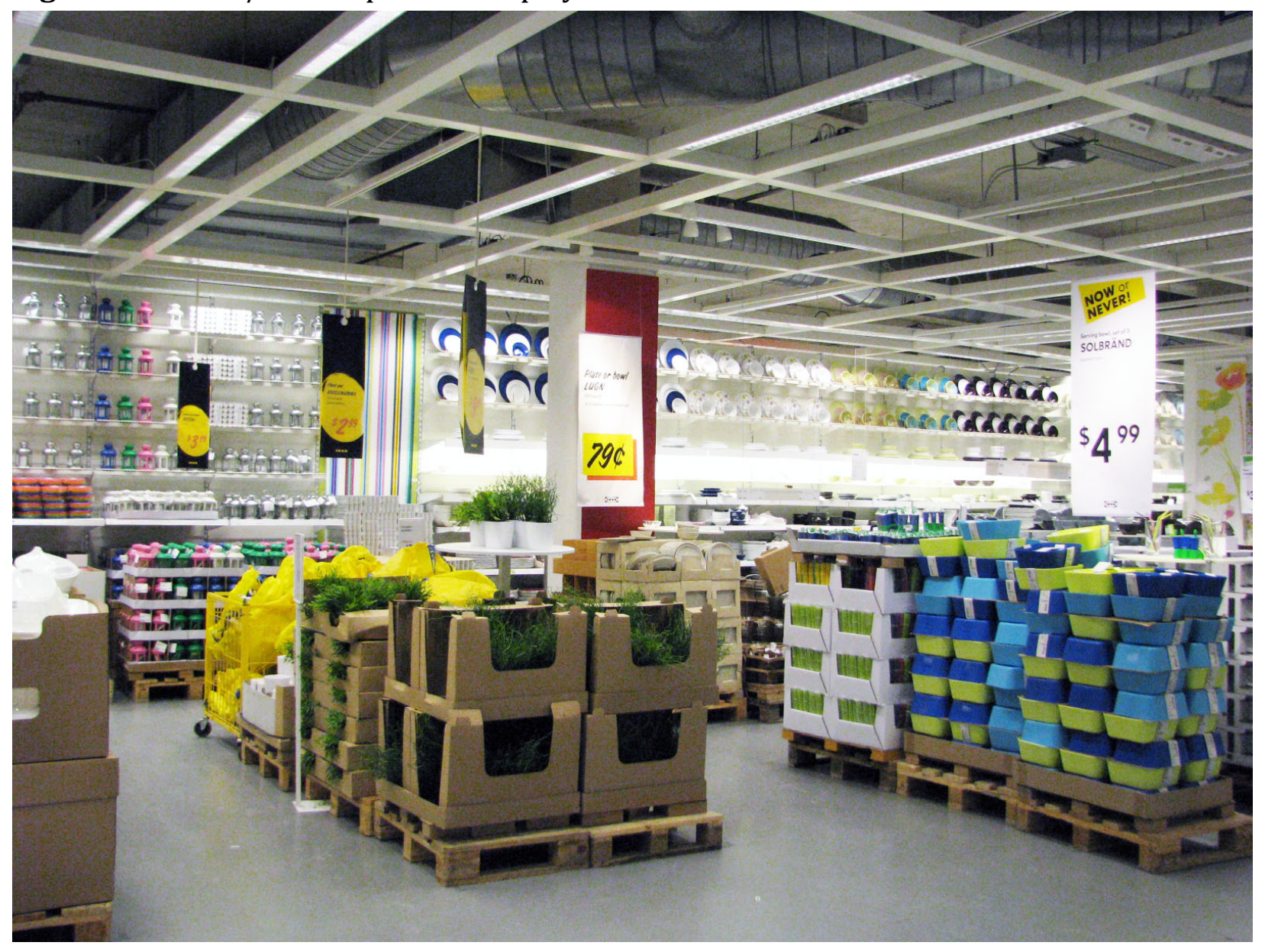

The LUGN/ÖPPEN product display is the first major display shoppers see upon entering the Market Hall from the Showroom (refer to Figure 24). The display stands out to shoppers because of the use of colour, which extends from the floor to the ceiling and makes the display very noticeable from a distance. But, it is only the sign, not the display structure or the products, that is apparent to shoppers from a distance. The display could benefit from making the products more prominent as it is not immediately clear what the display is selling only that the items, whatever they may be, are inexpensive. There is a single pot light pointed directly at the sign in the LUGN/ÖPPEN display. The sign is the 
most prominent feature of the display and therefore it makes sense that the only lighting element focused on the display structure is pointing towards the signage.

One of the reasons that the LUGN/ÖPPEN product display is obscured from shoppers' view is its location in the Market Hall. Figure 6 contains a map of IKEA North York's Market Hall. The LUGN/ÖPPEN product display is somewhat hidden behind a display of "Now or Never" sale items, which is in the aisle of the Market Hall. This display contains a random selection of brightly colored soon to be discontinued products that are offered at a low cost. Almost everyone that approaches the LUGN/ÖPPEN product display touches the products, but not that many shoppers come close to the display. This may be due, in part, to the display's hidden location, which does not allow for shoppers to see the items being sold from a distance. A lot of shoppers during my period of observation interacted with and purchased products from the "Now or Never" display, but did not even notice the LUGN/ÖPPEN display right beside it. Much like how the table display beside the FÄRGRIK product display detracted attention away from the FÄRGRIK display, the location and proximately of the "Now or Never" display is forcing attention away from what IKEA North York identifies as a BTI. While, from a distance, the signage of the LUGN/ÖPPEN product display attracts consumer attention, the location of a competitive display both obscures and detracts from this BTI from shoppers within the vicinity of the display.

The LUGN/ÖPPEN product display could benefit from being placed closer to the aisle, so that shoppers who are walking along the "Long Natural Way" will automatically be forced to interact with the display. However, considering the state of disarray that the display seems to be in, perhaps IKEA North York thinks that it is beneficial to have such a messy display is the background of the Market Hall. Regardless, while the LUGN/ÖPPEN 
product display was the most successful display, in terms of overall tactile responses and intended purchases, the display could be even more productive with a few simple design changes. At the moment, despite IKEA North York's identification of the LUGN/ÖPPEN product display as a BTI, the store appears to be hiding the display and downplaying its value in the Market Hall thus preventing consumer-driven desires. 


\begin{tabular}{|c|c|}
\hline $\begin{array}{l}\text { Information } \\
\text { Hierarchy }\end{array}$ & $\begin{array}{l}\text { Signage } \\
\circ \text { The exaggerated use of scale in the sign, including the increased visual } \\
\text { weight of the } ₫ \text { symbol, prioritize the product's low price. } \\
\text { Colour contrast in the sign adds visual interest and makes the overlaying } \\
\text { price tag stand out. } \\
\text { Product Display Structure } \\
\text { The red pillar contrasted with the white walls of the Market Hall and the } \\
\text { display signage, drawing viewers to the display structure. } \\
\text { The display structure was not very conducive to tactile responses due to } \\
\text { the proportionately too small table shelf. }\end{array}$ \\
\hline White Space & $\begin{array}{l}\text { Signage } \\
\circ \text { White space isolates the price tag, which prioritizes the price of the } \\
\text { product in the overall composition of the sign. } \\
\text { Additionally, white space deemphasizes all the other textual information } \\
\text { in the document. } \\
\text { Product Display Structure } \\
\text { The display structure contains a substantial amount of white space, which, } \\
\text { while visually unbalanced, draws attention to the display in the store } \\
\text { environment. }\end{array}$ \\
\hline Colour & $\begin{array}{l}\text { Signage } \\
\circ \text { The prominent use of yellow and orange in the sign emphasizes the } \\
\text { product price and the sign in the context of the Market Hall. } \\
\text { Product Display Structure } \\
\text { Located immediately behind the display structure is a large, red pillar, } \\
\text { which makes the display standout out in the store environment. } \\
\text { The overwhelming amount of brown cardboard in the display makes the } \\
\text { structure monochromatic and lackluster. }\end{array}$ \\
\hline Ambience & $\begin{array}{l}\text { Location } \\
\text { The display stands out to shoppers because of the use of colour, which the } \\
\text { display very noticeable from a distance. } \\
\text { However, the majority of the display is obscured from shoppers' view } \\
\text { because of its location behind a competitive display. }\end{array}$ \\
\hline
\end{tabular}




\section{Discussion}

From my analysis of the visual communication strategies utilized in the product displays at IKEA North York it is clear that this store strategically uses elements of design, including colour, information hierarchy, and white space, to persuade its shoppers to make purchases purely through the visual components of their product displays. In particular, both white space and information hierarchy were successfully used throughout both the display signage and structure to emphasize and prioritize specific pieces of information that IKEA North York deemed important to shoppers. In multiple instances, IKEA North York chose to place a high degree of importance on value-based products by increasing the size of price tags and surrounding the type with white space. Additionally, colour was often used to accent elements in the retail signage, including price. It is clear that the two displays that contained colour were the most successful in garnering both tactile responses and sales, therefore, it appears as though colour plays an important role in the retail environment especially on the traditional two-dimensional plane.

In general, the product displays' visual elements in the "Cookshop and Tableware" department at IKEA North York were somewhat effective in garnering sales from shoppers due their overreliance on garnering visual attention, rather than tactile responses. For the most part, each of the signs for the three observed product displays were well designed and effectively communicated a succinct message to shoppers. However, each of the three displays had major shortfalls in regards to creating display structures that effectively presented products for shoppers to interact with. While all three displays contained a table shelf with sample products, these shelves often contained incorrect product samples, were 
too small for the overall composition of the display, or simply blended into the display structure. Additionally, two of the three displays, FÄRGRIK and FÖRNUFT, sold products contained within product packaging, which further hindered shoppers' ability to touch the products being sold.

Touch sensation is an important aspect of the retail experience for shoppers and an effective strategy for making the retail environment more effective in garnering sales. Especially when shopping for household goods, the ability to touch products is crucial to consumers as "we live in a tactile-deprived society, and shopping is one of our few chances to freely experience the material world firsthand. Almost all unplanned buying is the result of touching... something on the premises of a store" (Underhill, 1999, p. 158).

Underhill (1999) refers to tactile interaction as "petting" and it can be done for obvious, physical reasons such as testing the quality of products; but, touching is also part of the shopping experience as it involves the consumer with the product firsthand and makes the item seem more attainable to them. Therefore, shoppers who have the ability to touch products of interest are more likely to purchase them due to their positive sensory experience. Due to the importance of petting in the retail environment, IKEA North York would benefit from designing their displays to further encourage tactile responses. While the table shelves in the display are a positive start, elements of design, such as scale, contrast, and colour, could be used to emphasize these shelves in the overall composition of the display structure.

Just as IKEA North York could emphasize tactile responses in their product displays, some other visual communication changes can be made to make the Market Hall at IKEA North York's retail space more conducive to consumer's behaviours and shopping habits. 
At the moment, IKEA North York successfully designs their retails space from a micro perspective, that is, the individual parts of their retail displays, such as signage, are generally quite effective forms of visual communication as they persuade shoppers to notice the product display. However, the display structure itself as well as the placement of the displays in the Market Hall seems to show an incomplete understanding of design on a three-dimensional plane. Kent (2003) states that, as part of the evolution of the retail brand, design "has moved beyond two-dimensional, visual expressions of format and product identity to embrace three-dimensional space of the store environment" (p. 131). Design, Kent (2003) elaborates, "has evolved from a graphical, 2D approach in the creation of an identity, to the combined concept of external architecture and internal spaces" (p. 140). Designing a retail space or store environment requires that the product display be visually persuasive as a whole, not just in parts. In particular, IKEA North York needs to focus on the hierarchy of information in their retail space and prioritize information that is being presented to the shopping public. As well, ambient qualities and elements of atmospherics must be taken into consideration, as these product displays do not exist in isolation, rather they have to work in the space as a whole.

Additional suggestions for improvement include avoiding overcrowding the Market Hall in order to allow the product displays on the floor ample room to attract shoppers' attention. As well, attention must be paid to neighboring displays. Often successful displays are ignored when placed next to a flashier, more heavily designed display structures. Lastly, IKEA North York should keep in mind that although shoppers should be browsing the store along the "Long Natural Way" often customers veer off this path and miss displays that are only designed to be viewed from a single, frontal angle. 
As well, while many display structures were effective to a degree, they suffered from a general lack of maintenance and upkeep. Both the FÖRNUFT and LUGN/ÖPPEN displays contained disorganized or messy stock, which left a poor visual impression on shoppers and, more importantly, failed to correspond with IKEA North York's clean and modern brand. Despite the fact that many retailers feel that customers do not buy from empty or near empty displays (Razzouk, N. Y., Seitz, V., \& Kumar, V., 2001), which often resulting in the daily restocking and completion of displays, "incomplete product displays can lead other shoppers to make positive assumptions about missing items and therefore purchase the same items" (Kopec, 2006, p.277). Research shows that by maintaining incomplete product displays, especially for new and slow-moving items, retailers can actually encourage customers to make purchases (Razzouk, N. Y., Seitz, V., \& Kumar, V., 2001). While IKEA North York probably does not purposefully have half empty or obviously tampered displays in the Market Hall, despite the negative visual impression, doing so might actually encourage consumer behaviour. True to this statement, both he FÖRNUFT and LUGN/ÖPPEN displays resulted in the highest number of intended purchases, while the tidiest display, FÄRGRIK, received none.

Despite the successful analysis and interpretation of the visual information collected from IKEA North York, and its connection to the corresponding consumer behaviour, the results garnered from this study cannot accurately be used to explain the persuasive communication latent in the product displays at IKEA North York due to the scale of this research project. As such, this study could have benefited from a broader data set including an examination of multiple IKEA Canada locations, the evaluation of product displays from different departments in the Market Hall, as well as the inclusion of a greater amount of 
product displays. Additionally, the results of the study could be more conclusive given a greater period of observation as well as longer observation segments by multiple researchers. As well, unlike similar research in the field of retail design and visual merchandising, this study did not consider shopper's personal opinions and firsthand experiences regarding the design of the store environment. Rather than focus on shoppers' reactions and personal motivations in regards to their intention to purchase products, this study relied solely on observational data, which could potentially be biased in favour of the researcher. Lastly, what is deemed "effective" visual communication is subjective to the viewer, and, therefore, alternative perspectives on the design success of each of the product displays may be held by readers. However, in following concepts derived from document design and visual communication theory, it is clear why and how the conclusions for each of the product display analyses were reached. Regardless of these methodological shortcomings, which are excusable given the scale of this study, the overarching conclusion from the research remains valid.

\section{Conclusion}

Through observing consumer behaviour, photo documenting product displays, and mapping the retail space in the "Cookshop \& Tableware" department in the Market Hall at IKEA North York, I was able to collect visual documents of three product displays and monitor the surrounding consumer behaviour. Then, by applying concepts from document design and visual communication, including colour, information hierarchy, white space, and ambience, to each of the product displays through a thorough visual analysis I was able to deconstruct the communication and persuasive qualities latent behind each of the display's signs, display structures, and locations and ambient surroundings. Through my 
analysis I was able to conclude that while IKEA North York is an organization that constructs effective visual messages in their retail environments through signage and traditional two-dimensional documents, while messages that sought to attract shoppers' attention on a three-dimensional plane were less successful in creating consumer-driven desires.

My research successfully analyzed and discussed how IKEA North York persuasively communicates to its shoppers through visuals in their product displays for the purpose of encouraging shopping behaviour and impacting purchasing decisions. Through my MRP, I was able to contribute to the definition of "communication" to include forms of persuasion and messaging that are more subtle and exist in retail spaces and store environments; more specifically, it is clear that visual design, to a certain extent, is able to drive consumer behaviour. 


\section{Appendix ${ }^{3}$}

\section{FÄRGRIK Signage}

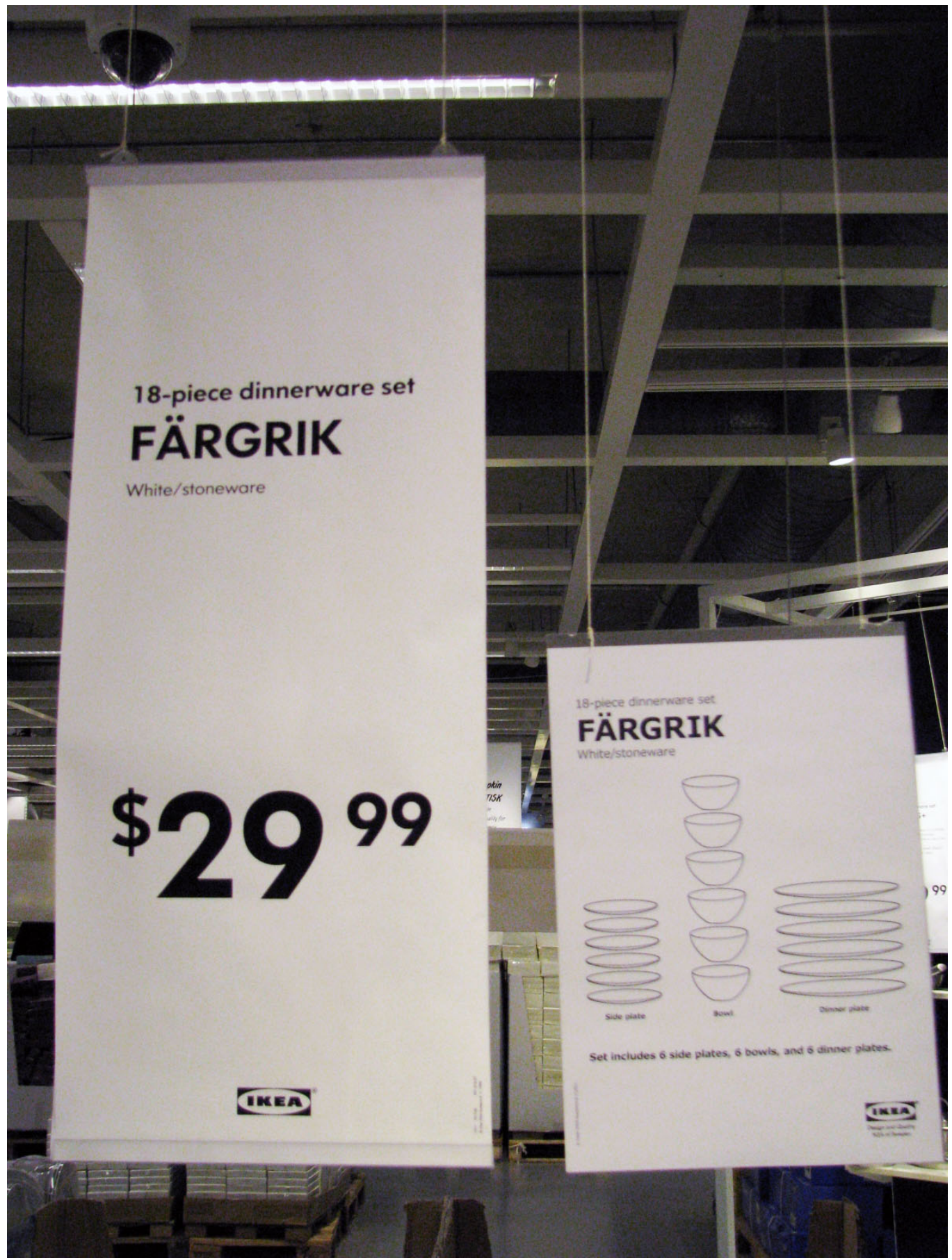

${ }^{3}$ Nima Naik took all photographs on site at IKEA North York on the days of observation. Written consent to take photographs was provided by IKEA Canada via IKEA North York. 
FÄRGRIK Sign 1

\section{8-piece dinnerware set FÄRGRIK}

White/stoneware

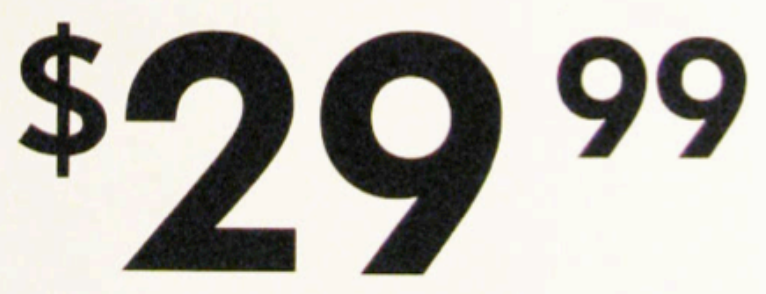

MEA 
FÄRGRIK Sign 2

18-piece dinnerware set

FÄRGRIK

White/stoneware

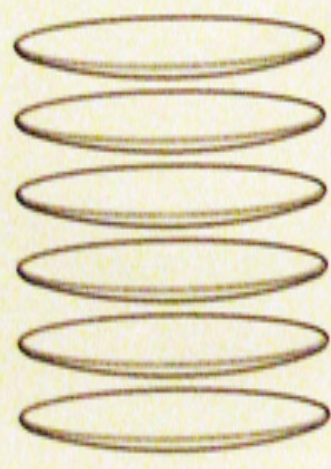

Side plate

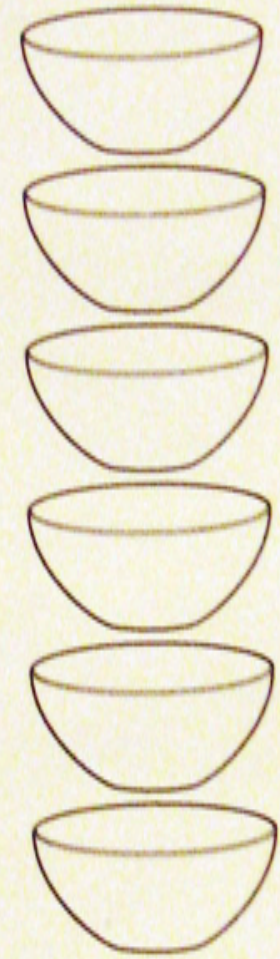

Bowl

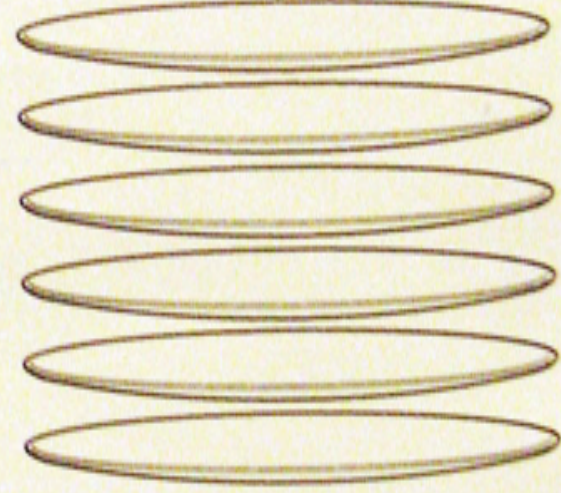

Dinner plate

Set includes 6 side plates, 6 bowls, and 6 dinner plates. 
FÄRGRIK Product Display Structure

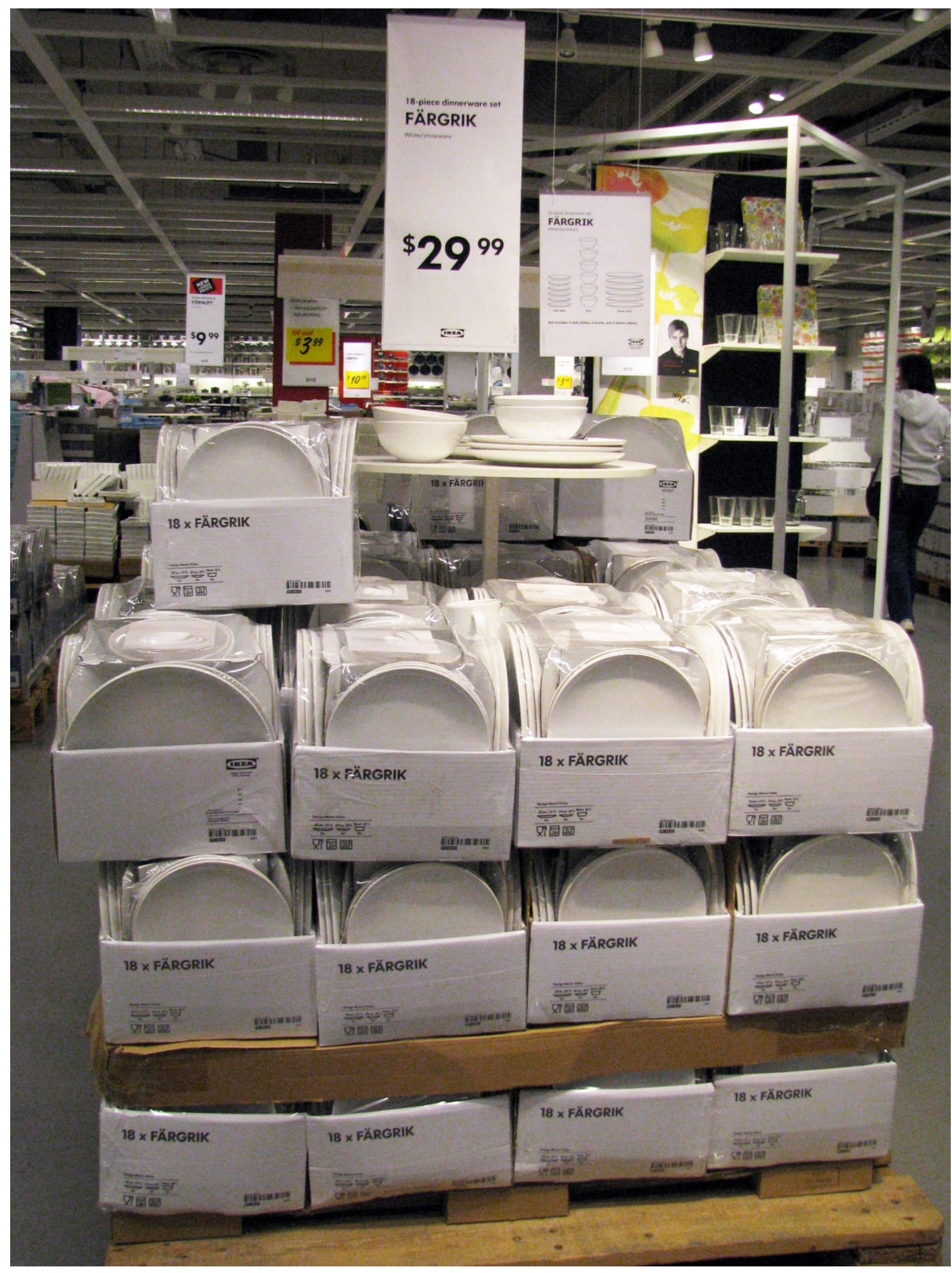


FÄRGRIK Product Display Ambience

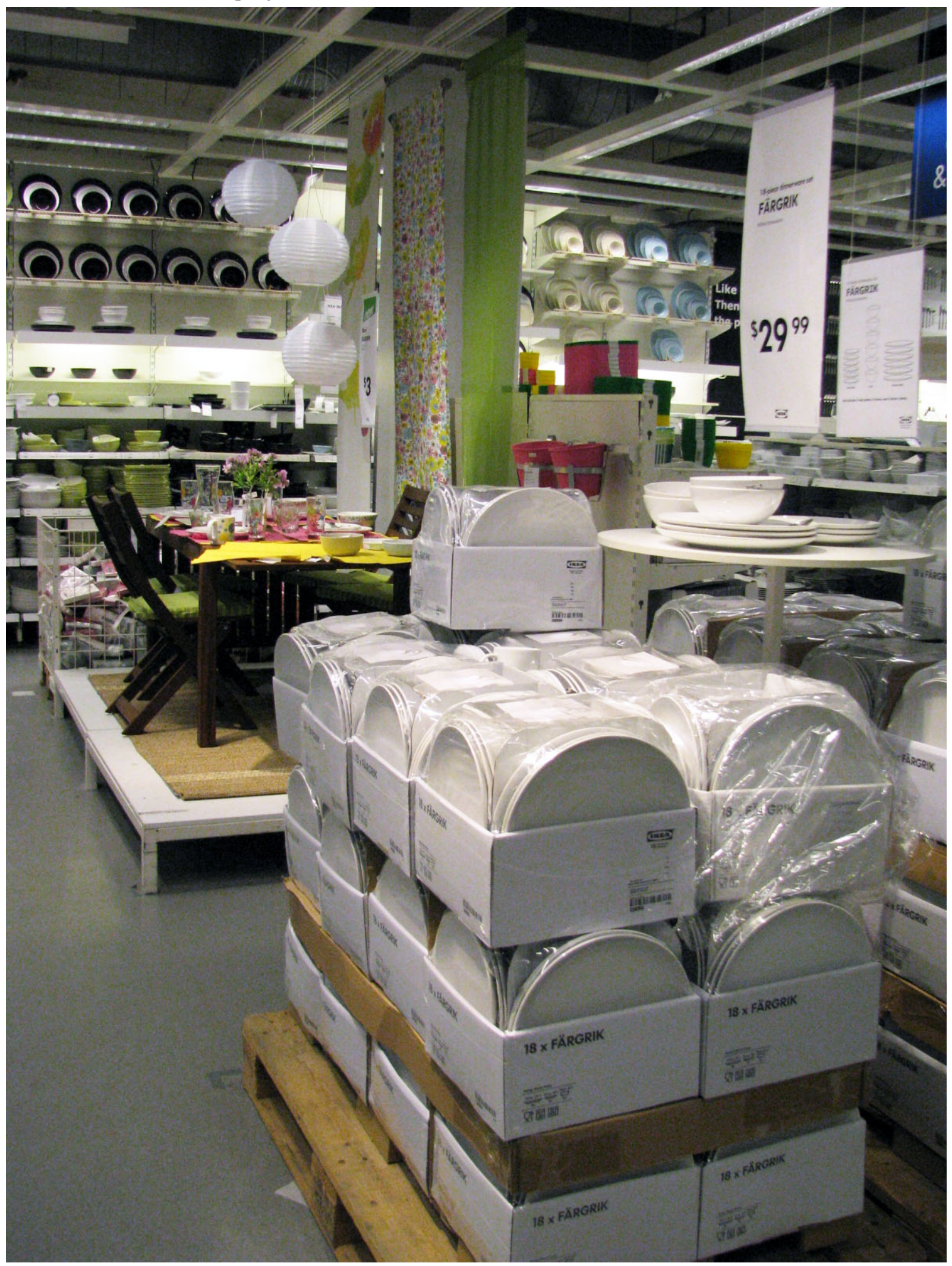


FÖRNUFT Signage

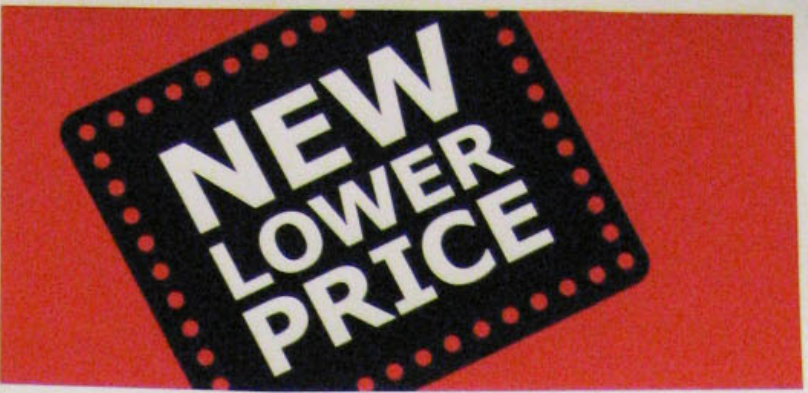

20-piece flatware set FÖRNUFT

Stainless steel
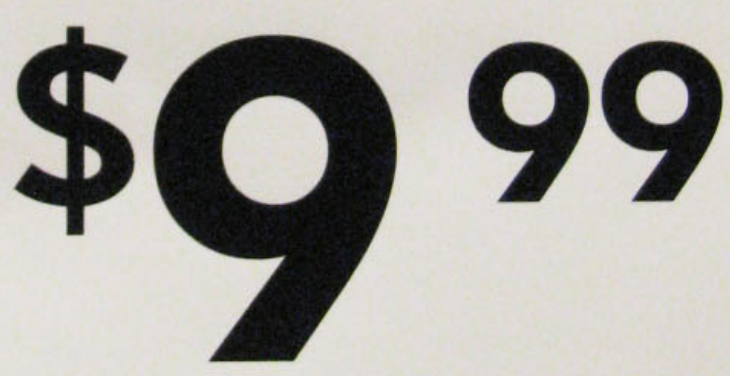

Last year's catalogue price: $\$ 10.99$

ITEA 
FÖRNUFT Display Structure

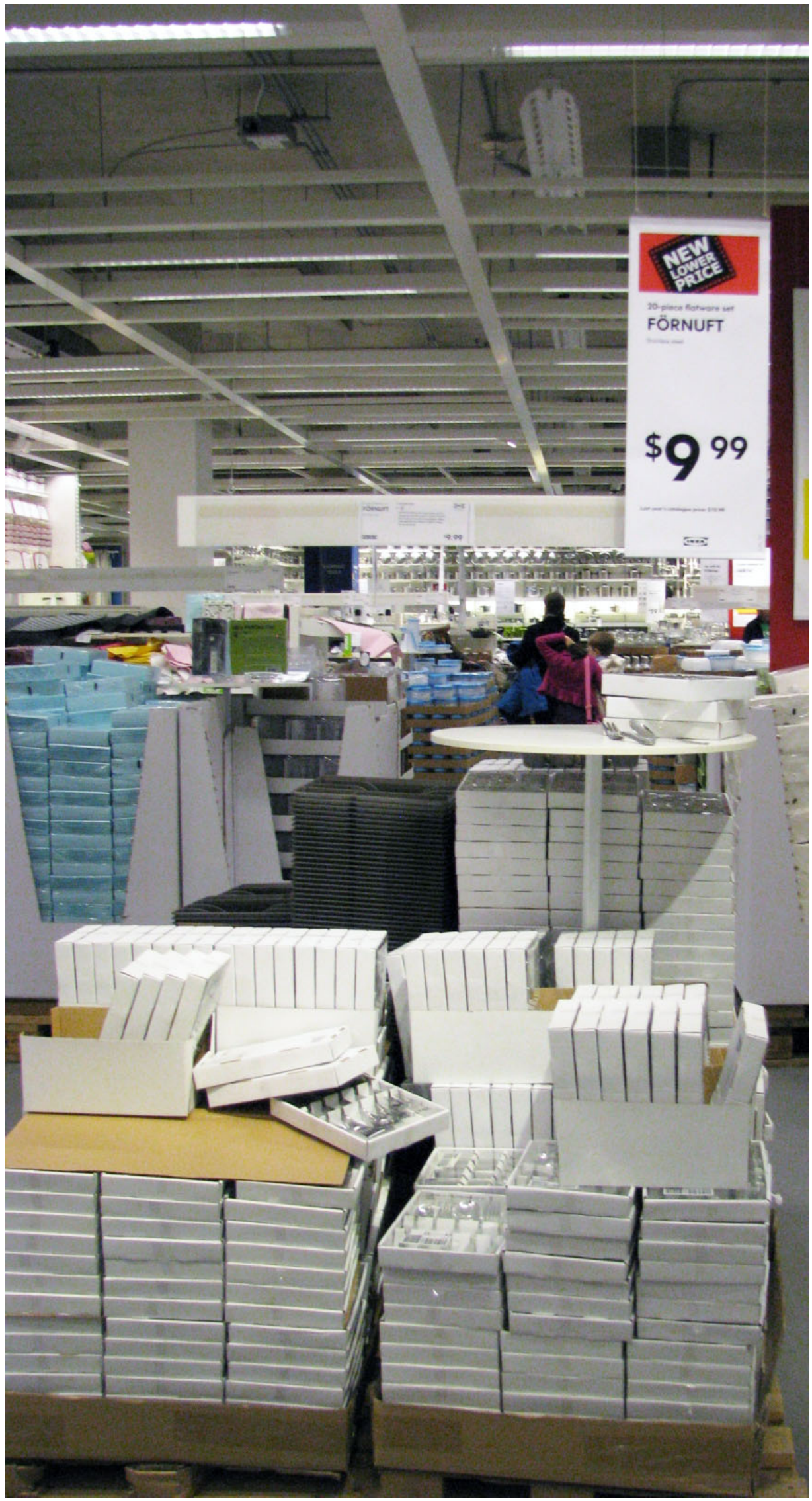


FÖRNUFT Display Ambience

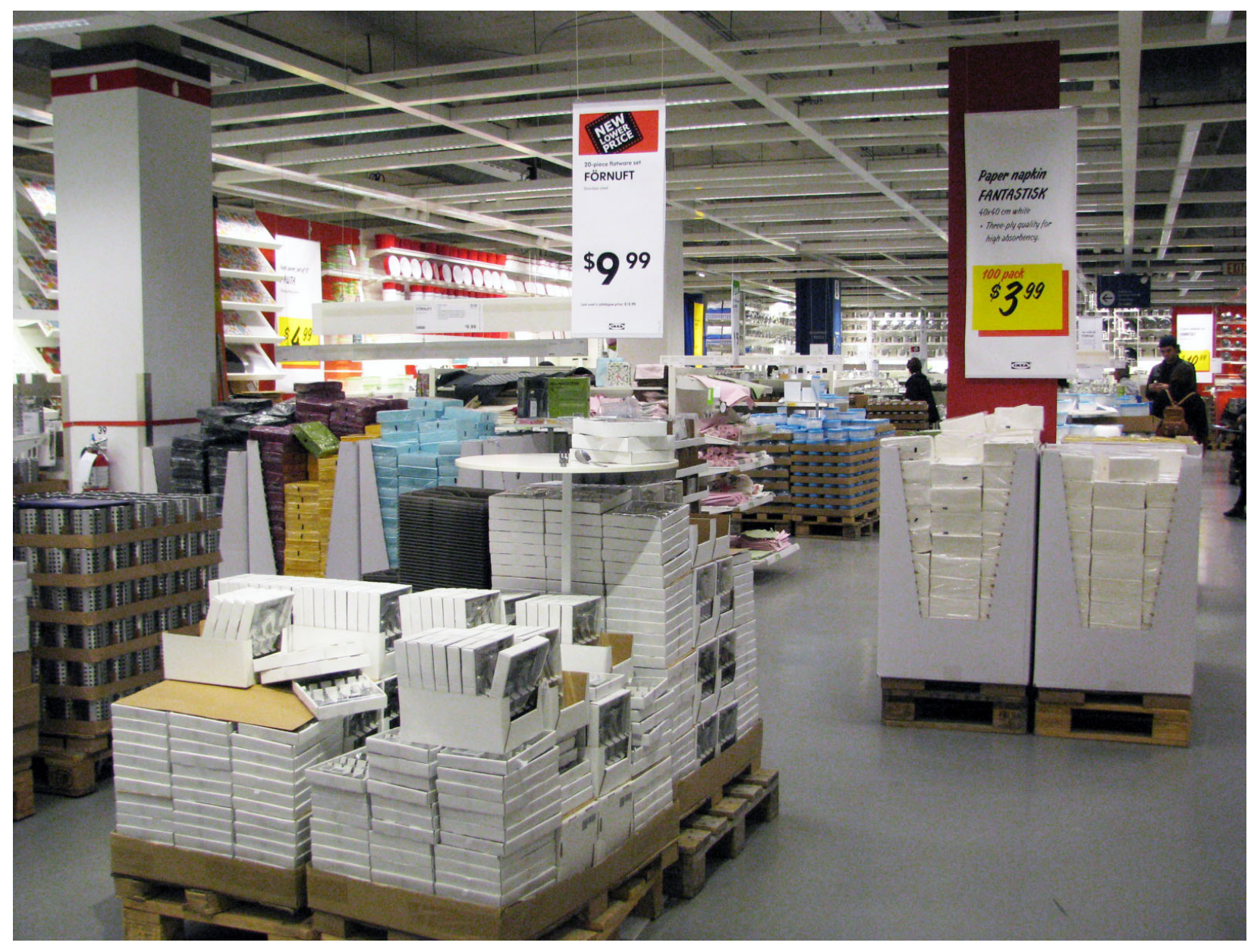


LUGN Signage

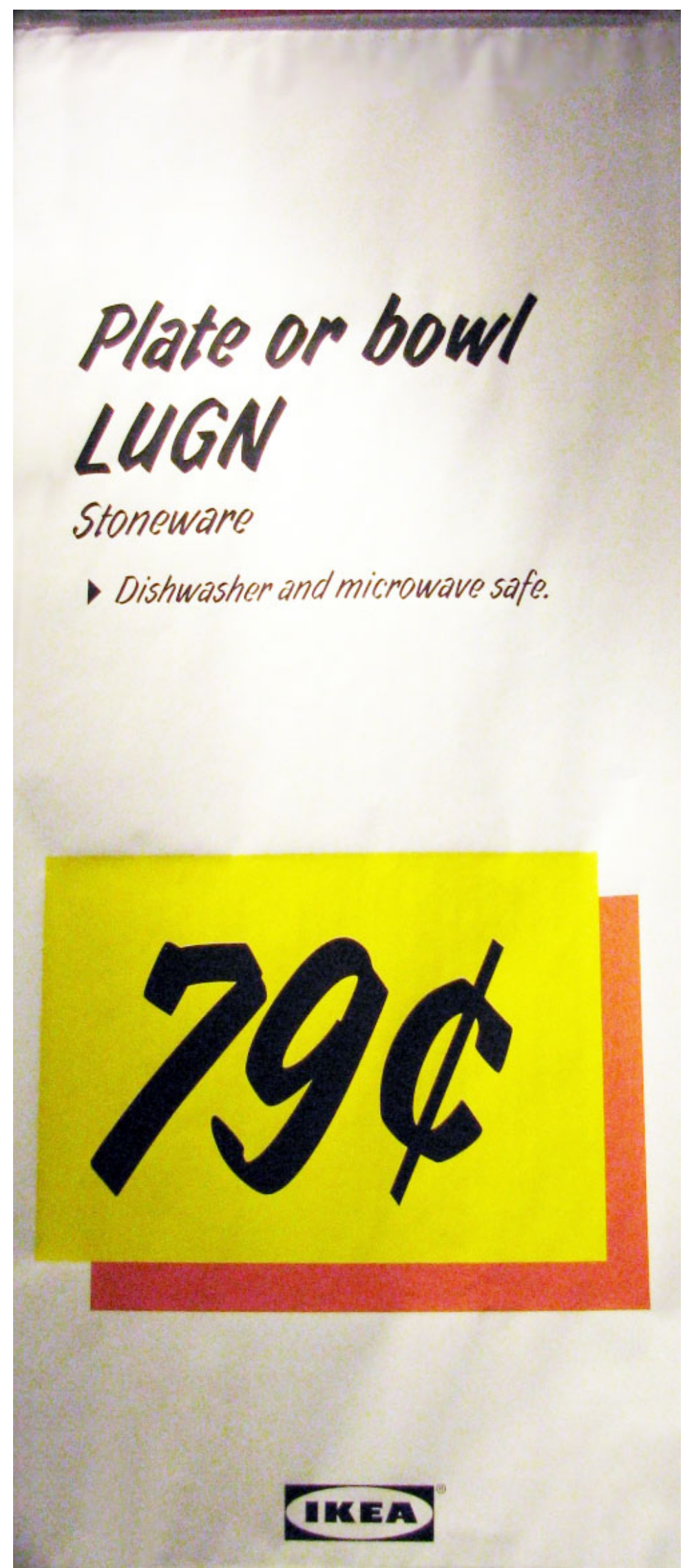


LUGN/ÖPPEN Display Structure

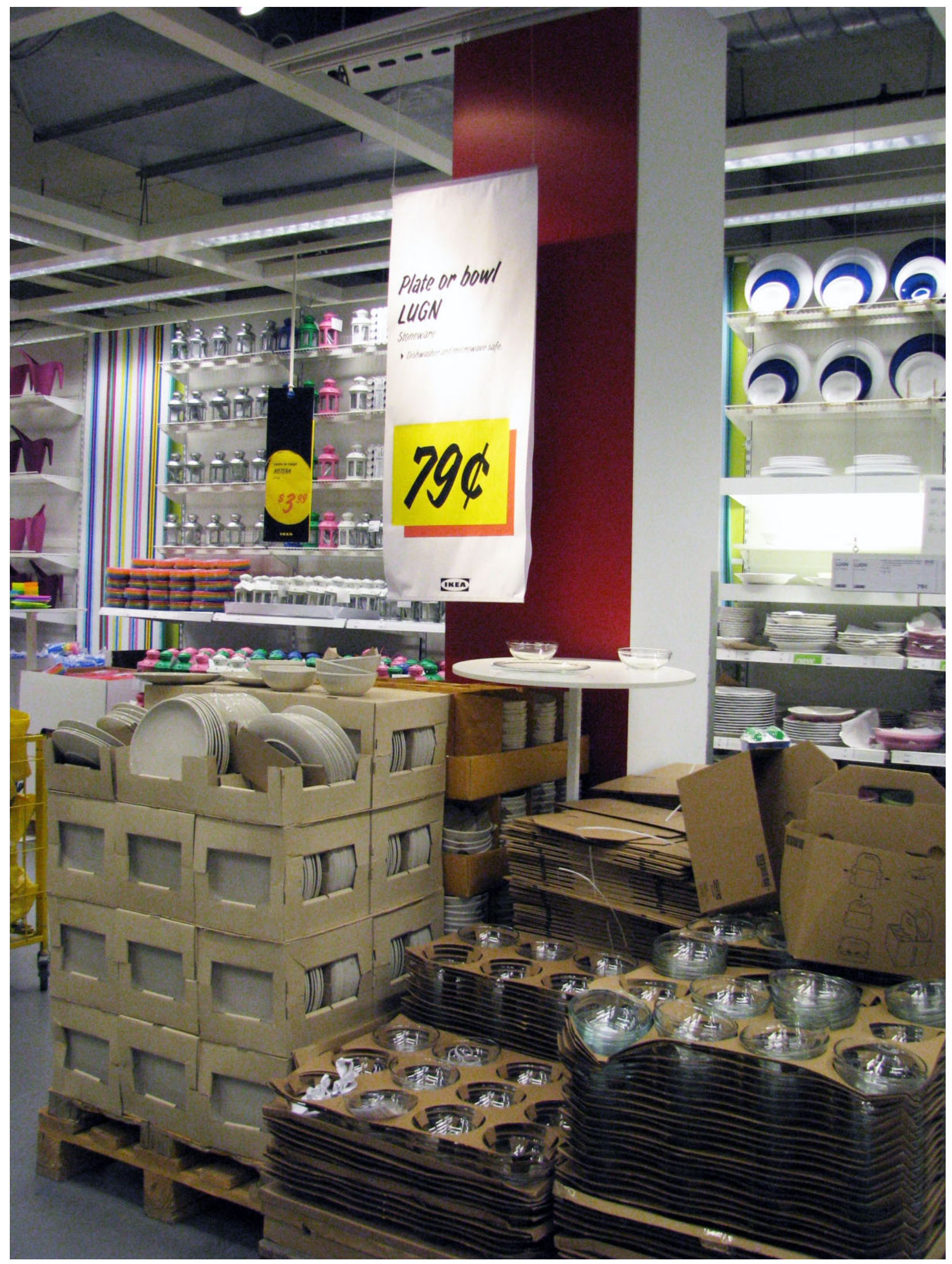


LUGN/ÖPPEN Display Structure

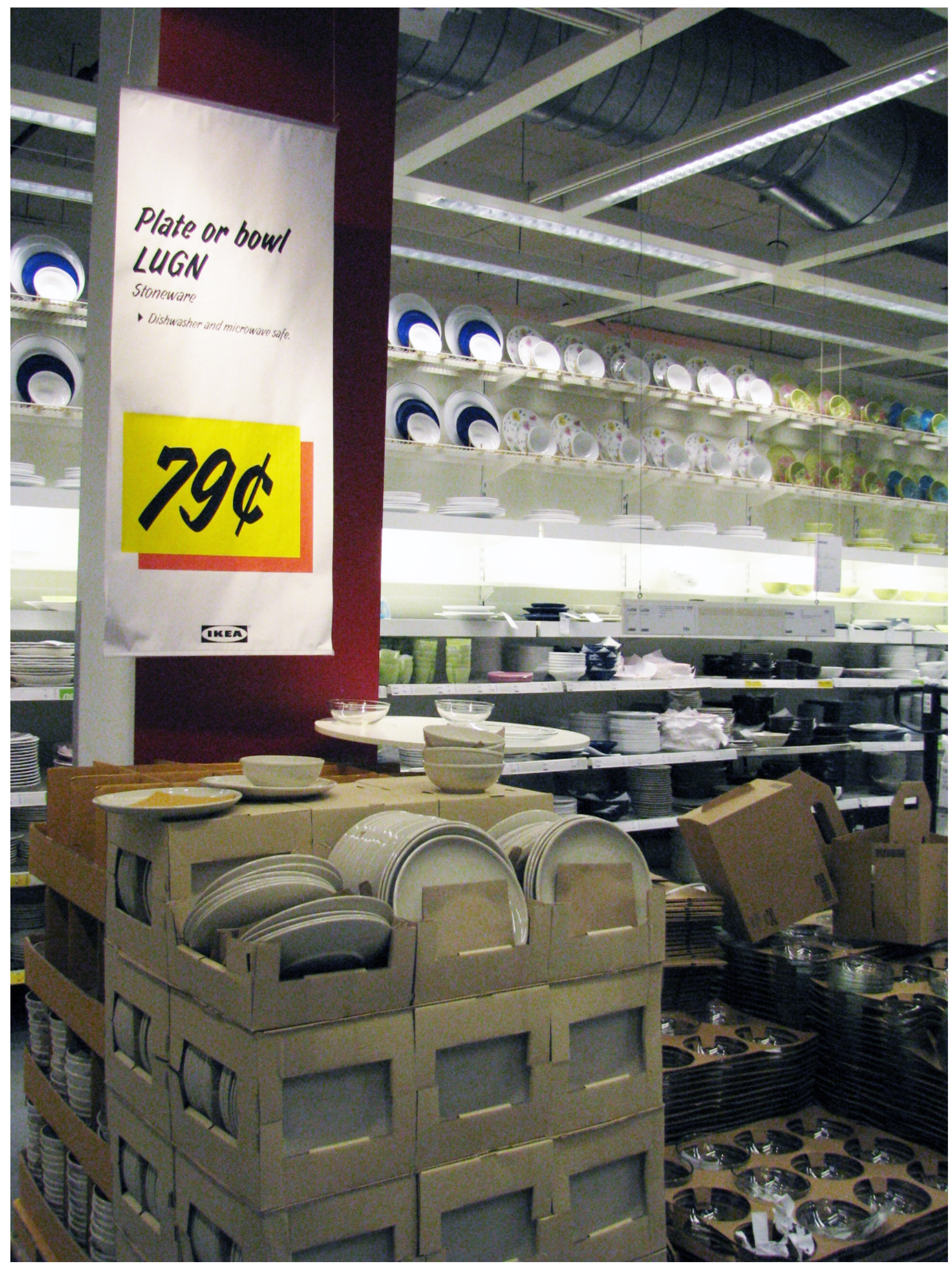


LUGN/ÖPPEN Product Display Ambience

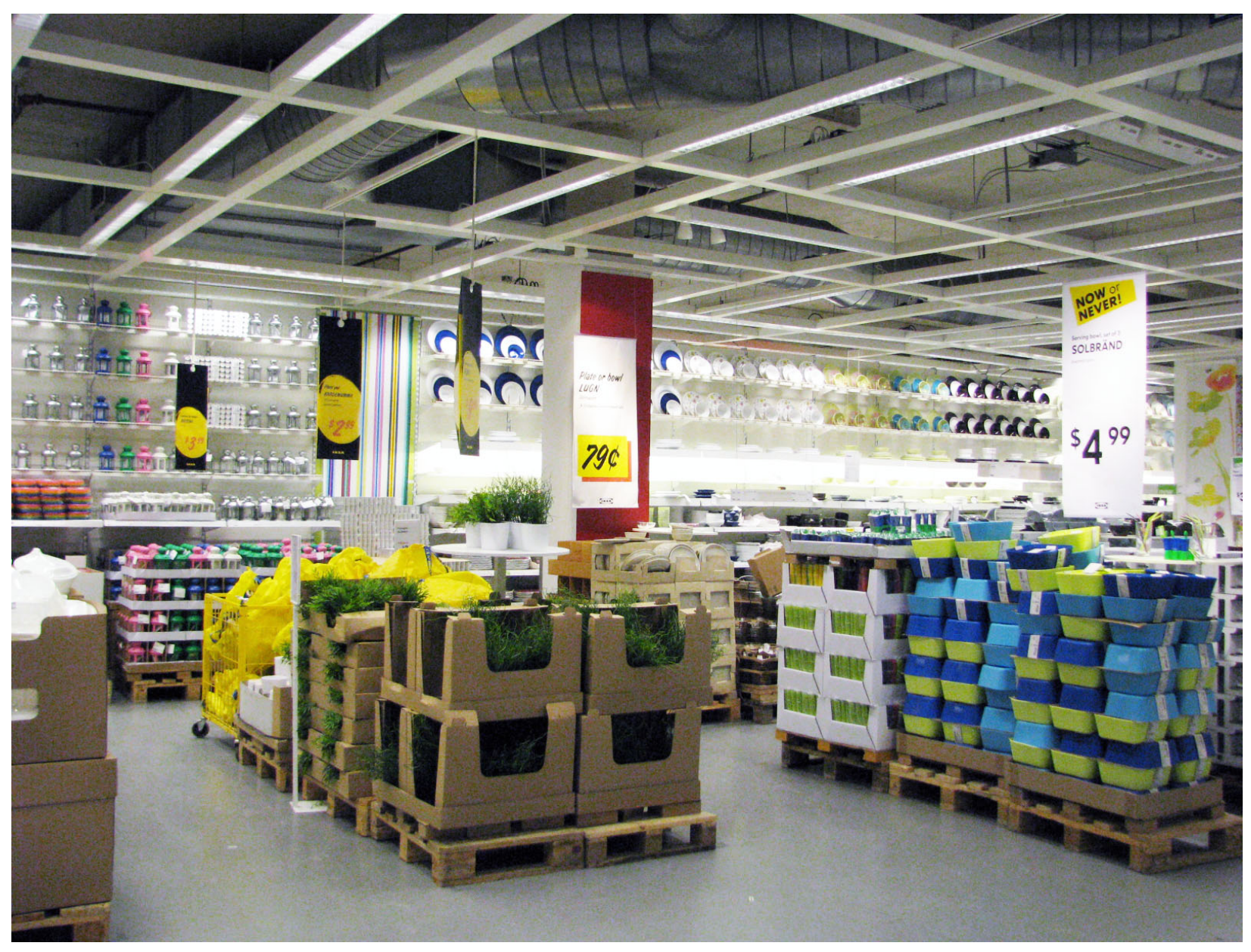




\section{References}

Babin, B., Hardesty, D. \& Suter, T. (2003), “Color and shopping intentions: the intervening effect of price fairness and perceived effect". Journal of Business Research, 56(7), $541-551$.

Baker, J., Grewal, D. \& Parasuraman, A. (1994). “The influence of store environment on quality inferences and store image". Journal of the Academy of Marketing Science, 22(4), 328-339.

Baker, J., Levy, M. \& Grewal, D. (1992). “An experimental approach to making retail store environmental decisions". Journal of Retailing, 68(4), 445-461.

Baker, J., Parasuraman, A., Grewal, D., \& Voss, G. (2002). “The Influence of Multiple Store Environment Cues on Perceived Merchandise Value and Patronage Intentions". Journal of Retailing, 66(2), 120-141.

Bellizini, J., Crowley, A., \& Hasty, R. (1983). "The effects of Color in Store Design”. Journal of Retailing, 59(1), 21-45.

Bitner, M.J. (1992). "Servicescapes: The Impact of Physical Surroundings on Customers and Employees." Journal of Marketing, 56 (April), 57-71.

Bloch, P.H. (1995). "Seeking the ideal form: product design and consumer response". The Journal of Marketing, 59(3), 16-23.

Bowers, J. (2003). Introduction to Two-Dimensional Design: Understanding Form and Function. Hoboken, NJ: John Wiley \& Sons.

Burke, K. (1950). A Rhetoric of Motives. Berkeley: University of California Press. 
Colborne, R. (1996). Visual merchandising: The Business of Merchandise Presentation. Albany, NY: Delmar Publishers.

Dickenson, G. \& C.M. Maugh. (2004). Placing Visual Rhetoric: Finding Material Comfort in Wild Oats Market. In C.A. Hill \& M.H. Helmers (Eds.), Defining Visual Rhetorics (pp. 259-276). Mahwah, NJ: Lawrence Erlbaum.

Dondis, D. A. (1973). A primer of visual literacy. Cambridge, MA: MIT Press.

Donovan, R.J. \& Rossiter, J.R. (1982). “Store atmosphere: An environmental psychology approach". Journal of Retailing, 58(1), 34 - 57.

Donovan, R.J., Rossiter, J.R., Marcoolyn, G. \& Nesdale, A. (1994). “Store atmosphere and purchasing behavior". Journal of Retailing, 70(3), 283-294.

Edvardsson, B., Enquist, B., \& Hay, M. (2006). “Values-based service brands: Narratives from IKEA". Managing Service Quality, 16(3), 230-246.

Elliott, R., Eccles, S. \& Ritson, M. (1996) “Reframing Ikea: commodity signs, consumer creativity and the social/self dialectic". Advances in Consumer Research, 23. 127131.

Eroglu, S. \& Harrell, G.D. (1986). "Retail crowding: theoretical and strategic implications”. Journal of Retailing, 62(4), 346-363.

Gilboa, S. \& Rafael, A. (2003). “Store environment, emotions and approach behaviour: applying environmental aesthetics to retailing". The International Review of Retail, Distribution and Consumer Research, 13 (2), 195-211. 
Greenland, S.J. \& McGoldrick, P.J. (1994). “Atmospherics, attitudes, and behavior: modeling the impact of designed space". International Review of Retail, Distribution, and Consumer Research, 4(1), 1-16.

Helmers, M.H., \& C.A. Hill. (2004). Introduction. In C.A. Hill \& M.H. Helmers (Eds.), Defining Visual Rhetorics (pp. 1-24). Mahwah, NJ: Lawrence Erlbaum.

Kellaris, J.J. \& Kent, R.J. (1992). “The influence of music on consumers' temporal perceptions: does time fly when you're having fun?". Journal of Consumer Psychology, 1(4), 365-76.

Kent, T. (2007). “Creative space: design and the retail environment". International Journal of Retail \& Distribution Management, 35(9), 734-745.

Kent, T. (2003). "2D23D: Management and design perspectives on retail branding". International Journal of Retail \& Distribution Management, 31(3), 131-142.

Kerfoot, S., Davies, B., \& Ward, P. (2003). “Visual merchandising and the creation of discernible retail brands". International Journal of Retail \& Distribution Management, 31(3), 143 - 152.

Kopec, D. A. (2006). Environmental psychology for design. New York: Fairchild Publications, Inc.

Kostelnick, C., \& Roberts, D. D. (1998). Designing visual language: Strategies for professional communicators. Needham Heights, MA: Allyn \& Bacon.

Kotler, P. (1974). “Atmospherics as a marketing tool”. Journal of Retailing, 49(4), 48-64. 
Lascano, R. (2009). "Principles of Information Design: Hierarchy." Arrows and Icons Magazine. (4).

Law, D., Wong, C., \& Yip, J. (2012). “How does visual merchandising affect consumer affective response?" European Journal of Marketing, 46(1/2), 112-133.

Mano, H. (1999). “The influence of pre-existing negative affect on store purchase intentions". Journal of Retailing, 75(2),149-172.

Markin, R.J., Lillis, C.M. \& Narayana, C.L. (1976). “Social-psychological significance of store space". Journal of Retailing, 52(1), 43-54.

Mehrabian, A. \& Russell, J.A. (1974). An Approach to Environmental Psychology, The MIT Press, Cambridge, MA.

Milliman, R.E. (1982). “Using background music to affect the behavior of supermarket shoppers". Journal of Marketing, 46(3), 86-91.

Pegler, M.M. (2006). Visual Merchandising and Display, $5^{\text {th }}$ Edition. New York: Fairchild Publications.

Phillips, H. \& Bradshaw, R. (1990). "How customers actually shop: customer interaction with the point of sale". Journal of the Market Research Society, 35(1), 51-62.

Razzouk, N. Y., Seitz, V., \& Kumar, V. (2001). “The impact of perceived display completeness/incompleteness on shoppers' in-store selection of merchandise: An empirical study". Journal of Retailing and Consumer Services, 9(1), 31-35.

Roncha, A. (2008). "Nordic brands towards a design-oriented concept". Journal of Brand Management, 16(1-2), 21-29.

Schriver, K. A. (1997). Dynamics in document design: Creating text for readers. New York: Wiley-Liss. 
Smith, J.M. \& McCombs, E. (1971). "The graphics of prose". Visible Language, 4 (Autumn), 365-369.

Spencer, H., Reynolds, L., \& Coe, B. (1974). “Typographic coding in lists and bibliographies”. Applied Ergonomics, 5, 136-141.

Strong, E.K. (1926). "Values of white space in advertising”. Journal of Applied Psychology, 10, 107-116.

Tai, S.H.C \& Fung, A.M.C. (1997). “Application of an environmental psychology model to instore buying behaviour". The International Review of Retail, Distribution and Consumer Research. 7(4), 311-337.

Turley, L.W. \& J.C. Chebat. (2002). “Linking Retail Strategy, Atmospheric Design and Shopping Behaviour". Journal of Marketing Management. 18(1-2), 125-144.

Turley, L. W. \& Milliman, R.E. (2000), “Atmospheric Effects on Shopping Behavior: A Review of the Experimental Evidence". Journal of Business Research, 49 (2), 193-211.

Underhill, P. (1999). Why We Buy: The Science of Shopping. New York: Simon \& Schuster. 